\title{
Consideraciones actuales y propuestas de reforma de lege lata y de lege ferenda para el derecho internacional privado de la insolvencia en Argentina y en el MERCOSUR*
}

\author{
Current issues and Reform Proposals \\ de lege lata and de lege ferenda to the \\ Private International Insolvency Law of \\ Argentina and the MERCOSUR
}

\section{Considerações atuais e propostas de reforma de lege lata e de lege ferenda para o direito internacional privado da insolvência na Argentina e no Mercosul}

Héctor José Miguens**

\footnotetext{
* $\quad$ Este artículo forma parte del plan de investigación del autor como miembro de la carrera de Investigador Científico del CONICET (Argentina) y de Fellow de la Fundación Alexander von Humboldt de Alemania.

** http://orcid.org/0000-0002-1659-8508. Investigador Independiente del Conicet, con lugar de trabajo en la Universidad Austral. hmiguens1@ius.austral.edu.ar
}

DOI: $10.5294 /$ dika.2020.29.1.4 


\section{Resumen}

Este trabajo tiene como objeto el estudio somero del status quaestionis y de propuestas de lege lata $\mathrm{y}$, sobre todo, de lege ferenda del derecho internacional privado de la insolvencia de la República Argentina y del Mercosur a la luz de la actividad legisferante de organismos internacionales, entidades no gubernamentales, y entidades científicas y profesionales en el área del derecho concursal internacional en los últimos 30 años. Este trabajo hace eco de las iniciativas elaboradas por instituciones como el Banco Mundial, el Fondo Monetario Internacional, Insol International, Insol Europe, el International Insolvency Institute, el American Bankruptcy Institute, el American Law Institute, la International Bar Association, y de normas vigentes como el Reglamento Europeo sobre Insolvencia de los años 2000 y 2015. El autor propone en este trabajo la adopción de normas como el Anteproyecto argentino del año 2002 sobre insolvencia transfronteriza, con algunas modificaciones y agregados, inspirado en la Ley Modelo sobre Insolvencia Transfronteriza de UNCITRAL de 1997.

\section{Palabras clave}

Derecho internacional privado; derecho internacional de la insolvencia; derecho internacional privado de la insolvencia argentino; derecho del Mercosur; insolvencia internacional; reorganización empresarial internacional; capítulo quince del Código de Bancarrotas de Estados Unidos; derecho europeo de insolvencia. 


\section{Abstract}

This paper aims to perfunctorily study the status quaestionis and lege lata and, particularly, lege ferenda proposals of private international insolvency law in the Argentine Republic and Mercosur, considering the legislative activity of international agencies, non-governmental organizations, and scientific and professional entities on international bankruptcy law in the last 30 years. It echoes the initiatives developed by institutions such as the World Bank, the International Monetary Fund, Insol International, Insol Europe, the International Insolvency Institute, the American Bankruptcy Institute, the American Law Institute, and the International Bar Association, as well as current regulations such as the European Insolvency Regulation of 2000 and 2015. The author proposes adopting regulations such as the Argentine cross-border insolvency bill of 2002 - with some amendments and additions - , inspired by the UNCITRAL Model Law on Cross-Border Insolvency of 1997.

\section{Keywords}

Private international law; international insolvency law; Argentine private international insolvency law; Mercosur law; international insolvency; international business reorganization; chapter fifteen of the United States Bankruptcy Code; European insolvency law. 


\section{Resumo}

O objetivo deste trabalho é estudar de forma breve o status quaestionis e as propostas de lege lata e, principalmente, de lege ferenda do direito internacional privado da insolvência da República Argentina e do Mercosul à luz da atividade legiferante de organizações internacionais e não governamentais, e entidades científicas e profissionais na área do direito de falência internacional nos últimos 30 anos. Este trabalho faz ecoar as iniciativas elaboradas por instituições como o Banco Mundial, o Fundo Monetário Internacional, a Insol International, a Insol Europe, o International Insolvency Institute, o American Bankruptcy Institute, o American Law Institute, a International Bar Association, e regulações vigentes como o Regulamento Europeu sobre Insolvência de 2000 e 2015. O autor propõe a adoção de regulamentações como o Anteprojeto argentino de 2002 sobre a insolvência transfronteiriça, com algumas modificações e agregados, inspirado na Lei Modelo da Insolvência Transfronteiriça da Uncitral de 1997.

\section{Palavras-chave}

Direito internacional privado; direito internacional da insolvência; direito internacional privado da insolvência argentino; direito do Mercosul; insolvência internacional; reorganização empresarial internacional; capítulo 15 do Código de Falências dos Estados Unidos; direito europeu da insolvência. 
Sumario: Introducción. Objeto de este trabajo. 1. Contexto histórico de las nuevas normas nacionales e internacionales de la insolvencia. 2. Los Principios del Banco Mundial. 3. La labor de CNUDMI/ UNCITRAL. 4. Guía Legislativa de CNUDMI/UNCITRAL sobre el régimen de la insolvencia. 5. Ley Modelo de UNCITRAL/CNUDMI sobre la Insolvencia Transfronteriza, de 1997. 6. La reorganización concursal como objeto del Derecho Internacional Privado de la Insolvencia. 7. Propuestas de lege lata y de lege ferenda. 8. Conclusiones esenciales de la investigación. Bibliografía.

\section{Introducción. Objeto de este trabajo'}

Este trabajo tiene como objeto el estudio del status quaestionis y de propuestas de lege lata $\mathrm{y}$, sobre todo, de lege ferenda de la materia de derecho internacional privado de la insolvencia de la República Argentina y del Mercosur a la luz de la actividad legisferante de organismos internacionales, entidades no gubernamentales, y entidades científicas y profesionales en el área del derecho concursal internacional en los últimos 20 años.

En el mismo, el autor ha querido brindar un panorama bibliográfico general sobre el tema. ${ }^{2}$

Este trabajo hace eco de las iniciativas elaboradas por instituciones tales como el Banco Mundial, el Fondo Monetario Internacional, Insol International, Insol Europe, el International Insolvency Institute, el American Bankruptcy Institute, el American Law Institute, la International Bar Association, y de normas vigentes como el Reglamento Europeo sobre Insolvencia de los años 2000 y 2015. En el mismo se propone la adopción de normas como el Anteproyecto argentino del año 2002 sobre insolvencia transfronteriza, con algunas modificaciones y agregados, inspirado en la Ley Modelo sobre insolvencia transfronteriza de la United Nations Commission on International Trade Law (UNCITRAL) de 1997.

\section{Contexto histórico de las nuevas normas nacionales e internacionales de la insolvencia}

Desde los primeros años del siglo XX, la bibliografía sobre las cuestiones de derecho internacional privado de la insolvencia en los distintos países de Europa y América se ha visto vertiginosamente incrementada, tanto respecto de obras monográficas sobre la insolvencia internacional en general ${ }^{3}$ como en monografías

$1 \quad$ Nota: respecto de las abreviaturas jurídicas utilizadas en este trabajo, el lector puede consultar estas dos obras: Hildebert Kirchner y Eike Böttcher (eds.), Abkürzungsverzeichnis der Rechtssprache, 8. neu bearb. und erw. Aufl. Berlin [u.a.]: De Gruyter, 2015. XI, 1006 pp., y AA.VV. Columbia Law Review (comp.), Mary Miles Prince (ed.), The Bluebook, A Uniform System of Citation, Cambridge, Harvard Law Review Association, 2015.

2 El autor agradece al Max Planck Institut für ausländisches und internationales Privatrecht de Hamburgo, por la estancia de investigación llevada a cabo en el año 2015, durante la cual tuvo acceso a bibliografía que ha sido citada en este trabajo, con el apoyo económico de la Fundación Alexander von Humboldt de Alemania.

3 Para algunas obras generales sobre el derecho internacional privado que tratan la materia, y obras monográficas sobre derecho concursal internacional pueden consultarse las siguientes, entre otras: María Elsa Uzal, 
Procesos de insolvencia en el Derecho Internacional Privado, Buenos Aires, La Ley, 2008; Germán Esteban Gerbaudo, Insolvencia transfronteriza, Buenos Aires, Astrea, 2011; Dennis Campbell (ed.), International Corporate Insolvency Law, London, Butterworths, 1992; Alison Clarke (ed.), Current Issues in Insolvency Law, London, Stevens and Sons, 1991; Neil Cooper y Rebecca Jarvis (eds.), Recognition and Enforcement of Cross-Border Insolvency, Hoboken, Wiley, 1996; Stefan Smid, Deutsches und Europäisches Internationales Insolvenzrecht, 2004; Kurt Hans Nadelmann, Conflicts of Law: International and Interstate - Selected Essays, The Hague, Nijhoff Verlag, 1972; Jürgen Schmidt, System des deutschen internationalen Konkursrechtes, Frankfurt am Main, Vittorio Klostermann, 1972; W. W. McBryde, A. Flessner y S. C. Kortmann (eds.), Principles of European Insolvency Law, Kluwer Law International, 2003; Philip Smart, Cross-Border Insolvency, 2 ed., London, Charlottesville, Dublin, 1998; Sheldon Richard (ed.), Cross-Border Insolvency, 3 ed., Bloomsbury, Haywards Heath, 2011; Paul J. Omar, European Insolvency Law, Burlington, Hants, 2004; J. P. Lessing y J. F. Corkery (eds.), Corporate Insolvency Law, Queensland, Taxation and Corporate Research Centre, Bond University, 1995, Lipstein (ed.), Harmonisation of Private International Law by the EEC (1977), Chameleon / Institute of Advanced Legal Studies, London; William McBryde, Axel Flessner y S. C. J. Kortmann (eds.), Principles of European Insolvency Law, Deventer, 2003; Peter Leonhardt, Stefan Smid y Mark Zeuner (ed.), Internationales Insolvenzrecht Kommentar, 2 ed., Stuttgart, Auflage, 2012; Rudolf Keppelmüller, Österreichisches internationales Konkursrecht, Wien, 1997 (tesis defendida en Linz en 1996); Louis Jacques Blom-Cooper, Bankruptcy in Private International Law, London, The Eastern Press, 1954; Jacob Ziegel (ed.), Current Developments in International and Comparative Corporate Insolvency Law, Oxford, Clarendon Press, 1994; Nis Carstens, Die internationale Zuständigkeit im europäischen Insolvenzrecht, Köln, Berlin, München, 2005 (publicación de la Tesis defendida en Kiel en 2004); Peter Gottwald, Grenzüberschreitende Insolvenzen. Europäische und weltweite Tendenzen und Lösungen, München, C.H. Beck; Auflage, 1997; Bob Wessels, International Insolvency Law, Berlín, Kluwer, 2006; AA.VV., Probleme des internationalen Insolvenzrechts, Verhandlungen der Fachgruppe für vergleichendes Handels- und Wirtschasftsrecht anläßlich der Tagung für Rechtsvergleichung 1981 in Frankfurt a. M. Herausgegeben von Wolfgang Frühr, Marschall von Bieberstein, Bonn, mit Referaten von Hans Hanisch, Genf, Jacques Lemontey, Paris, Stefan Riesenfeld, Berkeley und mit einem Bericht über die Diskussion von Peter Gottwald, Bonn. Arbeiten zur Rechtsvergleichung. Schriftenreihe der Gesellschaft für Rechtsvergleichung. Begründet von Hans Dölle. Herausgegeben von Ernst von Caemmerer und Hans-Heinrich Jescheck. Band 113. Frankfurt am Main, Alfred Metzner Verlag, 1982; Lea Meriggi, Contributo alla dottrina del fallimento in diritto internazionale privato, Genova Società editrice del "Nuovo stato", 1936; Neil H. Cooper y Rebecca Jarvis, Recognition and enforcement of cross-border insolvency. A guide to international practice, Chichester, John Wiley \& Sons, 1996; Centre for Cooperation with the Economies in Transition, Procédures de faillite et de restructuration des entreprises dans les pays de l'OCDE et d'Europe, Paris, Organisation de Coopération et de Développement Économique, 1994; Stefan Reinhart, Sanierungsverfahren im internationalen Insolvenzrecht. Eine rechtsvergleichende Untersuchung über die besonderen internationalrechtlichen Probleme liquidationsabwender Insolvenzverfahren, Berlin, Scriften des Instituts für internationales Recht des Spar-, Giro- und Kreditwesens an der Universität Mainz, Band 93, Duncker \& Humblot, 1995; Gilberto Boutin, "La quiebra en el derecho internacional privado panameño y comparado", Revista del Colegio Nacional de Abogados de Panamá 2 (1986); J. H. Dalhuisen, Dalhuisen on international insolvency and bankruptcy, vol. I, New York, Mattew Bender, 1986; Daniele Luigi, Il fallimento nel Diritto Internazionale Privato e Processuale, Padova, Cedam, 1987; Carlos Esplugues Mota, La quiebra internacional, Barcelona, Bosch, 1993; Ian Fletcher, Insolvency in private international law: National and international approaches, 2 ed., Oxford Clarendon Press, 2005; Matthias Florian, Das englische internationale Insolvenzrecht, Heidelberg, Verlag für Recht und Wirtschaft, 1989; Pierre-Robert Gilliéron, Les dispositions de la nouvelle loi fédérale de droit international privé sur la faillite internationale, Lausanne, 1991; Mario Giuliano, Il fallimento nel diritto processuale civile internazionale, Milano, Giuffrè, 1943; Markus Kieser, Die Typenvermischung über die Grenze, Ein Beitrage zum internationalen Gesellschafts- und Insolvenzrecht, Dissertation, Konstanz, 1988; Thomas Laut, Universalität und Sanierung im internationales Insolvenzrecht, Berlin, Duncker \& Humblot, 1997; Robert Leitner, Der grenzüberschreitende Konkurs, Lösungsmöglichkeiten und -modelle aus österreichischer Sicht, Wien, Manzscha Verlags- und Universitätsbuchhandlung, 1995; Angela Lupone, L'insolvenza transnazionale. Procedure concorsuali nello stato e beni all'estero, Padova, Cedam, 1995; Meunier-Dollfus, Des effets de la faillite et de la liquidation judiciaire dans les rapports internationaux, Paris, Larose, 1903; Jean-Pierre Rémery, La faillite internationale, Paris, Presses Universitaires de France, 1996; Hans Stoll, Stellungnahmen und Gutachten zur Reform des deutschen Internationalen Insolvenzrechts, Tübingen, Mohr Siebeck, 1992; Alexander Trunk, Internationales Insolvenzrecht, Systematische Darstellung des deutschen Rechts mit rechtsvergleichenden Bezügen, Tübingen, Mohr Siebeck, 1998; Richard Potok (ed.), Cross Border Unilateral: Legal Risk and the Conflict of Laws, London, Butterworths, 2002; Philip R. Wood, Principles of international insolvency, London, Sweet \& Maxwell, 1995; Paul J. Omar (ed.), International Insolvency Law, Themes and Perspectives, Aldershot, Ashgate, 2008; Dennis Campbell y Anthony E. Collins (eds.), Corporate Insolvency and Rescue: The International Dimension, Deventer, Kluwer, 1993; Gerhard Kegel y Jürgen Thieme (eds.), Vorschläge und Gutachten zum Entwurf eines EG-Konkursübereinkommens, Im Auftrag einer Sonderkommission des Deutschen Rates für internationales Privatrecht, Tübingen, 1988; Michel Trochu, Conflits de lois et conflits de juridicitions en matière de faillite, Paris, Librairie Sirey, 1967; AA.VV., Cross border insolvency. Problems and legal principles, London, The British Institute of International and Comparative Law, 1986; Ross Cranston (ed.), Making Commercial Law: Essays in Honour of Roy Goode, Oxford, Clarendon Press, 1997; Ian Fletcher (ed.), Cross-Border insolvency: Comparative dimensions. The Aberystwyth Insolvency Papers, London, The United Kingdom National Committee of Comparative Law, 1990; Friedrich Meili, Moder- 


\section{sobre temas específicos de los concursos internacionales. ${ }^{4}$ Asimismo, pueden}

ne Staatsverträge über das internationale Konkursrecht, Zürich, 1907; Ian Fletcher (ed.), Cross-border insolvency: National and Comparative studies, Reports delivered at the XIII International Congress of Comparative Law, Montreal, 1990, Mohr Siebeck, Tübingen, 1992; Lars von Westpfahl, Uwe Goetker y Jochen Wilkens, Grenzüberschreitende Insolvenzen, Köln, RWS-Verl, Kommunikationsforum, 2008; Arbeitskreis für Insolvenz und Schiedsgerichtswesen (Hrsg.), Kölner Schrift zur Insolvenzordnung, 3. Aufl., 2009; Beck / Depre (Hrsg.), Praxis der Insolvenz, 2. Aufl., 2010; Rajak, Horrocks and Bannister (eds.), European Corporate Insolvency: A Practical Guide, Hoboken, Wiley, 1995; Peter Kindler y Josef Nachmann, Handbuch Insolvenzrecht in Europa, 4. Erg.-Lfg., München, Beck, 2014; Bruce Leonard y Christopher W. Besant (ed.), Current issues in cross-border insolvency and reorganizations, London, International Bar Association Series, 1994; Friedrich Meili, Lehrbuch des internationalen Konkursrechts, Zürich, 1909; AA.VV., L'Unificazione del diritto internazionale privato e processuale. Studi in memoria di Mario Giuliano (1914-1986), Padova, Cedam, 1989; Paul J. Omar (ed.), International Insolvency Law. Themes and Perspectives, Aldershot, Ashgate, 2008; Peter Aird y Richard M. Jackson, The Scots Dimension to Cross-Border Litigation, Oxford, Clarendon Press, 1996; Alice Beicher, Corporate Rescue, London, Sweet and Maxwell, 1997; David Brown, Corporate Rescue: Insolvency Law in Praclice, Hoboken, Wiley, 1996; Brian Cheffins, Company Law Theory Structure and Operation, Oxford, Oxford University Press, 1998; Peter North y J. J., Fawcett, Cheshire and North's Private International Law, 3 ed., London, Butterworths, 1999; Paul Davies, Gower's Principles of Modern Company law, 6 ed., London, Sweet and Maxwell, 1997; Dicey y Morris, Conflict of Laws, 11 ed., Stevens and Sons, 1987; Louis Doyle, "Administrative Receivership: Law and Practice", en Law and Tax, Sweet \& Maxwell, 1995; Ian Fletcher, Conflict of Laws and European Community Law, North-Holland Publishing Co., 1982; Ian Fletcher, The Law of Insolvency, 3 ed. Sweet and Maxwell, 1999; Ian Fletcher, Insolvency in Private International Law, Clarendon Press, 1999 (hay segunda edición de 2007); Ronald Harry Graveson, Conflict of laws, 7 ed. Sweet and Maxwell, 1974; O. Kahn-Freund, General Problems of Private International Law, Nijhof, 1976; Paul Le Cannu et al., Entreprises en Difficulté, Joly Editions, 1994; P. Mayer, Droit International Prive, 4 ed. Monchrestien, 1994; Robert Pennington, Corporate Insolvency Law, 2ed. Butterworths, 1997; Bernard Soinne, Traité des Procedures Collectives, 2 ed., L1TEC, 1995; Anker Sorensen y Paul Omar, Corporate Rescue Procedures in France, Kluwer, 1996; Fiona Tolmie, Introduction to Corporate and Personal Insolvency Law, Sweet and Maxwell, 1998.

4 Cfr., como bibliografía de referencia, entre otras, las siguientes: Ángel Espiniella Menéndez, Procedimientos de insolvencia y grupos multinacionales de sociedades, Cizur Menor, Thomson Civitas, 2006; Pierre Lalive y Frank Vischer (eds.), Colloque international sur le droit international privé des groupes de sociétés, Gèneve, Centre d'Etudes Juridiques Européennes de la Faculté de Droit de Genève, 1973; Irit Mevorach, Insolvency within Multinationl Enterprise Groups, New York, Oxford University Press, 2009; Rike Werner, Der Insolvenzplan im Anwendungsbereich der europäischen Insolvenzverordnung, Jena, Otto Schmidt Verlagskontor, 2010 (Tesis defendida en Bielefeld 2010); Paul Michael Veder, Cross-Border Insoivency Proceedings And Security Rights. A Comparison of Dutch and German Law, the EC Insolvency Regulation and the UNC1TRAL Model Law on CrossBorder Insoivency, Deventer, Kluwer, 2004 (Tesis defendida en Nimega en 2004); Klemens Teipel, Die Bedeutung der lex fori für die Anknüpfung des Haftungsdurchgriff.;s, Heidelberg, Verlag Recht und Wirtschaft GmbH, 1994; Ulrich Tilman, Regeln des internationales Privatrechts über die Haftung des Gesellschafters oder der Verwaltung einer Kapitalergesellschaft, Göttingen, Dissertation, 1972; Eiji Takahashi, Konzern und Unternehmensgruppe in Japan, Regelung nach dem deutschen Modell?: Eine vergleichende Untersuchung nach japanischem und deutschem Konzernrecht, vol. 38, Studien zum ausländischen und internationalen Privatrecht, Tübingen, Mohr, 1994; Andreas Spahlinger, Sekundäre Insolvenzverfahren bei grenzüberschreitenden Insolvenzen, Eine vergleichende Untersuchung zum deutschen, US-amerikanischen, schweizerischen und europäischen Recht, Tübingen, Mohr Siebeck, Max Planck Institut, 1998; Gert Spennemann, Insolvenzverfahren in Deutschland-Vermögen in Amerika: Das Beispiel Herstatt, Fragen des Internationalen Insolvenzrechtes der Bundesrepublik Deutschland und der USA, Düsseldorf, Peter Mannhold, 1981; Andreas Rohr, Der Konzern im IPR unter besonderer Berücksichtigung des Schutzes der Minderheitsaktionäre und der Gläubiger, Zürich, Schulthess Polygraphischer Verlag, 1983; Claudia Schmidt, Der Haftungsdurchgriff und seine Umkehrung im internationalen Privatrecht, Eine systematische Untersuchung des direkten und des umgekehrten Haftungsdurchgriff im internationalen Privatrecht Deutschlands, der Schweiz und Österreichs, vol. 31, Studien zum ausländischen und internationalen Privatrecht, Tübingen, Mohr (Paul Siebeck), 1993; Sandra Werlen, Haftung für ausländische Gesellschaften. Sonderanknüpfung gesellschaftsrechtlicher Verantwortlichkeit. Art. 159 IPRG im Vergleigh mit den Equal Treatment Statutes und der Rechtsprechung zur Pseudo-Foreign Corporation in den Kollisionrechten der USA, Zürich, Dissertation, Universität Zürich, Schulthess Plygraphischer Verlag AG, 1999; Sixto Sánchez Lorenzo, Garantías reales en el comercio intemacional, Civitas, 1993; Daniela Favoccia, Vertragliche Mobiliarsicherheiten im internationalen Insolvenzrecht, Heymann, 1991; Peter Wilmowsky von, Europäisches Kreditsicherungsrecht. Sachenrecht und Insolvenzrecht under dem EG-Vertrag., Tübingen, Mohr, 1996 (Tesis de Habilitación defendida en Frankfurt a. M. en 1994); Paul L. C. Torremans, Cross Border Insolventes in EU, English and Belgian Law, Den Haag, London, New York, 2002; Eltje Aderhold, Auslandskonkurs im Inland. Entwicklung und System des deutschen Rechts mit praktischen Beispielen unter besonderer Berücksichtigung des Konkursrechts der Vereinigten Staaten von Amerika, England, Frankreichts sowie der Schweiz, Berlin, Dunker und Humblot, 1992; Mathias A. Wittinghofer, Der nationale und internationale Insolvenzverwaltungsvertrag. Koordination paralleler Insolvenzverfahren durch ad hoc-Vereinbarungen, Bielefeld, Gieseking, 2004 (publicación de la Tesis defendida en Münster en 2003); Jochen Beckmann, Internationales Insolvenzrecht im Mercosur, Baden Baden, Nomos Verlagsgesellschaft, 2000; Eberhard Schollmeyer, Gegenseitige Verträge im in- 


\section{encontrarse tratamientos sobre esta temática en monografías sobre otros temas que están relacionados con los concursos internacionales ${ }^{5}$ y en obras sobre de- recho concursal interno en las que se tratan aspectos internacionales. ${ }^{6}$ Final-}

ternationalen Insolvenzrecht, Bonn, Köln Berlin, 1997 (publicación de la Tesis defendida en Freiburg en 1996); Matthias Baierlipp, Die Haftung der Muttergesellschaft eines multinationalen Konzerns für die Verbindlichkeiten ihrer ausländischen Tochtergesellschaft. Eine vergleichende Untersuchung nach deutschem und französischem Recht, Hamburg, Verlag Dr. Kovac̃, 2002; Thomas Wazlawik, Die Konzernhaftung der deutschen Muttergesellschaft für die Schulden ihrer US-amerikanischen Tochtergesellschaft, Tübingen, Mohr Siebeck, 2004; AA.VV., Premier Séminaire de Droit International et de Droit Européen. Neuchâtel, 11-12 octobre 1985. Le droit de la faillite international, Zürich, Schulthess Plygraphischer Verlag, 1986; Phillip I. Blumberg, The multinational challenge to corporation law. The search for a new corporate personality, New York, Oxford, Oxford University Press, 1993; Louis Jacot, La faillite dans les relations de droit international privé de la Suisse. Thèse de Doctorat, Neuchatel, Imprimeries Réunies Borel \& Seiler SA, 1932; Jacques Van der Gucht, Droit de la faillite dans les six pays du Marché commun. Éditions Simon Stevin. Bruxelles. 1964; AAVV. Les problèmes internationaux de la faillite et la Marché Commun. Actes $d u$ Colloque International sur l'avant-projet de convertion C.E.E. en matière de faillite, concordats et procédures analogues, Milan, 12-14 juin 1970, Padova, Cedam, 1971; Johann Laubacher, Die Haftungsproblematik bei Konkurs einer Gesellschaft innerhalb eines transnationalen Unternehmens: eine Untersuchung auf der Grundlage des deutschen Aktienkonzernrechts, Konstanz, Hartung-Gorre, 1984; Rauls Henning, Das Reorganisationsverfahren der USA gemäß Chapter 11 BC im Deutschen Internationalen Privatrecht, Göttingen, Shaker Verlag, 1993, Dissertation; Klaus Tschernig, Haftungsrechtliche Probleme der Konzerinsolvenz: eine untersuchung nach deutshcem und USamerikanischen Recht unter besonderer Berücksichtigung der Problematik grenzüberschreintender Konzerninsolvenzen, Frankfurt am Main, Verlag Peter Lang, 1995; Iris-Claude Turck, Das Internationale Insolvenzrecht in Spanien in rechtsvergleichender Betrachtung, Frankfurt am Main, Verlag Peter Lang, 1995; Markus Wick, Der Durchgriff und das auf ihn anwendbare Recht gemäss IPRG, Zürich, Schulthess Polygraphischer Verlag, 1996; Alexandra Zenneck, Hauptverfahren grenzüberschreitender Insolvenzen von Kapitalgesellschaften und ihre Anerkennung durch unterstützende Nabenverfahren in Deutschland, der Schweiz und den USA, München, VVF, 1996; Laura García Gutiérrez, La compensación de creditos en Derecho internacional privado, Madrid, Univeridad Autónoma de Madrid, 2003. Daniel Staehlin, Die Anerkenung ausländischer Konkurse und Nachlassverträge in der Schweiz (Art. 166 ff. IPRG), Helbing \& Lichtenhahn, 1989.

5 Cfr., como bibliografía de referencia, entre otras, las siguientes: Jan Kropholler, Internationales Privatrecht, vol. 6, Tübingen, Auflage, 2006; Geimer, Internacionales Zivilprozessrecht, 4 ed. Köln, 2001; AA.VV. Runkel (ed.), Anwalts-Handbuch Insolvenzrecht, vol. 2, Aufl, 2008; AA.VV. Rauscher (ed.) Europäisches Zivilprozeßrecht, vol. 2, Auflage, 2006; AA.VV. Jacques van der Gucht (ed.), Idées nouvelles dans le droit de la faillite. Travaux de la 4. journée d'études juridiques Jean Dabin. 17 mai 1968, vol. 6, De Bruylant, Bruxelles, 1969 (Biblithèque de la Faculté de Droit de l'Université Catoholique de Louvain); Thomas Jackson, The Logic and Limits of Bankruplcy Law, Beard Books, 1986; Phillip I. Blumberg, The law of corporate groups: Bankruptcy Law, Boston y Toronto, Little, Brown \& Company, 1985 y Supplement 2000 (hay edición posterior de la obra completa); Roy Goode, Principles of Corporate Insolvency Law, 4 ed. London, Sweet \& Maxwell, 2011; Vesna Lazic, Insolvency proceedings and commercial arbitration, Stichting, The Hague, 1998; Bernhard Großfeld, Internationales Unternehmensrecht. Das Organisationsrecht transnationaler Unternehmen, Heidelberg, C. F. Müller Juristischer Verlag, 1986 (contiene análisis sobre la insolvencia internacional); Henry Hansmann y Reinier Kraakman, "The Essential Role of Organizational Law", en Yale L. J., 2000, pp. 387 y ss.; Miguel Virgós y Francisco Garcimartin, Derecho procesat civil internacional. Litigación intemacional, Civitas, 2000; AA.VV. Martin Gebauer (ed.), Zivilrecht unter europäischem Einfluss: die richtlinienkonforme Auslegung des BGB und anderer Gesetze; Kommentierung der wichtigsten EU-Verordnungen, vol. 2, Stuttgart, München, Hannover, Berlin, Weimar y Dresden, überarb. und erw. Aufl., Boorberg, 2010; Burkhard Hess, Europäisches Zivilprozessrecht: ein Lehrbuch, Heidelberg, Müller, 2010; Harry Rajak (ed.), Insolvency Law Theory and Practice, Sweet and Maxwell, 1993; AA.VV. Anker Sorensen (ed.), Directors' Liabilities in Case of Insolvency, Kluwer, 1998; AA.VV. M. Wheeler y R. Oldfield (eds.), International Insolvency Procedures, 2 ed. Blackstone, 1997.

6 Como bibliografía de referencia (solo se citan algunas obras), cfr., entre otras: Hans-Peter Kirhhof, Rolf Stürner y Horst Eidenmüller (eds.), Münchener Kommentar zur Insolvenzordnung, vol. 3, Auflage, München, Beck, Online-Ressource E-Buch, 2018; Klaus Wimmer (ed.), FK-InsO, Frankfurter Kommentar zur Insolvenzordnung: mit EuInsVO, InsVV und weiteren Nebengesetzen, vol. 6, Köln, Auflage Luchterhand, 2011; Wilhem Uhlenbruch, Insolvenzordnung, vol. 12, Auflage, 2003; Eberhard Braun (ed.), Bauch von Rüdiger, Insolvenzordnung (InsO), Kommentar, vol. 5, München y Beck, Auflage, 2012; Peter Gottwald (ed.), Insolvenzrechts-Handbuch, vol. 5, München y Beck, Auflage, 2015; Marie Luise Graf-Schlicker (ed.), Kommentar zur Insolvenzordnung: InsO, vol. 2, Köln, Auflage, RWS Verl. Kommunikationsforum, 2010; Marie Luise Graf-Schlicker y Ursula Schlegel, Insolvency Law \& Restructuring in Germany, München, Beck, 2015. Andreas Konecny (ed.), Kommentar zu den Insolvenzgesetzen, 2007. Insolvenzordnung (Heidelberger Kommentar), Heidelberg, München, Landsberg, Frechen y Hamburg; Müller (ed.), von Gerhart Kreft. Bearb. von Peter Depré .... - 6., neu bearb. Aufl., 2011; Bruno Kübler, Hanns Prütting y Reinhard Bork, Insolvenzordnung, Loseblatt, 2017; Andreas Schmidt (ed.) Hamburger Kommentar zum Insolvenzrecht, vol. 3, Auflage, 2009; Jean-Luc Vallens, L'insolvabilite des entreprises en droit compare, Paris, Joly, 2011. 


\section{mente, y no por ello menos importante, en los últimos años se han publicado numerosos artículos sobre el instituto en general ${ }^{7}$ y sobre aspectos específicos o particulares del mismo. ${ }^{8}$ Este desarrollo ya había comenzado en forma inci-}

7 Para algunos artículos que abordan un análisis general de la materia, cfr., como bibliografía de referencia, entre otros, los siguientes: Bob Wessels, "Current developments towards international insolvencies in Europe", en Int. Insolv. Rev. 13 (2004), pp. 43 y ss.; Jay Lawrence Westbrook, "A global solution to multinational default", en Mich. L Rev. 98 (2000), pp. 2276 y ss.; J. Taupitz, “Das zukünftige europäische Internationale Insolvenzrecht - insbesondere aus international - privatrechlicher Sicht", ZZP (1998), pp. 315 y ss.; Paul J. Omar, "The Landscape of International Insolvency Law", en Int. Insolv. Rev. 11 (2002), pp. 173 y ss.; Axel Flessner, "Philosophies of Business Bankruptcy Law: An International Overview", en Jacob S. Ziegel (ed.), Current Developments in International and Comparative Corporate Insolvency Law, Oxford, Oxford University Press, 1994; Axel Flessner, "Grundsätze des europäischen Insolvenzrechts", en ZEuP (2004), pp. 887 y ss.; Ian Fletcher, "Maintaining the Momentum: The Continuing Quest for Global Standards and Principles to Govern CrossBorder Insolvency"., en Brook. J. Int'l, L. 32 (2007), pp. 767 y ss.; AA.VV. Enciclopedia del diritto, vol XVI, Milano, Giuffrè, 1967; J. A. Pastor Ridruejo, "La faillite in droit international privé", en Recueil des Cours 133 (1971), pp. 141-221; Albéric Rolin, "Des conflicts de lois en matière de faillite", en Recueil des Cours 14 (1926), pp. 5-160; Donald T. Trautman, Jay Lawrence Westbrook y Emmanuel Gaillard, "Four models for international bankruptcy", en The American Journal of Comparative Law 41 (1993), pp. 573-625.

8 Para algunos artículos sobre aspectos particulares en esta materia pueden consultarse, entre otros, los siguientes autores de referencia: Keine Von Wilmowsky, "Aufrechnung in internationalen Insolvenzfällen-kollisionsrecht der Insolvenzauchrechnung", en KTS, 1998, pp. 343 y ss.; Alexander Trunk, "Regelungsschwerpunkte eines Ausführungsgesetzes zum Europäischen Insolvenzübereinkommen”, en Stoll (ed.) Vorschläge und Gutachten zur Umsetzung des EU-Übereinkommeus über Insolvenzverfahren im deutschen Recht, 1997, pp. 232 y ss.; Jürgen Thieme, "Partikularkonkurs", en Hans Stoll (ed.), Stellungnahmen und Gutachten zur Reform des deutschen Internationalen Insolvenzrechts, 1992, pp. 212 y ss.; Leipold Dieter, "Zum künftigen Weg des deutschen internationalen Insolvenzrechts", en AA.VV. Hans Stoll (ed.) Vorschläge und Gutachten zur Umsetzung des EU-Übereinkommens über Insolvenzverfahren im deutschen Recht, 1997, pp. 185 y ss.; Grasmann, "Effets nationaux d'une procédure d'execution collective étrangère", en Rev.crit.dr.internat.prive (1990), pp. 421 y ss.; Peter Von Wilmowsky, “Choice of Law in International Insolvencies - A Proposal for Reform-", en Jürgen Basedow y Kono Toshiyuki (eds.), Legal Aspects of Globalization, J. M. Smits, 2000, pp. 197 y ss.; S. Homann, "System der Anerkennung eines ausländischen Insolvenzverfahrens", en KTS (2000), pp. 343 y ss.; Erick Jayme y Christian Kohler, "Europäisches Kollisionsrecht 2000: Interlocales Privatrecht oder universelles Gemeinschaflsrecht?", en IPRax (2000), pp. 454 y ss.; Ulrich Spellenberg, "Des ordre public im Internationalen Insolvenzrecht", en Hans Stoll (ed.), Stellungsnamen und Gutachten zur Reform des deutschen Internationalen Insolvenzrechts, 1992, pp. 183 y ss.; K. Siehr, "International Aspects of Bankruptcy", en Transnational aspects of procedural law, 1998, pp. 873 y ss.; O. Reinhart, "Zur Anerkennung ausländischer Insolvenzverfahren, Eine Besprechung des Works- Data-Urleils des Bundesgerichtshofes", en ZIP (1997), pp. 1734 y ss.; Pielorz, “Inlandsvermögen im Auslandskonkurs. Zur Handlungsbegugnis ausländischer Konkursorgane in Deutschland", en ZIP (1980), pp. 239 y ss.; José Paz-Ares y Francisco Garcimartin, "Conflictos de leves y garantías sobre valores anotados en intermediarios financieros", en RDM (2000), pp. 1479 y ss.; Ernest Krings, "Unification legislative internationale récente en matière d'insolvabilité et de la faillile”, en Uniform L. Rev. (1997), pp. 657 y ss.; W. Henckel, “Die internationalprivatrechtliche Anknüpfung der Konkursanfechtung", en AA.VV. Beiträge zum internationalen Verharensrecht und zu Schiedsgerichtsbarkeit, Festschrift für Heinrich Nagel zum 75. Geburtstag, herausgegeben von Walther J. Babscheid und Karl Heinz Schwab, Aschendorff, Münster, 1987, pp. 93 y ss.; J. Haubold, “Europäisches Zivilverfahrensrecht und Ansprüche im Zusammenhang mit Insolvenzverfahren", en IPRax (2002), pp. 157 y ss.; Ulrik Rammeskow, "Asset Distribution in Transnational Insolvencies: Combining Predictability and Protection of Local Interests", en ABIJ (1999), pp. 385 y ss.; Hans Hanisch, "Die Wirkung dinglicher Mobiliarsicherungsrechte im grenzüberschreitenden Insolvenzverfahren", en Etudes de Droit International en l'Honneur de Paul Lalive (1993), pp. 61 y ss.; Hans Hanisch, “Die Wende im deutschen internationalen Insolvenzrecht», ZIP, 1985, pp. 1233 y ss. Huber, «Internationales lnsolvenzrecht in Europa", en ZZP (2001), pp. 133 y ss.; Jens Haubold, "Mitgliedstaatenbezug, Zuständigkeitserschleichung und Vermögensgerichtsstand im Internationalen lnsolvenzrecht", en IPRax (2003), pp. 34 y ss.; Marc-Philippe Weller, "Forum Shopping im Internationalen Insolvenzrecht?", en IPRax (2004), pp. 412 y ss.; Sven-Holger Undritz, "Restrukturierung in der Insolvenz", en ZGR (2010), pp. 201 y ss.; Jean-Luc Vallens, "Transfert du siege statutaire et transfert du centre des interets principaux", en Dalloz (2011), pp. 2915 y ss.; Felix Steffek, "Insolvenzgründe in Europa - Rechtsvergleich, Regelungsstrukturen und Perspektiven der Rechtsangleichung", en KTS (2009), pp. 317 y ss.; Heinz Vallender, "Die Insolvenz von Scheinauslandsgesellschaften", en ZGR (2006), pp. 425 y ss.; Heinz Vallender, "Gefahren für den Insolvenzstandort Deutschland", en NZI (2007), pp. 129 y ss.; Gerald Spindler, "Der Gläubigerschutz zwischen Gesellschafts- und Insolvenzrecht", en JZ (2006), pp. 839 y ss.; Renato Rordorf, "Cross Border Insolvency", en IILR (2010), pp. 16 y ss.; Wolfgang Lüke, “Das europäische Internationale Insolvenzrecht”, en ZZP 111 (1998), pp. 275 y ss.; Lynn M. LoPucki, "Cooperation in International Bankruptcy: A Post-Universalist Approach", en Com. L. Rev. 84 (1999), pp. 696 y ss; Frederick Alexander Mann, "Bemerkungen zum Internationalen Privatrecht 
der Aktiengesellschaft und des Konzerns, Wirtschaftsfragen der gegenwart”, en Festschrift für Carl Hans Bärz 65 (6) (1974). Herausgegeben von Robert Fischer, Philipp Möhring und Harry Westermann, Walter de Gruyter, Berlin, New York, 1974, pp. 219-238; Kurt H. Nadelmann, “Creditor Equality in Inter-State Bankruptcies: A Requisite of Uniformity in the Regulation of Bankruptcy", en U. Pa. Law Rev. 98 (1949), pp. 41 y ss.; Kurt H. Nadelmann, "Discrimination in Foreign Bankruptcy Laws Against Non-Domestic Claims", en Am. Bankr. L. J. 47 (1973), pp. 147 y ss.; Hans Hanisch, “Grenzüberschreitende Insolvenz. Drei Lösungsmodelle im Vergleich", en Andreas Heldrich y Takeyoshi Uchida (eds.), Festschrift für Hideo Nakamura 70 (2) (1996), pp. 221 y ss.; Hans Hanisch, "Internationale Insolvenzrechte des Auslandes und das Gegenrecht nach Art. 166 Abs. 1 IPRG", en Sweizerische Zeitschrift für internationales und europäisches Recht (1992), pp. 3-32; AA.VV. Enciclopedia del diritto, vol. XVI, Milano, Giuffrè, 1967, pp. 264-265; Dieter Leipold, “Internationale Zuständigkeit, inländische Einzelrechtsverfolgung trotz eines Auslandskonkurses, Auswirkungen eines ausländischen Konkurses auf im Inland anhängige Zivilprozesse. Bemerkungen zum Vorentwurf für eine Regelung des Internationalen Insolvenzrechts, insbesondere aus verfahrensreclitlicher Sicht", en AA.VV. Hans Stoll (ed.), Stellungnahmen und Gutachten zur Reform des deutschen Internationalen Insolvenzrechts. Im Auftrag der Sonderkommission "Internationales Insolvenzrecht" des Deutschen Rates für Internationales Privatrecht. Tübingen, Mohr, 1992, pp. 72 y ss.; AA.VV., "Seminar on the occasion of the Tenth Anniversary of Forum Internationale. Cross border insolvency", en Forum Internationale 19 (1994), pp. 3-55; Dieter Leipold, "Zur internationalen Zuständigkeit im Insolvenzrecht", en Festschrift für Gottfried Baumgärtel zum 70. Geburtstag. Herausgegeben von Hanns Prütting. Carl Heymanns Verlag KG. Köln, 1990, pp. 291-309; David Aronofsky, “Piercing the Transnational Corporate Veil: Trends, Developments and the Need for Widespread Adoption of Enterprise Analysis", North Carolina Journal of International Law and Commercial Regulation 10 (1985), pp. 31-86; Raj Bhala, "International dimensions of Japanese insolvency law: A contextual approach", en Discussion Paper n. 99-E-26, Institute for Monetary and Economic Studies, Bank of Japan, 1999; Ulrich Drobnig, "Secured credit in international insolvency proceedings", en Texas International Law Journal 33 (1998), pp. 54-70; Wolfgang Lüke, "The new european law on international insolvencies: A german perspective", en Bankr. Dev. J. 17 (2001), pp. 369 y ss; Paolo Fois, "Considerazioni sulla delibazione delle sentenze straniere di estensione del fallimento", en Rivista di Diritto Internazionale Privato e Processuale (1967), pp. 246-267; Hartmut Fromm, "Haftungsfolgen bei der Verwaltung ausländischer Tochtergesellshaften", en IPRAX (1983), pp. 83-97; A. D. Grace, "Law of liquidations: the recognition and enforcement of foreign liquidation orders in Canada and Australia, A critical comparison", en International and Comparative Law Quarterly 35 (1986), pp. 664-703; Hans Hanisch, "Internationale Insolvenzrechte des Auslandes und das Gegenrecht nach Art. 166 Abs. 1 IPRG", Sweizerische Zeitschrift für internationales und europäisches Recht (1992), 3-32; Klaus J. Hopt, Legal issues and questions of policy in the comparative regulation of groups", en AA.VV. I gruppi di società. Atti del Convegno Internazionale di studi. (Venezia. 16-18 novembre 1995), volume primo, Milano, Giuffrè, 1996, pp. 45-64; Dieter Leipold, "Zur internationalen Zuständigkeit im Insolvenzrecht", en Festschrift für Gottfried Baumgärtel zum 70. Geburtstag. Herausgegeben von Hanns Prütting, Köln, Carl Heymanns Verlag KG, 1990, pp. 291-309; Frederick Alexander Mann, “Bemerkungen zum Internationalen Privatrecht der Aktiengesellschaft und des Konzerns, Wirtschaftsfragen der gegenwart", en Festschrift für Carl Hans Bärz zum 65. Geburtstag am 6. Dezember 1974. Herausgegeben von Robert Fischer, Philipp Möhring und Harry Westermann, Berlin y New York, Walter de Gruyter, 1974, pp. 219-238; Kurt H. Nadelmann, "Bankruptcy treaties", en University of Pennsylvania Law Review (1944), pp. 58-97; Stefan Riesenfeld, “Das neue Gesicht des deutschen Internationalen Konkursrechts aus ausländischer Sicht”, Festschrift für Franz Merz. Zum 65. Geburststag am 3. Februar 1992. Hrsg. Von Walter Gerhardt. Köln,Kommunikationsforum Recht, 1992; Christoph G. Paulus, "A New German Decision on International Insolvency Law", en American Journal of Comparative Law 41 (1993), pp. 667-674; Arnold M. Quittner, "Cross-border Insolvencies. Ancillary and Full Cases: the Concurrent Japanese and United States Cases of Maruko Inc.", en International Insolvency Review 4 (1995), pp. 171-188; Kurt H. Nadelmann, "Ausländisches Vermögen unter dem Vorenlwurf eines Konkursabkommens für die EWG-Staaten”, en KTS (1971), pp. 65 y ss.; Sixto Sanchez Lorenzo, "Eficacia de la declaración de un concurso pronunciado en el extranjero: paralización de las acciones individuales", en $\mathrm{La}$ Ley (España) 2 (1989), pp. 1029-1036; Alberto Santa María, "Problemi attinenti al diritto internazionale privato e processuale delle società", en Rivista delle Società (1987), pp. 1473-1500; Philip St. J. Smart, "International insolvency and the enforcement of foreign revenue laws", en International and Comparative Law Quarterly 35 (1986), pp. 704-710; Paul Volken, "Europäische Harmonisierung des Konkursrecht: frühe Staatsverträge", en Beiträge zum schweizerischen und internationalen Zivilprozeßrecht. Festschrift für Oscar Vogel, Universitätsverlag, Freiburg. Schweiz, 1991, pp. 465-481; Jay Lawrence Westbrook, "Extraterritoriality, conflict of laws, and the regulation of transnational Business", en Texas International Law Journal 25 (1990), pp. 71-97; Jay Lawrence Westbrook, "Theories of parent company liability and the Prospects for an International Settlement", en Texas International Law Journal 20 (1985), pp. 321-331; J. W. Woloniecki, “Co-operation Between National courts in International Insolvencies: recent United Kingdom legislation", en International and Comparative Law Quarterly 35 (1986), pp. 644-663; Philip R. Wood, "Principles of international insolvency (Part I)", en International Insolvency Review 4 (1995), pp. 94-103 y 109-138; Koresuke Yamauchi, “Internationales Konzernrecht in Japan”, en ZGR (1991), pp. 235-251; Michael Bogdan, "Rezension”, en Gerhard Kegel y Jürgen Thieme (eds.), Vorschläge und Gutachten zum Entwurf eines EG-Konkursübereinkommens. Im Auftrag einer Sonderkommission des Deutschen Rates für internationales Privatrecht, Tübingen, 1988, RabelsZ 53 (1989), pp. 573 y ss. 
piente a fines del siglo $\mathrm{XIX},{ }^{9} \mathrm{y}$ también se vio enriquecido con estudios históricos sobre la temática de la insolvencia internacional. ${ }^{10}$ De la misma manera, se han puesto en contraste las reglas teóricas y prácticas involucradas en la insolvencia transnacional. ${ }^{11}$

Por otra parte, y particularmente en las últimas tres décadas, se ha intensificado la internacionalización de la actividad empresarial, económica y financiera, lo que ha provocado una mayor conflictividad entre acreedores y deudores en los foros multinacionales, especialmente en casos de grupos de sociedades que operan en diversos países. ${ }^{12}$ Esto no se da solo entre las partes contendientes, sino también entre tribunales de distintos países respecto de activos o pasivos concursales de un mismo deudor que opera en ellos, lo que plantea problemas de competencia, jurisdicción y de derecho aplicable. Como frecuentemente no existe una autoridad superior que dirima esas disputas de competencia, en ese periodo se han implementado normas de fuente interna o internacional sobre coordinación, cooperación y comunicación entre los tribunales intervinientes, como el Reglamento sobre Procedimientos de Insolvencia ("Reglamento") de la Unión Europea de 2000, el Reglamento de la Unión Europea de 2015 o la Ley Modelo de UNCITR A L sobre Insolvencia Transfronteriza (en adelante Ley Modelo o LMIT) de 1997.

Por otra parte, las crisis sistémicas regionales, como por ejemplo, la del este asiático en la segunda mitad de la década de los noventa, o las crisis latinoamericanas de los años noventa y principios de 2000 y años subsiguientes; la

9 Cfr., como bibliografía de referencia Paul Nachbaur, De la faillite en droit international privée ou des effets du Jugement déclaratif rendu à l'étranger, Nancy, Typographie G. Crépin-Leblond, 1883; Vincenzo Pennetti, Fallimento delle società commerciali nei rapporti internazionali, Torino-Paris, Nabu Press, 1898; Josephus Jitta, La Codification du Droit international de la Faillite, Den Haag, Belinfante, 1895; Edmond Eugene Thaller, Des faillites en droit compare avec une etude sur le règlement des faillites en droit international, Paris, Hachette Livre-bnf, 1887; Francis Wharton, A Treatise on the Conflicts of Laws or Private International Law, Including a Comparative View of Angloamerican, Roman, German, and French Jurisprudence, Philadelphia, Nabu Press, 1872.

10 Cfr., como bibliografía de referencia, entre otros, Friedrich Meili, Die geschichtliche Entwicklung des internationalen Konkursrechtes, Zürich, Kessinger Pub Co, 1908; Kurt H. Nadelmann, "Codification of Conflicts Rules for Bankruptcy", en Schw. Jb. Int. R. 30 (1974), pp. 57 y ss.; Kurt H. Nadelmann, "An International Bankruptcy Code: New Thoughts on an Old Idea", en Int. Comp. Law Q. 10 (1961), pp. 70 y ss.; Kurt H. Nadelmann, "Henry Wheaton on 'American Law' in "The Jurist" (London)", en N. Y. L. F. 4 (1958), pp. 59 y ss.; Christoph G. Paulus, "Josef Köhler und die Entwicklung des modernen Insolvenzrechts", en Stefan Grundmann (ed.), Festschrift 200 Jahre Juristische Fakultät der Humboldt-Universität zu Berlin, Berlin, Geschichte, Gegenwart und Zukunft, 2010, pp. 1131; Hans Hanisch, "Bemerkungen zur Geschichte des internationalen Insolvenzrechts", en Festschrift für Franz Merz. Zum 65. Geburststag am 3. Februar 1992. Hrsg. Von Walter Gerhardt. Köln, Kommunikationsforum Recht, 1992; David Graham, “Discovering Jabez Henry. Part I. Cross-Border Insolvency Law in the 19th Century", en Int. Insolv. Rev. 10 (2001), pp. 153 y ss.; David Graham, "In Search of Jabez Henry - Part II: The Readership of Foreign Law", en Int. Insolv. Rev. 14 (2005), pp. 223 y ss.

11 Cfr., entre otros, Jay Lawrence Westbrook, "Theory and pragmatism in global insolvencies: Choice of law and choice of forum”, en Am. Bankr. L. J. 65 (1991), pp. 457 y ss.; Lars Westpfahl, “Die Praxis der grenzüberschreitenden Konzerninsolvenz", en Michael Dahl, Lians-Gerd H. Jauch y Christian Wolf (eds.), Festschrift für Klaus Hubert Görg zum 70, München, Geburtstag, 2010, pp. 569 y ss.

12 Sobre la cuestión de grupos societarios multinacionales en situación concursal puede consultarse, entre otras, la siguiente bibliografía de referencia: Ángel Espiniella Menéndez, Procedimientos de insolvencia y grupos multinacionales de sociedades, Cizur Menor, Thomson Civitas, 2006; Sarkis Bezelgues, Konzerninsolvenzen in der Europäischen Union. Mamburg, 2008 (Tesis Doctoral defendida en Berlín en 2007); Klaus Pannen, "Aspekte der europäischen Konzerninsolvenz", en ZInsO (2014), pp. 222 y ss. Ver también las monografías sobre temas particulares citadas en la nota 3 de este trabajo y la bibliografía citada en la nota 55 de este trabajo. 
incorporación de los países de la antigua Unión Soviética a la economía capitalista de mercado; la carencia de sistemas normativos concursales adecuados de algunos países de Asia y de otros países; la obsolescencia de ciertos sistemas normativos concursales en otras latitudes y, en algunos casos, la inexperiencia práctica para resolver la insolvencia empresarial, han sido algunos de los factores que se han dado en los últimos 30 años. Ello ha conducido a la identificación -de modo rápido y coordinado- de los mejores principios o buenas prácticas en el área de las relaciones de crédito y de la insolvencia, con miras a la utilización de tales principios para medir el grado de efectividad de los respectivos sistemas legales en esas áreas, y, posteriormente, para alentar a los países a reformar sus legislaciones nacionales a fin de acercarlas a ideales de efectividad internacionalmente reconocidos. Ante ello, la comunidad internacional, a través de diversas entidades o agencias de la Organización de las Naciones Unidas (ONU), asociadas a otros organismos multilaterales de crédito, a federaciones internacionales de profesionales de la insolvencia y a organizaciones privadas, ha venido desarrollando una intensa y prolífica actividad en el área del derecho de la insolvencia y las relaciones de crédito en el sector privado de la economía. ${ }^{13}$

En tal sentido, se ha puesto de relieve que solo regímenes legales predecibles en el área concursal, aplicados de manera congruente por una judicatura independiente, imparcial y eficiente, alientan a los acreedores a negociar con los deudores para evitar el cierre o la liquidación de una empresa en dificultades, más que a retirar el flujo de crédito y lanzarse a la ejecución individual de los activos a la primera señal de dificultad financiera o económica. Además, las leyes saludables de insolvencia, bien aplicadas, promueven la eficiente redistribución de los activos de las empresas fracasadas hacia otros emprendimientos con mejores perspectivas, tanto en el caso de reorganización empresarial como de liquidación. ${ }^{14}$

De este modo, modernos y saludables sistemas de insolvencia y de regulación legal de las relaciones entre acreedores y deudores constituyen uno de los cimientos de la inversión, el crédito y el desarrollo económico duradero, contribuyen a la estabilidad del sistema financiero de un país, y proveen una válvula de seguridad a la hora de los fracasos empresariales, a fin de preservar valor, empleos y protección social. ${ }^{15}$

Luego de las crisis asiáticas de 1997 y 1998, el tema del derecho nacional de insolvencia se instaló en numerosos encuentros y agendas de organismos mul-

13 Acerca de esta actividad promotora de legislaciones sobre la insolvencia, especialmente en el ámbito internacional, pueden verse las fundamentadas consideraciones vertidas por Adolfo Rouillon (ed.) y Daniel F. Alonso (coord.), Código de Comercio comentado y anotado, t. VII. Buenos Aires, La Ley, 2009, p. 4.

14 Idem.

15 Cfr. Banco Mundial, Principios de los sistemas efectivos de insolvencia y derechos de los acreedores, abril de 2001. Disponible en www.worldbank.org/gild 
tilaterales y de grupos de países tales como el G-7 y el G-22. En abril de 1998, el Grupo de Trabajo sobre Crisis Financieras Internacionales del G-22 produjo un informe en el que identifica los objetivos y las características principales de cualquier régimen de insolvencia, lo que fue el origen de dos principales iniciativas posteriores: los Principios y líneas rectoras de los sistemas efectivos de insolvencia y de derechos de crédito (en adelante los Principios) del Banco Mundial (2001) y la Guía legislativa sobre el régimen de insolvencia (en adelante la Guía o Guía legislativa) de UNCITRAL (2004). La base común fundante de estas dos iniciativas ha sido sistematizada por la doctrina en el sentido de reconocer que, aunque los tratamientos nacionales puedan diferir, los sistemas efectivos de insolvencia deben estar dirigidos a los siguientes objetivos:

- Integrarse con la restante legislación comercial del país.

- Maximizar el valor del activo de la empresa en marcha a fin de proporcionar un amplio sistema de reorganización.

- Establecer un equilibrio entre liquidación y reorganización.

- Proporcionar un tratamiento igualitario a las distintas categorías de los acreedores, incluidos los acreedores locales y extranjeros.

- Proveer a la resolución oportuna, eficiente e imparcial de las insolvencias.

- Evitar el desmembramiento prematuro del activo del deudor por los acreedores individuales que persiguen sentencias rápidas.

- Proveer un procedimiento concursal transparente que contemple incentivos para reunir y revelar información necesaria para las partes.

- Reconocer los derechos preexistentes de los acreedores y respetar la prioridad de los créditos mediante un proceso concursal predecible y establecido.

- Poner en vigor un marco para las insolvencias transnacionales, con reconocimiento de los procedimientos extranjeros. ${ }^{16}$

Estas nuevas perspectivas y orientaciones en el derecho concursal comparado no solo se han visto reflejadas en el derecho sustantivo y procesal interno de algunos países que serán mencionados en este trabajo, sino también en el campo del derecho internacional privado concursal, de las que este autor quiere hacerse cargo en esta ocasión.

En lo que respecta a nuestra materia, cabe analizar al respecto la Guía legislativa UNCITR A L sobre el régimen de la insolvencia de los años 2004, 2010 y 2013, la Ley

16 Cfr. Rouillon, Código, t. VII, op. cit., p. 6. Sobre la labor de los organismos multilaterales en orden al derecho de insolvencia internacional puede verse, entre otros: Christoph G. Paulus, "Global insolvency law and the role of multinational institutions", en Brook. J. Int'l. L. 32 (2007), pp. 755 y ss. 
Modelo de UNCITRAL sobre Insolvencia Transfronteriza de 1997, la Guía de prácticas de UNCITRAL sobre cooperación en la insolvencia transfronteriza de 2009 y el Reglamento europeo sobre insolvencia transfronteriza de 2000 y de 2015.

\section{Los Principios del Banco Mundial}

Los Principios del Banco Mundial para los sistemas efectivos de insolvencia y de derechos de crédito ${ }^{17}$ comenzaron a identificarse en 1999, mediante la constitución de un comité ad hoc de organizaciones asociadas, ${ }^{18}$ un ente coordinador $\mathrm{y}$ varios grupos de trabajo que reunieron a unos 70 expertos de diferentes países. Antes de su aprobación por el Directorio del Banco Mundial en abril de 2001, los Principios fueron sometidos al examen de cinco seminarios regionales en los que participaron varios cientos de expertos de unos 75 países. Los Principios no constituyen una ley modelo ni aspiran a uniformar las leyes nacionales sobre un modelo único. Su rasgo dominante es la flexibilidad de sus postulados, que no constituyen detalladas y rígidas prescripciones legales para su adopción por los sistemas nacionales, sino que son un destilado de diferentes sistemas y experiencias jurídicas nacionales, de diverso origen y tradición, cuyo resultado es una lista de principios o estándares que deberían observar los regímenes legales e institucionales de cualquier país, en el área de la insolvencia y de los derechos de crédito, para poder considerar que un determinado sistema nacional permite efectivizar las mejores prácticas internacionales universalmente aceptadas en la materia. ${ }^{19}$

Los principios comprenden cuatro aspectos fundamentales:

Sección A: el marco legal para los derechos de crédito, exista o no insolvencia del deudor. Aquí se contemplan las instituciones que compatibilizan la ejecución individual con los procesos colectivos o universales.

Sección B: el manejo del riesgo crediticio, la responsabilidad de los administradores o directores de la empresa insolvente o en el periodo cercano a la insolvencia, y los mecanismos informales de solución de las crisis empresariales o de la insolvencia.

Sección C: el marco legal para los procesos concursales de reorganización y de liquidación.

17 Tanto la versión original (de abril de 2001) de los Principios, como su versión revisada en 2005 pueden verse en distintos idiomas en las siguientes páginas web del Banco Mundial: www.wordlbank.org/gild o bien www. wordlbank.org/ifa/ipg_esp.pdf. Sobre este tema puede verse la descripción que realiza Rouillon, Código, op. cit., t. VII, pp. 6-9. En las pp. 59 a 207 de esta obra se encuentra una versión de los Principios del Banco Mundial en castellano.

18 Incluyendo al Fondo Monetario Internacional (FMI), la Organización para la Cooperación el Desarrollo Económicos (OCDE), los bancos regionales de desarrollo, UNCITRAL, INSOL International y el Comité J de la Asociación Internacional de Abogados.

19 Cfr. Rouillon, Código, op. cit., t. VII, p. 7. 
Sección D: el marco institucional, o sea, las características de un sistema judicial y de un sistema de sindicatura concursal eficientes.

Un rasgo importante de los Principios es considerar que, en el sistema concursal y de derechos de crédito de todo país, es fundamental conocer no solo las leyes, sino también las instituciones encargadas de aplicarlas y, a la vez, analizar ambas en la teoría y en su funcionamiento práctico.

Estos Principios fueron desarrollados para testear la efectividad de los sistemas de insolvencia y derechos de crédito de cualquier país. Ese estudio lo realiza el Banco Mundial por acuerdo con las autoridades de un país, mediante un programa llamado ICR ROSC (Insolvency and Creditor Rights Report on the Observance of Standards and Codes - Informe sobre la Observancia de Estándares y Códigos sobre Insolvencia y Derechos de Crédito). Este programa se está llevando a cabo en unos cincuenta países de diferentes regiones del mundo. En América Latina se ha realizado en Argentina, Bolivia, Brasil, Chile, Colombia, Ecuador, El Salvador, Guatemala, Haití, Honduras, Nicaragua, República Dominicana y Uruguay. Este programa constituye una herramienta de diagnóstico que ayuda a las autoridades de un país a identificar las principales debilidades de su sistema legal o institucional en el área de la insolvencia y el crédito para facilitarle promover o acelerar las reformas necesarias a fin de poner a las leyes, instituciones y prácticas concursales más cerca de los estándares internacionales aceptados en la materia. Los informes que se elaboran como consecuencia de este programa son confidenciales, para uso exclusivo de las autoridades del respectivo país, a menos que estas autoricen la publicación de un sumario de quince páginas del informe. ${ }^{20}$

En 2005 se terminó de elaborar la segunda versión de los Principios. En esta versión revisada, se incorporan las lecciones de los casi 30 programas llevados a cabo desde fines de 2001 hasta fines de 2004, más las observaciones de numerosos expertos internacionales, formuladas en varios eventos internacionales organizados o coorganizados por el Banco Mundial en igual periodo, entre los cuales cabe destacar el Foro Global sobre el Manejo del Riesgo Crediticio, el Foro de Insolvencia en Latino América, varios foros sobre reforma de la insolvencia en Asia y el Foro Global de Jueces. ${ }^{21}$ La metodología actualmente en uso de los ICR ROSC se elaboró sobre la base de la versión del año 2005 de los Principios del Banco Mundial y las Recomendaciones de la Guía legislativa sobre insolvencia, de UNCITRAL. ${ }^{22}$

Consideramos trascendentes estos Principios, por una parte, con base en la metodología utilizada para elaborarlos descrita precedentemente y, por otra, por 
cuanto el derecho internacional privado de la insolvencia (DIPRI) debe tenerlos en cuenta a fin de proponer nuevas normas más eficaces, más eficientes y más modernas sobre esta materia, sobre todo en aquellos países donde la legislación de insolvencia internacional es notoriamente insuficiente, desactualizada y con rasgos de obsolescencia que es menester reformar.

\section{La labor de CNUDMI/UNCITRAL}

La Comisión de las Naciones Unidas para el Derecho Mercantil Internacional (CNUDMI, también conocida como UNCITRAL - United Nations Commission on International Trade Law), como órgano subsidiario de la Asamblea General de la ONU, prepara textos legislativos internacionales para ayudar a los Estados a modernizar el derecho mercantil y textos no legislativos para facilitar las negociaciones entre las partes en operaciones comerciales.

\section{Guía legislativa sobre el régimen de la insolvencia de CNUDMI/UNCITRAL}

Uno de esos textos legislativos es la Guía legislativa sobre el régimen de insolvencia que fue aprobada en sus dos primeras partes en el año 2004, la tercera parte lo fue en el año 2010 y la cuarta parte en 2013.

Este texto fue elaborado por el Grupo de Trabajo V (Régimen de la Insolvencia), a quien fue otorgado el mandato de preparar una descripción general de los objetivos fundamentales y las características esenciales de un sólido régimen en materia de insolvencia y de las relaciones jurídicas entre deudores y acreedores, incluso la reorganización judicial o extrajudicial de las empresas insolventes, y una Guía legislativa que contuviera criterios flexibles para la consecución de estos objetivos y características, y que incluyera un examen de las diversas soluciones posibles y sus correspondientes ventajas e inconvenientes. ${ }^{23}$

En julio de 2001, el Grupo de Trabajo V de UNCITRAL (Régimen de la Insolvencia) examinó el primer proyecto de la Guía legislativa sobre el régimen de la insolvencia y su labor ulterior se desarrolló durante siete periodos de sesiones de una semana de duración, el último de ellos celebrado a fines de marzo de 2004. Además de los representantes de los 36 Estados miembros de la Comisión, participaron activamente en los trabajos preparatorios los representantes de muchos otros Estados y de varias organizaciones internacionales, tanto intergubernamentales como no gubernamentales. La labor también se llevó a cabo en estrecha cooperación con el Grupo de Trabajo VI de UNCITRAL (Garantías Reales), a fin de velar por la coordinación del tratamiento de estas

23 ONU, Documentos Oficiales de la Asamblea General, quincuagésimo quinto periodo de sesiones, Suplemento $n .17(\mathrm{~A} / 55 / 7)$, párrs. 400 a 409. 
garantías en la insolvencia con la Guía legislativa sobre las operaciones garantizadas elaboradas por la Comisión.

Las negociaciones finales sobre el proyecto de Guía legislativa acerca del régimen de la insolvencia tuvieron lugar durante el $37^{\circ}$ periodo de sesiones de UNCITRAL, celebrado en Nueva York del 14 al 21 de junio de 2004, y el texto fue aprobado por consenso el 25 de junio del mismo año. Posteriormente, la Asamblea General aprobó la Resolución 59/40, de 2 de diciembre de 2004, en la que expresó su reconocimiento a la Comisión por haber completado y aprobado la Guía legislativa. ${ }^{24}$

Este documento contiene, en sus primeras dos partes, 198 recomendaciones a los Estados sobre el régimen de insolvencia, con una introducción sobre su alcance y un glosario de términos.

\subsection{Finalidad}

En la Guía legislativa se exponen exhaustivamente los objetivos fundamentales y los principios que deberían quedar reflejados en el régimen de la insolvencia de un Estado. Tiene como finalidad informar y contribuir a la labor de reforma de los regímenes de la insolvencia de todo el mundo, y servir de referencia a las autoridades nacionales y los órganos legislativos que preparen nuevas leyes y reglamentaciones o se planteen una revisión de las ya existentes. El asesoramiento que ofrece pretende compaginar lo siguiente: la necesidad de resolver con la mayor rapidez y eficiencia posibles las dificultades financieras del deudor; los intereses de las diversas partes directamente afectadas por esas dificultades financieras, que son principalmente los acreedores, el deudor y otras partes que tienen intereses en los negocios del deudor; y las consideraciones de orden público tales como, por ejemplo, el empleo y los impuestos. La Guía legislativa ayuda al lector a evaluar los distintos criterios y soluciones posibles y a optar por el que resulte más adecuado en el ámbito local. En sus propias palabras, la Guía no es una "Ley Modelo de procesos de insolvencia". ${ }^{25}$

La Guía no provee un único juego de soluciones modelo para abordar los temas centrales de una eficiente y efectiva ley concursal, sino que ayuda al usuario a evaluar los diferentes enfoques disponibles y a elegir el más adecuado a su contexto nacional o regional. En sus propias palabras, esto se debe a que

... no existe ninguna solución universal para elaborar un régimen de insolvencia, ya que las necesidades de los países no coinciden, como tampoco coinciden sus le-

$24 \quad$ El texto de este documento y de los restantes de la UNCITRAL puede encontrarse en seis idiomas en la página web de UNCITRAL, en www.UNCITRAL.org. Entre otros, puede verse el comentario a la misma de varios autores en UNCITRAL, Guía Legislativa de UNCITRAL sobre el Régimen de la Insolvencia, Madrid, La 
gislaciones sobre otras cuestiones de importancia fundamental para la insolvencia, tales como las garantías reales, el derecho de propiedad y los derechos contractuales, las vías de recurso y los procedimientos de ejecución. ${ }^{26}$

\subsection{Importancia para el comercio internacional}

Cada vez goza de mayor reconocimiento la idea de que, para todo Estado, el hecho de disponer de un régimen de la insolvencia sólido y eficaz es importante a fin de prevenir o limitar las crisis financieras y facilitar la solución rápida y ordenada de situaciones de endeudamiento excesivo. Tal régimen puede facilitar la reasignación ordenada de recursos financieros de empresas que no son viables, canalizándolos hacia actividades más eficientes y rentables; ofrecer incentivos que no solamente alienten a los empresarios a invertir, sino que también animen a los directivos de empresas fallidas a adoptar a tiempo medidas para hacer frente a la quiebra y mantener los puestos de trabajo, reducir el costo de los negocios, y aumentar la oferta de crédito. El análisis comparativo de la eficacia de los regímenes de la insolvencia se ha convertido en una práctica habitual y esencial a efectos de la concesión de un préstamo, y afecta a los Estados a todos los niveles del desarrollo económico.

Una gran parte del derecho relativo a sociedades comerciales y, en particular, el tratamiento de esas sociedades en casos de insolvencia ha sido pensada en función de la empresa individual, a pesar de que las sociedades están actuando cada vez más, tanto en el plano nacional como en el internacional, mediante grupos de empresas, a veces muy grandes, en los que las sociedades están interconectadas por diversas formas de propiedad y control. Esos grupos, que se hallan con mucha frecuencia tanto en los mercados emergentes como en los desarrollados, son un vehículo habitual para la práctica del comercio y las finanzas internacionales. Cuando algunas partes integrantes de uno de esos grupos, o todas ellas, pasan a ser insolventes, ningún régimen internacional o regional, y muy pocos regímenes legislativos internos, pueden actualmente coordinar con eficacia los procedimientos de insolvencia resultantes, que a menudo afectan a numerosas jurisdicciones. ${ }^{27} \mathrm{Si}$ la temática es de por sí inasible en el plano interno o doméstico comparado, con mayor razón en el plano internacional.

\subsection{Disposiciones principales}

La Guía legislativa se divide en cuatro partes. ${ }^{28}$ En la primera parte se examinan los objetivos principales de un régimen de la insolvencia, cuestiones es-

\footnotetext{
26 Cfr. UNCITRAL, Guía Legislativa, Primera Parte, op. cit., I. C. 17.

27 Cfr. las fuentes citadas en la nota 3 de este trabajo, en lo que se refiere a monografías específicas sobre grupos de sociedades multinacionales en situación concursal, y la citada en la nota 55 de este trabajo.

28 Sobre la Ley Modelo puede verse la siguiente bibliografía de referencia, entre otros autores: Olaf Benning y Axel Das Wehling, "Model Law on Cross-Border Insolvency der Vereignten Nationen”, en EuZW (1997), pp.
} 
tructurales o sistémicas como la relación entre el derecho de la insolvencia y otras ramas de la legislación, los tipos de mecanismos de que se dispone para resolver las dificultades financieras de un deudor, y el marco institucional necesario para apoyar un régimen de la insolvencia eficaz.

En la segunda parte se tratan las características esenciales de un régimen de la insolvencia eficaz, siguiendo de cerca, en la medida de lo posible, las diversas etapas de un procedimiento de insolvencia, desde su apertura hasta que se saldan las deudas del deudor concursado y se clausura el procedimiento. Algunos elementos clave que se determinan en el texto son los siguientes: criterios normalizados para la apertura del procedimiento; la suspensión para proteger los bienes de la masa de la insolvencia, aplicable también a las acciones entabladas por acreedores garantizados; la financiación posterior a la apertura; la participación de los acreedores en el proceso; la previsión de un proceso de reorganización agilizado; requisitos simplificados para la presentación y comprobación de reclamaciones; transformación del procedimiento de reorganización en otro de liquidación si fracasa el primero; normas claras para liberar al deudor de sus deudas y la conclusión del procedimiento de insolvencia.

En la tercera parte se aborda el tratamiento dado a los grupos de empresas en situaciones de insolvencia, tanto en el ámbito nacional como en el internacional. Si bien muchas de las cuestiones tratadas en las partes primera y segunda son aplicables también a los grupos de empresas, hay otras que solamente proceden en el contexto de los grupos de empresas (lo que ha dado en llamarse en la jerga del derecho estadounidense Enterprise Law, como contraposición al tradicional derecho societario de los entes aislados, Entity Law). Así, la tercera parte se basa en las dos primeras y las complementa. En el plano interno, el comentario y las recomendaciones de la tercera parte incluyen varios mecanismos que se pueden utilizar para racionalizar procedimientos de insolvencia respecto de dos o más empresas pertenecientes a un grupo. Algunos de ellos son: la coordinación de diversos procedimientos relativos a diferentes deudores; cuestiones relativas a la financiación en la etapa posterior a la solicitud y la apertura del procedimiento en el contexto de los grupos de empresas; disposiciones que rigen la anulación de actos realizados por el deudor; la consolidación patrimonial entre procedimientos de insolvencia que afecten a dos o más miembros del grupo; el nombramiento de un único o un mismo representante para todos los miembros del grupo afectados por la insolvencia, y los planes de reorganización coordinados. En cuanto al tratamiento internacional de los grupos, la tercera parte se centra en la cooperación y la coordinación, amplía

618 y ss.; Irit Mevorach, "On the road to universalism: A comparative and empirical study on the UNCITRAL Model Law on Cross-Border Insolvency", en EBOR 12 (2011), pp. 517 y ss. 
las disposiciones basadas en la LMIT al contexto de los grupos de empresas $\mathrm{y}$, mutatis mutandis, aborda la aplicabilidad en el contexto internacional de los mecanismos propuestos para hacer frente a las insolvencias de grupos de empresas en el contexto nacional. ${ }^{29}$

La cuarta parte se centra en las obligaciones que se podrían imponer a los responsables de adoptar decisiones con respecto a la administración de una empresa cuando se enfrenta a una insolvencia inminente o la insolvencia se hace inevitable. El propósito de imponer esas obligaciones, que son exigibles una vez que se ha iniciado el procedimiento de insolvencia, es proteger los intereses legítimos de los acreedores y demás interesados, y proporcionar alicientes para que se actúe con prontitud a fin de minimizar los efectos de las dificultades financieras que atraviesa la empresa. ${ }^{30}$

\section{Ley Modelo de UNCITRAL/CNUDMI sobre la Insolvencia Transfronteriza, de 1997}

Otra elaboración referida a la insolvencia internacional de UNCITRAL es la Ley Modelo sobre la Insolvencia Transfronteriza (LMIT), que fue aprobada por la Comisión por consenso el 30 de mayo de 1997; en las negociaciones intervinieron los 36 Estados miembros de la Comisión, representantes de 40 Estados observadores y 13 organizaciones internacionales. ${ }^{31}$

El Grupo de Trabajo V (Derecho de Insolvencia) de UNCITR A L decidió que se limitaría a la finalidad restringida, pero valiosa, de facilitar la cooperación internacional, el acceso de los administradores de la insolvencia extranjera y el reconocimiento de los procedimientos de insolvencia extranjeros. En otros términos, solo trata algunos aspectos procesales para posibilitar su funcionamiento en el derecho interno.

29 Sobre este tema pueden verse, entre otros: Christian Brünkmans, Die Koordinierung von Insolvenzverfahren konzernverbundener Unternehmen nach deutschem und europäischem Insolvenzrecht, Berlin, Duncker \& Humblot, 2009 (publicación de la Disertación defendida en Bonn en 2008). Asimismo: Ulrich Ehricke, "Verfahrenkoordination bei grenzüberschreitenden Unternehmensinsolvenzen", en Jürgen Basedow (ed.), Aufbruch nach Europa, 75 Jahre MaxPlanck-Institut für Privatrecht, Tübingen, Mohr, 2001, pp. 337 y ss; Ulrich Ehricke, "Probleme der Verfahrenskoordination - Eine Analyse der Kooperation von Insolvenzverwaltern und Insolvenzgerichten bei grenzüberschreitenden Insolvenzverfahren nach der EulnsVO", en Peter Gottwald (ed.), Europäisches Insolvenzrecht - Kollektiver Rechtsschutz, Bielefeld, Gieseking, 2008, pp. 127 y ss.; Stephen J. Taylor, "Beyond CoMi - The Duty to Cooperate under EU Insolvency Regulation 1346/2000", en Int. C. R. 2 (2005), pp. 173 y ss.

30 Sobre esto puede verse, entre otros autores: Irit Mevorach, "Forum shopping in time of crisis: A directors' duties perspective", en ECFR (2013), pp. 523 y ss.

31 El texto de la Ley Modelo y de la Guía para su adopción por los Estados está disponible en seis idiomas en www.UNCITRAL.org. Sobre esto puede verse, entre otros, el artículo de Jenny Clift, "The UNCITRAL Model Law on Cross Border Insolvency - A Legislative Framework to Facilitate Coordination and Cooperation in Cross-Border Insolvency", en Tulane Journal of International and Comparative Law 12 (2004), pp. 307 y ss.; Jenny Clift, The UNCITRAL Model Law on Cross-Border Insolvency - A Brief Introduction, publicado en www. ibanet.org; Irit Mevorach, "On the road to universalism: A comparative and empirical study on the Uncitral Model Law on Cross-Border Insolvency", en EBOR 12 (2011), pp. 517 y ss.; Klaus Wimmer, "Die UNCITRALModellbestimmungen über grenzüberschreitende insolvenzverfahren", en ZIP (1997), pp. 2220 y ss. 
La LMIT tomó en cuenta los resultados de otros trabajos, entre ellos la Convención de la Unión Europea relativa al procedimiento de Insolvencia (1995), ${ }^{32} \mathrm{el}$ Convenio europeo sobre ciertos aspectos internacionales de la quiebra (Convenio de Estambul de 1990), los tratados de Derecho Internacional Privado de Montevideo de 1889 y 1940, la Convención sobre la Quiebra en los Estados Nórdicos de 1933, la Convención de La Habana de 1928 (Código Bustamante) y también las consideraciones propuestas por organizaciones no gubernamentales como la Model International Insolvency Cooperation Act (MIICA) y el Cross Border Insolvency Concordat, creadas por el Comité de la Sección de Derecho de Insolvencia de la Asociación Internacional de Abogados (International Bar Association - IBA).

Las disposiciones de una ley modelo se preparan con el fin de ofrecer una pauta a los legisladores para que se planteen la posibilidad de incorporar la ley modelo a su derecho interno. Dado que los Estados que promulgan legislación basada en una ley modelo pueden actuar con toda flexibilidad y apartarse de su texto, la lista de los Estados que se enuncia más abajo es solo una indicación de los textos promulgados por ellos, siguiendo esta base en mayor o menor medida de acuerdo con la información que se ha dado a conocer a la Secretaría de CNUDMI/UNCITRAL.

Los países que han aprobado legislación basada en la LMIT en 41 Estados en un total de 42 jurisdicciones, son: Australia, Benin, Burkina Fasso, Camerún, Canadá, Chad, Chile, Colombia, Comoras, Congo, Costa de Marfil, Eslovenia, Eritrea, Estados Unidos de América, Filipinas, Gabón, Grecia, Guinea, Guinea Ecuatorial, Guinea Bissau, Japón, Kenya, Malawi, Mali, Mauricio, México, Montenegro, Niger, Nueva Zelanda, Reino Unido de la Gran Bretaña e Irlanda del Norte, Islas Vírgenes Británicas, Polonia, República Centroafricana, República de Corea, República Democrática del Congo, Rumania, Senegal, Serbia, Seychelles, Sudáfrica, Togo, Uganda y Vanuatu. En Latinoamérica existen proyectos o anteproyectos para adoptar la LMIT en Argentina, El Salvador y República Dominicana. ${ }^{33}$

\subsection{Finalidad}

La LMIT tiene por objeto ayudar a los Estados a dotar a sus respectivos regímenes de la insolvencia de un marco legislativo moderno para resolver con

32 Sobre algunos aspectos de la Convención Europea pueden consultarse, entre otras fuentes: Ulrich Drobnig, "Secured credit in international insolvency proceedings", en Texas International Law Journal 33 (1998), pp. 5470; Rudolf C. Keppelmüller, An der Schwelle zu einem europäischen Insolvenzrecht? Das EU-Übereinkommen über Insolvenzverfahren, wbl, 1996, pp. 337 y ss; Donna McKenzie Skene, “The EC Convention on Insolvency Proceedings", en Eur Priv. L. 4 (1996), pp. 181 y ss.; Manfred Balz, “The European Union Convention on Insolvency Proceedings", en Am. Bankr. L. J., 70 (1996), pp. 485 y ss.; Ian Fletcher, “The European Union Convention on Insolvency Proceedings: Choice-of-Law Provisions", en Tex. Int'l L. J. 33 (1998), pp. 119 y ss.

33 Pueden verse los comentarios de diversos autores sobre la adopción de estos países de la Ley Modelo en AA.VV., Cross-Border Insolvency - A Commentary on the UNCITRAL Model Law, 2 ed., Look Chan HO (ed.), London, Globe Business Publishing, 2009. 
mayor eficacia los casos de insolvencia transfronteriza en que el deudor se encuentre en una situación financiera muy precaria o en estado de insolvencia. Su principal función es autorizar y alentar la cooperación y la coordinación entre jurisdicciones en lugar de promover la unificación del derecho sustantivo en materia de insolvencia, y respeta las diferencias entre los diferentes derechos sustanciales y procesales de cada país. A los efectos de la LMIT, una insolvencia transfronteriza es aquella en la que el deudor tiene bienes en más de un Estado o en la que algunos de los acreedores del deudor no son del Estado donde se está tramitando el procedimiento de insolvencia. ${ }^{34}$

\subsection{Importancia para el comercio internacional}

Si bien desde la década de los noventa del siglo pasado ha aumentado notablemente el número de casos de insolvencia transfronteriza, esta tendencia no se ha reflejado en el número de regímenes jurídicos, tanto nacionales como internacionales, adoptados para hacer frente a las cuestiones que plantean estos casos. Muchas veces, la falta de tales regímenes ha hecho que se adopten criterios inadecuados y descoordinados en casos de insolvencia transfronteriza que no solamente son imprevisibles y largos de aplicar, sino que además carecen de transparencia y de los instrumentos necesarios para afrontar las disparidades y, en algunos casos, los conflictos que pueden surgir entre las distintas leyes nacionales sobre la insolvencia en conflicto, aplicables en un caso con elementos multinacionales. Esos factores han obstaculizado la protección del valor de los bienes de empresas con dificultades financieras y han dificultado su rehabilitación en el plano internacional. ${ }^{35}$

\subsection{Disposiciones principales}

La LMIT se centra en cuatro elementos considerados esenciales en la tramitación de casos de insolvencia transfronteriza: el acceso, el reconocimiento, las medidas otorgables (asistencia) y la cooperación.

\subsubsection{Acceso}

En las disposiciones relativas al acceso se otorga a los representantes de procedimientos de insolvencia extranjeros y a los acreedores el derecho a recurrir a los tribunales de un Estado promulgante para solicitar asistencia, y se autoriza a los representantes de procedimientos que se estén tramitando en el Estado promulgante a que soliciten asistencia en otros lugares.

$34 \quad$ Cfr. estas consideraciones en la página web de la UNCITRAL, en lo que se refiere a la LMIT. www.UNCITRAL.org 35 Idem. 


\subsubsection{Reconocimiento}

Uno de los objetivos fundamentales de la LMIT es establecer trámites más sencillos para reconocer procedimientos extranjeros que cumplan determinados requisitos, con el objetivo de evitar largos procesos de legalización y de otra índole que con frecuencia se deben realizar, y ofrecer certidumbre respecto a la decisión que se pretende reconocer. En esas disposiciones esenciales se establece que se reconocerán las órdenes dictadas por tribunales foráneos por las que se declaren abiertos procedimientos que cumplan ciertos requisitos y se nombre el representante extranjero de esos procedimientos. Siempre y cuando se den determinadas circunstancias, un procedimiento extranjero deberá reconocerse, o bien como procedimiento principal, que se tramita en el Estado en que el deudor tiene el centro de sus principales intereses en la fecha de apertura del procedimiento extranjero, o bien como procedimiento no principal, que se tramita donde el deudor tiene un establecimiento. ${ }^{36} \mathrm{El}$ reconocimiento de los procedimientos extranjeros en virtud de la LMIT tiene varios efectos. El más importante de ellos es que se permite otorgar medidas para prestar asistencia a dicho procedimiento.

\subsubsection{Medidas otorgables}

Un principio básico de la LMIT es que las medidas consideradas necesarias para llevar a cabo ordenada y equitativamente un procedimiento de insolvencia transfronteriza deberían ser otorgables para prestar asistencia a los procedimientos extranjeros. Especificando las medidas otorgables, la LMIT no incorpora las consecuencias de la legislación extranjera al régimen interno de la insolvencia del Estado promulgante ni aplica al procedimiento extranjero las medidas que serían otorgables con arreglo a la ley del Estado promulgante. Algunas de las medidas otorgables más importantes son las siguientes: medidas cautelares a discreción del tribunal, desde la presentación de una solicitud de reconocimiento hasta que se resuelva esa solicitud; una suspensión automática cuando se reconozca el procedimiento principal, y medidas a discreción del tribunal aplicables a los procedimientos principales y no principales después del reconocimiento.

\subsubsection{Cooperación y coordinación}

En esas disposiciones se trata la cooperación entre los tribunales de los Estados en que estén ubicados los bienes del deudor y la coordinación de los procedimientos paralelos relativos a ese deudor. La LMIT faculta expresamente a los

36 Sobre los procedimientos concursales principales en distintas jurisdicciones puede verse: Margreet BJ, de Boer y Bob Wessels, "The dominance of main lnsolvency proceedings under the european lnsolvency regulation", en Paul J. Omar (ed.), International Insolvency Law. Themes and Perspectives, Aldershot, Routledge, 2008, pp. 185 y ss. 
tribunales para cooperar con sus homólogos extranjeros en los ámbitos que la regulan, y para comunicarse directamente con ellos. También autoriza la cooperación entre los tribunales y los representantes extranjeros, así como entre representantes, tanto extranjeros como locales. Las disposiciones relativas a la coordinación de los procedimientos paralelos tienen por objeto fomentar decisiones óptimas que permitan lograr los objetivos de todos los procedimientos, tanto si se trata de procedimientos internos y extranjeros como si se trata de varios procedimientos extranjeros.

\subsubsection{Información adicional}

La LMIT viene acompañada de una Guía para su incorporación al derecho interno. La Guía va dirigida ante todo a las entidades ejecutivas de los gobiernos y a los legisladores encargados de preparar la legislación necesaria de incorporación al derecho interno, pero también resultará útil a los encargados de interpretar y aplicar la LMIT, por ejemplo, a los jueces y otros usuarios del texto, como los profesionales de la insolvencia y el personal académico.

\subsection{Descripción de la normativa}

La doctrina ha destacado que el texto de la LMIT constituye un intento de promover una legislación moderna y equitativa que armonice o asimile las soluciones que los Estados pueden adoptar libremente frente al problema de la insolvencia con características multinacionales, especialmente, cuando se trata de un mismo deudor con activos o pasivos localizados en distintas jurisdicciones territoriales de diversos países. Esto se lograría mediante la adopción de este texto por el derecho interno de los distintos Estados en un número significativo de manera similar o semejante entre sí. Como consecuencia de esa asimilación se ganaría en previsibilidad en las soluciones que puedan adoptar los distintos sujetos y hasta los tribunales intervinientes en los siguientes tópicos: el reconocimiento del proceso concursal extranjero, el acceso al concurso local de los representantes del concurso extranjero y de los acreedores extranjeros, la coordinación de los concursos abiertos en plurales países respecto de un mismo deudor, y la cooperación entre tribunales de distintos países y representantes de los plurales concursos del mismo deudor que se encuentren en diferentes países. Los principales objetivos de la LMIT son: alentar la cooperación internacional en materia de insolvencias transfronterizas o internacionales, lograr la seguridad jurídica, proteger los intereses de todos los sujetos afectados por las insolvencias internacionales, proteger los bienes del deudor procurando la optimización de su valor, y facilitar la reorganización de empresas en dificultades financieras o económicas a fin de proteger el capital invertido y preservar el empleo. ${ }^{37}$

37 Cfr. Rouillon, Código, op. cit., t. VII, p. 26. 
A fin de concretar esos objetivos, la doctrina ha resumido o sistematizado las disposiciones fundamentales establecidas por la norma del siguiente modo: ${ }^{38}$

i.) Derecho de acceso directo del representante del concurso extranjero a los tribunales de otro Estado donde existan bienes del mismo deudor, para poder peticionar la apertura de un nuevo proceso concursal o medidas precautorias.

ii.) Reconocimiento de los acreedores extranjeros en pie de igualdad con los acreedores locales para solicitar la apertura del concurso o participar en él.

iii.) Deber de no colocar a los acreedores extranjeros en un rango de privilegio inferior al de los acreedores locales comunes o quirografarios, pudiendo excluirse de este régimen a los acreedores tributarios o de seguridad social.

iv.) Deber de notificar a los acreedores extranjeros de la apertura del concurso en su propio domicilio en el exterior.

v.) Deber de limitar las formalidades necesarias para el reconocimiento de la sentencia concursal extranjera o de otras resoluciones judiciales de ese proceso extranjero, tales como, por ejemplo, la exigencia de exhorto diplomático y procedimientos de exequátur.

vi.) Deber de que ese reconocimiento de la sentencia extranjera se haga de manera rápida para habilitar el despacho de las medidas cautelares que sean necesarias o convenientes.

vii.) Establecimiento legal del principio-deber de cooperación del tribunal y de los órganos del concurso local con el tribunal y los representantes del concurso extranjero "en la medida de lo posible", para lo cual el juez local puede establecer "comunicación directa" con el tribunal extranjero y también los órganos del concurso local -"en ejercicio de sus funciones y bajo la supervisión del tribunal"- pueden hacer lo mismo con sus pares del extranjero.

viii.) Como medida para hacer efectiva la cooperación práctica, se permite: la comunicación de información "por cualquier medio" (teléfono, videoconferencia, correo electrónico, etc.); la coordinación de la administración y supervisión de bienes y negocios del deudor en distintos países; la aprobación o aplicación de acuerdos relativos a coordinación de procedimientos (los llamados "protocolos"); y la coordinación de procedimientos simultáneos.

ix.) Existen previsiones para coordinar casos de pluralidad de procesos concursales, ya sea que se considere a uno de ellos como procedimiento ex- 
tranjero "principal" previo, y a otro como procedimiento "no principal" local posterior, o a todos como procedimientos simultáneos, es decir, uno en el extranjero y otro local.

x.) Finalmente, se establece una presunción de insolvencia por la existencia del procedimiento extranjero principal (similar a la primera oración del artículo 4 de la ley concursal argentina actualmente vigente) y una regla de pago para procedimientos paralelos casi idéntica a la regla de la "paridad de dividendos" del último párrafo de dicho artículo de la ley concursal argentina.

\subsection{Análisis de la norma}

En el Preámbulo de la LMIT se define su finalidad y se enumeran sus objetivos: a) la cooperación entre los tribunales y demás autoridades competentes de este Estado y de los Estados extranjeros que hayan de intervenir en casos de insolvencia transfronteriza; b) una mayor seguridad jurídica para el comercio y las inversiones; c) una administración equitativa y eficiente de las insolvencias transfronterizas, que proteja los intereses de todos los acreedores y de las demás partes interesadas, incluido el deudor; d) la protección de los bienes del deudor, y la optimización de su valor; e) facilitar la reorganización de empresas en dificultades financieras, a fin de proteger el capital invertido y de preservar el empleo.

Seguidamente, la norma se estructura en cinco capítulos conforme al siguiente orden: I) disposiciones generales; II) reglas que rigen el acceso de los representantes y acreedores extranjeros a los tribunales del Estado donde tramita el proceso concursal; III) regulación del reconocimiento de un procedimiento extranjero de insolvencia y de las medidas otorgables, principalmente cautelares; IV) principios y formas de cooperación entre tribunales y representantes, locales y extranjeros; y V) sistemas de coordinación de procedimientos paralelos de insolvencia de un mismo sujeto.

\subsubsection{Capítulo I. Disposiciones generales}

El artículo 1 delimita el ámbito de aplicación de sus disposiciones, definiendo los casos internacionales a los que ella se aplica o puede no aplicarse (v. g. entidades bancarias o aseguradoras que tengan un régimen especial de insolvencia).

El artículo 2 realiza una serie de definiciones en un breve glosario a fin de unificar los términos utilizados por la norma. En el mismo se definen los conceptos de "procedimiento extranjero", "procedimiento extranjero principal", "procedimiento extranjero no principal", "representante extranjero", "tribunal extranjero" y "establecimiento". 
En el artículo 3 se establece que las obligaciones internacionales del Estado primarán por sobre las normas de la LMIT, sin ser ambas incompatibles si fueran coexistentes, lo que jerárquicamente encuadra con el artículo 75, inciso 22 de la Constitución Argentina.

El Estado debe identificar el tribunal competente en materia de insolvencia en lo que se refiere a la aplicación de la LMIT (art. 4) y el órgano representante de un proceso concursal abierto (art. 5).

El artículo 6 consagra la excepción de orden público, que prevalecerá en caso de manifiesto conflicto con la LMIT.

El artículo 7 establece la validez de la asistencia judicial adicional al representante extranjero, más allá de lo previsto por la LMIT.

El artículo 8 brinda una pauta de interpretación a la norma, basada en su origen internacional y la necesidad de promover la uniformidad de su aplicación y la observancia de la buena fe.

Aunque nada se expresa en la norma sobre regímenes de reciprocidad, no obsta que el Estado adopte una regla sobre ella, como ocurrió con el caso de México en 2000 y Sudáfrica en 2001. El artículo 3 del Anteproyecto argentino de 2002 así lo prevé. ${ }^{39}$

\subsubsection{Capítulo II. Acceso de los representantes y acreedores extranjeros a los tribunales del Estado}

\section{Reglas sobre acceso al proceso del funcionario concursal}

El artículo 9 establece la legitimación del representante extranjero para comparecer directamente ante un tribunal. ${ }^{40}$

El artículo 10 establece los límites de la jurisdicción a la que se somete el peticionante en un concurso extranjero, que se limita solo a lo peticionado.

El artículo 11 confiere legitimación al representante extranjero para solicitar la apertura de un procedimiento local, y el artículo 12 para participar en todo

39 Cfr. ibid., p. 39. En el año 2000, este autor propuso un posible texto legislativo en el sentido de establecer una presunción de la reciprocidad iuris tantum hasta la prueba de la inexistencia de la reciprocidad: cfr. Adolfo A. N. Rouillon, "Concursos con repercusión trasnacional. La Ley Modelo de la CNUDMI (UNCITRAL) sobre Insolvencia Transfronteriza", en Anales de la Academia Nacional de Derecho y Ciencias Sociales de Buenos Aires 38 (XLV) (2000), pp. 144 y ss.

40 Esta posibilidad estaba expresamente prevista en el artículo 1531 del Código de Comercio argentino de 1859 (1862), en un párrafo derogado en 1889 y que no fue posteriormente reimplantado en las legislaciones concursales argentinas posteriores. Cfr. sobre esto Rouillon, Código, t. VII, op. cit., p. 39, nota 67. 
procedimiento abierto respecto del mismo deudor, conforme al derecho interno del país.

\section{Reglas sobre acceso de los acreedores extranjeros}

La norma no establece cuál será el criterio para distinguir entre acreedores extranjeros y locales, esto quedaría librado al derecho interno de cada país, lo que resulta conveniente. En Argentina ha sido tradicional distinguir en el derecho interno a los acreedores (o mejor, a los créditos) con base en el lugar de exigibilidad de la obligación. ${ }^{41}$ El Anteproyecto argentino de 2002 establece que se entenderá por "acreedor extranjero" aquel que fuera titular de un crédito pagadero exclusivamente fuera del territorio de la República (art. 2 inc. g), y por "acreedor local" aquel que fuera titular de un crédito pagadero exclusivamente en la República o un crédito con más de un lugar alternativo de pago, a opción del acreedor, siempre que uno de los lugares de pago fuera en el territorio de la República (art. 2 inc. h).

En cuanto a los acreedores extranjeros, el artículo 13 establece que ellos gozarán de los mismos derechos que los acreedores locales para solicitar la apertura de un procedimiento de insolvencia y para participar en estos conforme al derecho interno del Estado adoptante de la LMIT. Para el derecho vigente argentino, existe un criterio similar a esa equiparación, conforme la jurisprudencia argentina en los casos José M. Vicario y Gerold Sager. ${ }^{42}$ Esta equiparación, a juicio de la doctrina, derogaría la vigente regla de reciprocidad, tal como actualmente está concebida en el penúltimo párrafo del artículo 4 de la Ley concursal argentina $24.522,{ }^{43}$ sin perjuicio de que podría legislarse de modo general sobre la reciprocidad, lo que tiene la ventaja de ser abarcadora de cualquier cuestión de DIPRI, no solo del acceso de los créditos foráneos al concurso local conforme el artículo 4 de la Ley 24.522. ${ }^{4}$

En materia de privilegios, el segundo párrafo del artículo 13 de la LMIT deja a salvo el orden de prelación de los créditos que establezca el derecho interno del país donde se tramita el proceso concursal, aunque ese país haya adoptado ese texto legal, lo que implica acoger el principio, generalmente aceptado, de que los privilegios en los concursos se rigen por la lex fori ${ }^{45} \mathrm{~A}$ continuación, la norma limita los privilegios locales en el sentido de que no se asignará a los créditos extranjeros una prelación inferior a la de los acreedores comunes o

$41 \quad$ Cfr., para esto, Rouillon, “Créditos locales y créditos extranjeros. Concepto”, en Rouillon, Código, t. IV-A, op. cit., p. 82.

42 Cfr. Rouillon, “El acreedor extranjero: ¿puede pedir la quiebra del deudor domiciliado en la Argentina?", en Rouillon, Código, t. IV-A, op. cit., pp. 90 y ss.

43 Cfr. Rouillon, "Verificación concursal de los créditos extranjeros. La regla de la reciprocidad", en Rouillon, Código, t. IV-A op. cit., pp. 82 y ss.

44 Cfr. Rouillon, Código, t. VII op. cit., p. 41.

45 Cfr. Rouillon, “Ley que rige los privilegios o prioridades de los créditos extranjeros que concurren al concurso abierto en la Argentina", en Rouillon, Código, t. IV-A, op. cit., pp. 75 y ss. 
quirografarios locales, salvo que el crédito extranjero fuera equivalente a un crédito local que tuviese rango inferior a quirografario, supuesto en el cual se asignaría al crédito foráneo este último rango subordinado. Finalmente, la norma otorga flexibilidad al Estado adoptante para que contemple la posibilidad de excluir del proceso concursal local a los créditos extranjeros por concepto de impuestos o seguridad social.

Finalmente, el artículo 14 de la norma establece la obligatoriedad de notificar tanto a los acreedores locales como a los extranjeros de la existencia del concurso en el país adoptante de la LMIT, en forma separada para cada uno de ellos, a menos que el tribunal disponga otra forma de notificación más adecuada de acuerdo con las circunstancias del caso. No se podrá requerir la emisión de cartas rogatorias ni ninguna otra formalidad similar. Por último, se establecen unos requisitos mínimos en la notificación.

\subsubsection{Capítulo III. Reconocimiento de un procedimiento extranjero y medidas otorgables}

En este capítulo (arts. 15 a 24) se regula con detalle la posibilidad de que el representante extranjero de un proceso concursal pueda solicitar el reconocimiento del proceso extranjero de insolvencia en el que hubiera sido designado, así como las formalidades de esa solicitud, para lo cual se ofrecen alternativas y se faculta al tribunal requerido a presumir que los documentos son auténticos, estén o no legalizados. También se establecen los efectos de la solicitud de reconocimiento del proceso extranjero en el país adoptante de la LMIT, los efectos del reconocimiento en sí mismo y la descripción de las medidas que pueden otorgarse en dicho Estado, en protección de los acreedores y de otras personas interesadas, incluido el deudor.

A partir de la solicitud de reconocimiento del proceso extranjero el tribunal puede otorgar, a pedido del representante foráneo, en casos de necesidad y urgencia, medidas provisionales, entre otras: la paralización de las ejecuciones contra los bienes del deudor; la conservación o la inmediata realización de bienes del deudor cuando ello fuera necesario para preservar el valor por ser bienes perecederos, susceptibles de devaluación o estén amenazados; la suspensión del derecho de enajenar o gravar bienes del deudor; el aseguramiento de pruebas; o cualquier otra medida cautelar reconocida por el derecho interno del país adoptante de la LMIT (arts. 19 y 21).

Luego del reconocimiento del proceso extranjero (en cuyo acto el tribunal debe calificar al mismo como "principal" o "no principal") se pueden otorgar medidas similares a las mencionadas. Si el proceso es calificado como "principal", las medidas operan automáticamente, si es calificado como "no principal" es necesaria una decisión judicial expresa y con el previo requerimiento o instancia del representante extranjero (arts. 20 y 21). 
El tribunal del Estado adoptante de la LMIT debe asegurarse de que quedan debidamente protegidos los intereses de los acreedores y de otras personas interesadas, incluido el deudor, al otorgar, denegar, modificar o dejar sin efecto cualquier medida. También puede supeditar toda medida a las condiciones que juzgue convenientes. $\mathrm{Y}$ es posible modificar o dejar sin efecto cualquier medida, a instancia del representante extranjero, de toda persona afectada y aun de oficio (art. 22).

Con posterioridad al reconocimiento del proceso extranjero, el representante del mismo tiene legitimación para entablar acciones tendentes a dejar sin efecto actos perjudiciales a los acreedores e intervenir en todo proceso en que el deudor sea parte, de acuerdo con las reglas procesales internas del Estado adoptante (art. 23). ${ }^{46}$

\subsubsection{Capítulo IV. Cooperación entre tribunales y representantes, locales y extranjeros}

Los artículos 25 y 26 establecen el deber de cooperación internacional "en la medida de lo posible". A tal fin, el tribunal local está facultado para ponerse en comunicación directa con los tribunales o representantes extranjeros o para recabar información o asistencia directa de estos. También los órganos del concurso local en ejercicio de sus funciones y bajo la supervisión del tribunal están facultados para ponerse en comunicación directa con los tribunales o los representantes extranjeros. Esta comunicación y cooperación entre los tribunales y los órganos concursales y entre sí constituye uno de los mayores desafíos de la LMIT, a fin de imprimir celeridad a los procedimientos y superar posibles obstáculos tales como las diferencias de las legislaciones aplicables, los prejuicios, las barreras idiomáticas y culturales, alcanzar del mejor modo posible la finalidad de establecer mecanismos eficaces para la resolución de los casos de insolvencia transfronteriza. ${ }^{47}$

Este llamado a la comunicación y cooperación abierta y directa es, por una parte, revolucionario, $y$, por otra, imprescindible si se pretende actuar con rapidez y específicamente en lo atinente a objetivos y situaciones tales como la existencia de multiplicidad de procesos concursales principales y no principales, la diferencia de legislaciones aplicables, la necesaria coordinación de los procesos multinacionales, la reorganización concursal con la eventual continuación de la explotación de la empresa multinacional, la maximización del

\footnotetext{
46 Un caso argentino en el que se planteó la ineficacia de un acto perjudicial del deudor fue Federal SA (Delbene Hnos y Sabia Ltda.) s/ quiebra s/inc. de medidas cautelares, del Juzgado Nacional de Primera Instancia en lo Comercial 2, del 14 de octubre de 1987, publicado en El Derecho 132-371, con comentario de Alejandro P. Radzyminski, "La acción de ineficacia concursal en el Derecho Internacional Privado Argentino". Cfr. para esto, Rouillon, Código, t. VII, op. cit., p. 43, nota 72. 
valor de los bienes y de la empresa en marcha, la preservación de los empleos $\mathrm{y}$, eventualmente, una rápida liquidación. ${ }^{48}$

Esta convocatoria a la comunicación abierta y directa entre jueces y órganos concursales se complementa con la también amplia fórmula del artículo 27 respecto de las "formas de cooperación", que puede ser puesta en práctica por cualquier medio apropiado $\mathrm{y}$, en particular, mediante las siguientes medidas, entre otras posibles que se puedan disponer: el nombramiento de una persona o de un órgano para que actúe bajo la dirección del tribunal; la comunicación de información por cualquier medio que el tribunal considere oportuno; la coordinación de la administración y la supervisión de los bienes y negocios del deudor; la aprobación o la aplicación por los tribunales de los acuerdos relativos a la coordinación de los procedimientos y la coordinación de los procedimientos que se estén llevando a cabo simultáneamente respecto a un mismo deudor.

\subsubsection{Capítulo V. Procedimientos paralelos y reglas finales}

En este capítulo final, la norma resuelve tres posibles conflictos entre procedimientos paralelos en distintas jurisdicciones:

a. Cuando a un procedimiento extranjero principal previo le sucede luego un procedimiento no principal local posterior, en cuyo caso, de tener bienes en el Estado donde tramita el primer proceso y de existir bienes del deudor, los efectos de este procedimiento se limitarán a tales bienes, tanto respecto de las medidas de cooperación y coordinación como de administración de los bienes (art. 28).

b. Cuando se tramitan simultáneamente, respecto del mismo deudor, un procedimiento de insolvencia extranjero y otro local, los tribunales deberán cooperar y coordinar los procedimientos conforme a las normas del capítulo anterior y los términos de este artículo; así mismo se deberán distinguir las distintas situaciones y soluciones según se trate, antes o después del reconocimiento del procedimiento extranjero $y$, finalmente, esta norma da pautas respecto del otorgamiento, la prórroga o la modificación de las medidas concedidas por el tribunal a un órgano concursal de un proceso extranjero no principal (art. 29).

c. Cuando existan dos o más procedimientos extranjeros respecto del mismo deudor, los tribunales deberán cooperar y coordinar los procedimientos conforme a las normas del capítulo anterior y los términos de este artículo, brindando soluciones sobre las medidas otorgadas respecto de los bienes (art. 30). 
El artículo 31 de la LMIT establece una presunción iuris tantum de la insolvencia del deudor si se dispone el reconocimiento de un procedimiento extranjero principal a los efectos de la apertura de un procedimiento concursal con arreglo a la legislación interna del Estado adoptante de la LMIT. Esta norma es semejante a la establecida en la primera oración del artículo 4 de la ley concursal argentina, aunque contrasta con ella en el sentido de que en esta la presunción es iuris et de iure. ${ }^{49}$ La LMIT es más conveniente al interés de las empresas argentinas que tienen en la República sus mayores activos, y actividades secundarias en países extranjeros. ${ }^{50}$

El artículo 32 de la LMIT establece una regla de paridad en los dividendos semejante a la del último párrafo del vigente artículo 4 de la ley concursal argentina, mutatis mutandis. ${ }^{51}$

Sobre este tema, la doctrina ha profundizado respecto de la coordinación de los distintos procedimientos, principales y secundarios, en los últimos años, especialmente en la órbita de los institutos regulados por la antigua fallida Convención europea y por el hoy vigente Reglamento europeo sobre insolvencia. ${ }^{52}$

49 Cfr. la opinión de Adolfo A. N. Rouillon, "Extraterritorialidad limitada de la sentencia concursal extranjera", en Rouillon, Código, t. IV-A, op. cit., pp. 78 y ss.

$50 \quad$ Ibid., p. 45.

51 Ibid., pp. 92 y ss.

52 Cfr., entre otros, vg.: Kai S. Staak, "Mögliche Probleme im Rahmen der Koordination von Haupt- und Sekundärinsolvenzverfahren nach der Europäischen Insolvenzverordnung (EulnsVO)”, en NZI (2004), pp. 480 y ss.; Hans Hanisch, "Parallel-insolvenzen und Kooperation im internationalen Insolvenzfall", en Festschrift für F. W. Bosch, Bielefeld, 1976, pp. 381-392; Klaus Wimmer, “Die Besonderheiten von Sekundärinsolvenzverfahren unter besonderer Berücksichtigung des Europäischen Insolvenzrechtsübereinkommens", en ZIP (1998), pp. 982 y ss.; Mankowsky, "Konkursgründe beim inländischen Partikularkonkurs", en ZIP (1995), pp. 1650 y ss. Klaus Wimmer, “Die Besonderheiten von Sekundärinsolvenzverfahren unter besonderer Berücksichtigung des europäischen Insolvenzübereinkommens", en ZIP (1998), pp. 982 y ss.; Wolf-Georg Ringe, "Sekundärinsolvenzverfahren nach der Europäischen Insolvenzverordnung", en Iprax (2013), pp. 330 y ss.; Stephen J. Taylor, "Avoiding Secondary Proceedings in EU Insolvency Regulation Cases", en Int. C. $R$ 4 (2007), pp. 7 y ss.; Andrew Seidl y Andreas Paulick, “Sekundärinsolvenz und Sanierungsinsolvenzplan, Das Zustimmungserfordernis des Art. 34 Abs. 2 EulnsVO", en ZInsO (2010), pp. 125 y ss.; Andreas Gewichtiger, Verfahrenskoordination im Europäischen Insolvenzrecht. Die Abstimmung von Haupt- und Sekundärinsolvenzverfahren nach der EulnsVO, Wien, 2010 (Tesis defendida en Viena en 2009); De este mismo autor: Andreas Gewichtiger, "Die Koordinierung von Parallelverfähren nach der EulnsVO", en Selena Clavora y Thomas Garber (eds.), Grenzüberschreitende Insolvenzen im europäischen Binnenmarkt - die EulnsVO. 1. Österreichische Assistententagung zum Zivil- und Zivilverfahrensrecht der Karl-Franzens-Universität Graz, Wien, Graz, 2011, pp. 123 y ss; Birgit Melanie Kompat, Die neue Europäische Insolvenzverordnung. Ihre Auswirkungen auf das Internationale Insolvenzrecht ausgewählter Mitgliedstaaten, Hamburg, 2006 (Tesis defendida en Berlin en 2006); Barbara Haidmayer, "Sanierungsverfahren in der EulnsVO - Schwierigkeiten bei der Eröffnung von Sekundärinsolvenzverfahren", ZIK 65 (2013), pp. 46 y ss; Heinz Vallender, "Gerichtliche Kommunikation und Kooperation bei grenzüberschreitenden Insolvenzverfahren im Anwendungsbereich der EulnsVO - eine neue Herausforderung für Insolvenzgerichte", en KTS (2008), pp. 59 y ss.; Hans Hanisch, "Parallel-Insolvenzen und Kooperation im Internationalen Insolvenzrecht", en Walter J. Habscheid, Hans Friedhehn Gaul y Paul Mikat (eds.), Festschrift für Wilhelm Bosch, , Bielefeld, 1976, pp. 381 y ss.; Stephan Kolmann, Kooperationsmodelle im internationalen Insolvenzrecht - Empfiehlt sich für das deutsche internationale Insolvenzrecht eine Neuorientierung?, , Bielefeld, 2001 (Tesis defendida en Regensburg en 2000); Heinz Vallender, “Die Aussetzung der Verwertung nach Art. 33 EulnsVO in einem deutschen Sekundärinsolvenzverfahren", en Heribert Hirte, Hans Haarmeyer, Hans-Peter Kirchhof y Friedrich Graf von Westphahlen (eds.), Verschulden - Haltung - Vollstreckung - Insolvenz. Festschrift für Gerhart Kreft zum 65, Geburtstag, Recklinghausen, Nomos, 2004, pp. 565 y ss.; Heinz Vallender, "Die Voraussetzungen für die Einleitung eines Sekundärinsolvenzverfahrens nach der EulnsVO", en Andreas Konecny (ed.), Insolvenz-Forum 2004. Vorträge anlässlich des II. Insolvenz-Forums Grundlsee im November 2004, Wien, Graz, 2005, pp. 225 y ss. 


\subsection{Valoración crítica de la Ley Modelo sobre Insolvencia Transfronteriza de UNCITRAL}

En nuestra opinión, cabe emitir la siguiente valoración crítica respecto de la LMIT, en parte tomada de los propios términos de la Guía para la incorporación al derecho interno de la Ley Modelo sobre insolvencia transfronteriza y de la doctrina sobre el tema: ${ }^{53}$

1. La norma recoge las prácticas, en materia de insolvencia internacional transfronteriza, que caracterizan a los sistemas más modernos y eficientes de administración de las insolvencias internacionales, especialmente en países del sistema jurídico del Common Law.

2. Ella respeta las diferencias que se dan entre los distintos derechos procesales y no intenta unificar el derecho sustantivo de la insolvencia, pero su régimen sí ofrece soluciones que pueden ser útiles a cualquier Estado que quiera dotar a su derecho de insolvencia con una normativa moderna, equitativa y armonizada para resolver con mayor eficacia y eficiencia los casos de insolvencia internacional.

3. Es una propuesta realista, alejada de las fantasías inalcanzables de la legislación sustantiva concursal unificada o de la universalidad o unidad concursal más allá de las fronteras nacionales. Este realismo estriba, sobre todo, en ofrecer soluciones modestas, pero significativas y alcanzables, ya que pueden ser fácil y rápidamente adoptadas por todos los países, cualquiera sea el origen, orientación, objetivos y principios inspiradores de sus respectivos derechos internos sobre insolvencia.

4. Por otra parte, ese realismo radica en que, frente al complejo y caleidoscópico panorama de los distintos derechos nacionales que pueden ser aplicables a un caso concursal multinacional, la propuesta aboga virtualmente por una solución ad casum mediante la comunicación de información, cooperación y coordinación de los distintos procesos concursales, en forma consensuada entre los tribunales, los acreedores, el deudor y los órganos concursales, entre los que debería lograrse una conformidad -al menos mayoritaria o con una mayoría calificada- en las soluciones adoptadas.

5. Esta norma no abdica de las preocupaciones tradicionales y antiguas de las normas internacionales de insolvencia (v. g. el problema del reparto equitativo de los bienes liquidados entre acreedores locales y extranjeros, el reconocimiento del proceso extranjero, el otorgamiento de medidas res-

53 Compartimos plenamente la opinión de Rouillon sobre este tema expresada en Rouillon, Código, t. VII, op. cit., pp. 46-47, como también lo expresado en la muy documentada y amplia tesis doctoral de la doctora María Elsa Uzal, Procesos de insolvencia en el Derecho Internacional Privado, Buenos Aires, La Ley, 2008, pp. 315-369 y 492-518, y en el trabajo monográfico de Germán Esteban Gerbaudo, Insolvencia transfronteriza, Buenos Aires, Astrea, 2011, pp. 241 a 272. 
pecto de los bienes, etc.), sino que incorpora reglas hasta hoy inexistentes en la mayoría de los países, incluida Argentina, en temas tales como:

- El acceso directo de los funcionarios concursales al proceso extranjero.

- La reorganización de empresas multinacionales como concurso previo o preventivo de la quiebra liquidativa.

- La distribución de los activos de empresas multinacionales en forma más equitativa.

- La preservación del valor de los bienes y de la empresa en marcha.

- El reconocimiento del proceso concursal extranjero con nuevos alcances.

- El acceso al concurso local de los representantes del concurso extranjero y de los acreedores extranjeros.

- La coordinación de los concursos abiertos en plurales países respecto de un mismo deudor en forma rápida y simplificada.

- La cooperación entre tribunales de distintos países y representantes de los plurales concursos del mismo deudor que se encuentren en diferentes países.

- La aceptación de criterios normalizados para la apertura del procedimiento.

- La suspensión de ejecuciones para proteger de la insolvencia los bienes de la masa, aplicable también a las acciones entabladas por acreedores garantizados.

- La financiación posterior a la apertura del proceso.

- La participación de los acreedores en el proceso.

- El reconocimiento de la empresa multinacional en crisis o insolvencia.

- La previsión de un proceso de reorganización agilizado.

- requisitos simplificados para la presentación y comprobación de reclamaciones.

- Transformación del procedimiento de reorganización en otro de liquidación si fracasa el primero.

- Normas claras para liberar al deudor de sus deudas.

- La conclusión del procedimiento de insolvencia.

6. Es una norma flexible por cuanto, como Ley Modelo, hace posible a cada Estado introducir modificaciones al texto uniforme, siempre que lo sean en un número razonable a fin de no perjudicar el grado de armonización deseable. 
7. El acento en la cooperación internacional entre jueces y órganos concursales o representantes de procedimientos concursales, sumado al claro estímulo a la comunicación directa entre ellos, pueden permitir una rápida actuación con miras a limitar o impedir el ocultamiento o transferencia fraudulenta de activos concursales a otras jurisdicciones, a fin de evitar el fraude internacional. Esa informalidad deberá preservar, no obstante, por una parte, la veracidad y legalidad de los documentos públicos extranjeros, de la que deberá cerciorarse el tribunal ad quem además del tribunal a quo, so pena de caer en un aumento del riesgo de fraude procesal internacional; $y$, por otra, la claridad y certidumbre de las soluciones consensuadas a las que pueda arribarse, con procesos de negociación transparentes y equitativos, a fin de satisfacer a todas las partes intervinientes y las exigencias de los distintos tribunales intervinientes, en un pie de igualdad.

8. Permite poner en práctica, de modo internacionalmente coordinado, soluciones preventivas o de reorganización de la empresa en crisis o en estado de cesación de pagos que redunde en beneficio de los acreedores cuya posibilidad de cobro es usualmente mayor en los procesos preventivos que en los liquidativos, a la vez que aumenta la posibilidad de rescatar empresas viables, lo que maximiza el valor empresarial y preserva empleos.

9. Contribuye a afianzar los bienes o valores de previsibilidad y seguridad jurídica que son factores tenidos en cuenta a la hora de calificar el riesgo país. En palabras de la Guía para la incorporación del derecho interno: "La falta de previsibilidad sobre cómo se administrará una eventual insolvencia transfronteriza obstaculiza el flujo de capitales y desincentiva la inversión transfronteriza"; mientras que, por el contrario,

... todo dispositivo de derecho interno que permita coordinar la administración de insolvencias transfronterizas abre vías para adoptar soluciones sensatas que pueden interesar tanto a los acreedores como al deudor, por lo que la presencia de ese tipo de mecanismos en el derecho interno de un Estado es percibida como un factor ventajoso para toda inversión u operación comercial en ese Estado.

En este sentido, el aumento de previsibilidad en un área especialmente sensible y muy tenida en cuenta por el inversor extranjero, cual es la existencia de reglas claras, concretas y no discriminatorias para tratar las relaciones entre acreedor y deudor en contextos de crisis o de insolvencia, es factor que debería incidir directamente en la disminución de la tasa de riesgo del país. Como beneficio no menor, la adopción de la LMIT daría una importante señal de previsibilidad y seguridad jurídica a la inversión foránea.

10. Ninguna de las disposiciones de la LMIT es contraria a nuestra Constitución Nacional, ni a los principios generales del derecho argentino o a su orden público, ni a los verdaderos y principales intereses del país. Por el contrario, es conveniente para ellos y permitiría, de manera rápida y sen- 
cilla - pues el trabajo, en lo fundamental, ya está hecho- actualizar nuestras obsoletas reglas de DIPRI, en línea con la más moderna tendencia universal.

11. Quizá lo que habría que concretar es los términos de la cooperación, comunicación, y, finalmente, la coordinación de los procesos multinacionales, pero, como se dijo supra en el punto 4 de este apartado, ello se verificará en cada caso particular, sea mediante los así denominados Protocolos -herramientas jurídicas ad hoc que pueden utilizar los tribunales conjuntamente con las partes intervinientes-, o bien, mediante las soluciones que puedan adoptar los distintos tribunales actuantes en cada caso particular, previa coordinación.

\section{La reorganización concursal como objeto del derecho internacional privado de la insolvencia}

Como hemos visto supra, los principales documentos sobre insolvencia, elaborados por la comunidad internacional en los últimos años (entre los que se encuentran los Principios del Banco Mundial, la Guía legislativa de UNCITRAL sobre insolvencia y la Ley Modelo sobre Insolvencia Transfronteriza) reconocen la importancia de los mecanismos de reorganización empresarial para "lograr que los acreedores perciban lo más posible por sus créditos, que los resultados sean mejores que en caso de la liquidación de la empresa deudora y que las empresas sigan siendo viables, para así preservar los puestos de trabajo de los empleados y las posibilidades comerciales para los proveedores". ${ }^{4}$ Tomada en muchos aspectos del proceso de reorganización del Chapter Eleven del United States Bankruptcy Code de Estados Unidos, la problemática de la reorganización ha comenzado a ser estudiada en mayor profundidad en los últimos años. ${ }^{55}$

Los mencionados documentos tienen una visión favorable a la reorganización y proveen recomendaciones sobre las prácticas utilizadas en numerosos países

54 Cfr. Guía, Segunda Parte, IV., A., número 3.

55 Puede verse, al respecto, la notable obra, en Alemania, de Horst Eidenmûller, Unternehmenssanierung zwischen Markt und Gesetz. Mechanismen der Unternehmensreorganisation und Kooperationspflichten im Reorganisationsrecht, Köln, O. Schmidt, 1999 (publicación de la Tesis de Habilitación defendida en Múnich en 1998), y la ya clásica obra de Axel Flessner, Sanierung und Reorganisation. Insolvenzverfahren für Großunternehmen in rechtsvergleichender und rechtspolitischer Untersuchung, Tübingen, Mohr, 1982 (Tesis de Habilitación defendida en Hamburgo en 1979). También puede verse: Ulrich Foersie, "Gläubigerautonomie und Sanierung im Lichte des ESUG", en ZZP 125 (2012), pp. 265 y ss; Marc Fritze, "Sanierung von Groß- und Konzernunternehmen durch lnsolvenzpläne DZ", en WIR (2007), pp. 89 y ss; Solveig Lieder, Grenzüberschreitende Unternehmenssanierung im Lichte der EulnsVO, Berlin, Gruyter Recht, 2007 (Tesis defendida en Kiel en 2006); Carsten Oliver Müller-Seils, Rescue Culture und Unternehmenssanierung in England und Wales nach dem Enterprise Act 2002, Baden-Baden, Nomos, 2006 (Tesis defendida en Colonia en 2006); Stefan Reinhart, Sanierungsverfahren im internationalen Insolvenzrecht. Eine rechtsvergleichende Untersuchung über die besonderen internationalrechtlichen Probleme liquidationsabwendender Insolvenzverfahren, Berlin, 1995 (Tesis defendida en Frankfurt a. M. en 1994); Carsten Rumberg, "Entwicklung der "Rescue Culture" im englischen Insolvenzrecht", en RIW (2010), pp. 358 y ss.; Heinz Vallender, "Sanierungsoptionen bei grenzüberschreitenden Insolvenzen nach dem ESUG. (Gesetz zur weiteren Erleichterung der Sanierung von Unternehmen)" en GrnbHR (2012), pp. 478 y ss.; Jay Lawrence Westbrook, "Avoidance of Pre-Bankruptcy Transactions in Mulitnational Bankruptcy Cases", en Tex. Int', L. J. 42 (2007), pp. 899 y ss. 
para la obtención de acuerdos de reestructuración en negociaciones voluntarias, y las legislaciones que establecen la posibilidad de convertir, de manera acelerada, a los acuerdos prenegociados extrajudicialmente en planes de reorganización que obligan de la misma manera que los planes obtenidos en los tradicionales procesos de reorganización "formal" en sede judicial. Siguiendo la sistemática y terminología adoptadas por Rouillon, ${ }^{56} \mathrm{y}$ conforme a los sistemas modernos y eficientes de insolvencia que pueden adoptar los distintos países, la reorganización de las empresas insolventes no queda ya limitada al clásico proceso judicial liquidativo o, incluso, al concurso preventivo de la quiebra también denominados en el Common Law "reorganization", sino que actualmente los mecanismos de reorganización o preventivos de la quiebra liquidativa se han ampliado, y pueden abarcar las siguientes alternativas:

1. Reorganización mediante negociaciones puramente voluntarias, regidas por el derecho contractual común (por ejemplo, los Workouts o institutos similares en Estados Unidos).

2. Reorganización como producto de la negociación voluntaria cuyo plan se somete a un procedimiento agilizado, que puede alcanzar las ventajas del plan aprobado en el proceso concursal clásico o "completo" (por ejemplo, el denominado Prepackaged Chapter Eleven en Estados Unidos).

3. Reorganización obtenida en un proceso "formal" o "completo", ya sea: a) en un sistema concursal "unitario" (proceso concursal único, redireccionado luego hacia la reorganización o la liquidación); b) en un sistema "dual" (procesos concursales distintos para la reorganización y la liquidación); c) aún dentro de una liquidación, a través de la enajenación y transferencia de la empresa en marcha. Ejemplos de estos son, principalmente, el proceso del Chapter Eleven de reorganización y, para la liquidación judicial, el Chapter Seven de liquidación concursal de Estados Unidos.

Esta ampliación del objeto del derecho concursal de la reorganización empresarial tiene sus consecuencias en el campo del derecho internacional privado de la insolvencia por cuanto puede ocurrir la reorganización empresarial con elementos multinacionales, como se ha venido debatiendo en el seno de $U N$ CITR AL desde 2006 y ha ocurrido en algunos casos en los últimos años. ${ }^{57}$

Cabe destacar que el derecho interno puede establecer reglas internacionales específicas para la reorganización empresarial, lo que por otra parte es posible en el marco de la LMIT.

\footnotetext{
56 Cfr. Rouillon, Código, t. VII, op. cit., p. 24. En las páginas 11 a 23 este autor explica los conceptos acuñados y la terminología adoptada.

57 Cfr. http://www.UNCITRAL.org/UNCITRAL/es/commission/working_groups/5Insolvency.html. Cabe citar aquí el paradigmático caso de General Motors Co.
} 


\section{Propuestas de lege lata y de lege ferenda}

Las consideraciones de lege lata sobre la vetustez y las limitaciones del ordenamiento internacional argentino sobre la insolvencia han sido vertidas, supra, en diversos lugares, adonde remitimos al lector.

En cuanto a las consideraciones de lege ferenda, tal como hemos destacado supra, valoramos al Anteproyecto argentino como un instrumento adecuado y perfeccionador del régimen internacional argentino vigente, que soluciona numerosos problemas que plantea la cuestión, con las salvedades y consideraciones vertidas en este trabajo que juzgamos pertinentes.

\section{Conclusiones esenciales de la investigación}

Como conclusiones esenciales de la investigación cabe afirmar lo siguiente: ${ }^{58}$

1. Tanto si se trata de crisis sistémicas de algunos países o regiones que no tienen experiencia en la solución de crisis empresariales o insolvencias de empresas multinacionales, como si se trata de países que cuentan con una razonable y moderna legislación, el derecho de insolvencia ha sido puesto a prueba en los últimos treinta años, y ha requerido la respuesta por parte del legislador para renovar el plexo normativo frente a su vetustez y antigüedad.

2. Las relaciones comerciales y de inversión se han internacionalizado, interrelacionado y tecnificado electrónicamente cada vez más, lo que acarreará un incremento en las soluciones que el legislador habrá de tener en cuenta e implementar prudencialmente para enfrentar estos nuevos problemas, especialmente en el campo de la reorganización y liquidación de empresas multinacionales.

3. La visión jurídica sobre los problemas concursales actuales ha evolucionado desde los tradicionales problemas y soluciones de derecho internacional privado de la segunda mitad del siglo XIX y principios del siglo XX -tales como la distribución de los activos concursales locales y el tratamiento de los créditos extranjeros- hacia el surgimiento de nuevos problemas tales como la reorganización de empresas multinacionales, los mecanismos de preservación del valor de los activos concursales, el otorgamiento de medidas judiciales, la optimización de porcentajes de recupero crediticio, la preservación del valor de la empresa en marcha, la prevención del fraude internacional, la conservación de las fuentes de trabajo internacionales $y$, finalmente, la mayor comunicación, coordinación y cooperación entre los distintos tribunales intervinientes a través de plurales jurisdicciones.

58 Coincidimos con lo expresado por la doctrina en, por ejemplo, Rouillon, en Código..., cit., tomo VII, ps. 57-58. 
4. Algunos países de Latinoamérica han comenzado a transitar hacia ordenamientos concursales internacionales más adecuados a los nuevos problemas, pero lamentablemente otros países continúan con sistemas internacionales de tratamiento de la insolvencia anticuados, obsoletos, ineficaces y aislacionistas. Al propio tiempo, la percepción de esos nuevos conflictos ha puesto de relieve la común desnudez de la mayoría de los sistemas de América Latina para enfrentar eficientemente los acuciantes, complejos y casi siempre urgentes problemas actuales de la insolvencia internacional.

5. En estos tiempos se ha despertado también el interés de la comunidad internacional sobre la necesidad de que los países cuenten con sistemas efectivos de insolvencia para alentar la inversión, disminuir la tasa de riego país, contribuir a la estabilidad de los sistemas financieros y resolver de manera eficiente las dificultades empresariales a fin de preservar el valor económico y proteger empleos.

6. En los últimos treinta años hemos asistido a una suma de múltiples esfuerzos en marcha, internacional e institucionalmente coordinados para contribuir a paliar las consecuencias de la insolvencia empresaria internacional y para afianzar sistemas legales e institucionales que hagan posible soluciones justas y equitativas para esas crisis multinacionales. Vale la pena aprovechar esos esfuerzos e implementar reformas normativas locales más modernas y adecuadas.

7. En la actualidad hay una mayor conciencia de la importancia global de los sistemas de insolvencia y se está construyendo conocimiento a partir del intercambio de información jurídica y de experiencia comparada que se pone cada vez más a disposición de los operadores jurídicos.

8. Hay diferentes visiones sobre cuáles reformas deben ser las pertinentes y más adecuadas, según cada país, cada época y cada circunstancia. Por ello, es posible afirmar que no caben las soluciones únicas o rígidas, pero es alentador comprobar que el deseo de mejorar los sistemas de insolvencia comparados cuenta hoy con el elemento auxiliar de iniciativas y documentos internacionales como los aquí estudiados (los trabajos del Banco Mundial y de la UNCITRAL), que demuestran solvencia científica y práctica para resolver los problemas planteados.

9. Las normas proyectadas por el Ministerio de Justicia de la República Argentina en el 2002 se hacen cargo de esos modernos problemas y de esas adecuadas soluciones, principalmente la comunicación, cooperación y coordinación judiciales. Por ello, este proyecto es encomiable, adecuado, razonable, proporcionado y merece ser adoptado como instrumento legal en el futuro inmediato, con algunas variantes que seguidamente proponemos.

10. Por lo expuesto entendemos que la mejor opción actual para los países del Mercosur consiste en la adopción de los Principios y propuestas de normas tales como las del Banco Mundial y la UNCITRAL, más que una compli- 
cada negociación internacional para llegar a hipotéticas normas en tratados multilaterales internacionales, por razones prácticas y por las dificultades diplomáticas inherentes a esa negociación.

11. En nuestra opinión, por exigencia de pautas de justicia se podría proyectar la eliminación del requisito de la reciprocidad y el añadido de otros temas, tales como normas específicas para grupos de sociedades, la responsabilidad de los directores de sociedades concursadas internacionalmente y el proceso de reorganización internacional, entre otros posibles. En tales condiciones, el Anteproyecto de 2002, puede ser un instrumento eficaz de inspiración para avanzar en el campo legislativo del derecho internacional privado de la insolvencia de la Argentina y, de modo indirecto, en otros países del Mercosur y de la región latinoamericana.

\section{Bibliografía}

AA.VV., Arbeitskreis für Insolvenz und Schiedsgerichtswesen (ed.), Kölner Schrift zur Insolvenzordnung, 3. Aufl., 2009.

AA.VV., Siegfried Beck y Peter Depré (eds.), Praxis der Insolvenz, 2 Aufl., München, Verlag Franz Vahlen, 2010.

AA.VV., Braun, Eberhard, bearb. von Rüdiger Bauch, Insolvenzordnung (InsO), Kommentar, $5^{\circ}$ neu bearb. Auflage. München, Beck, 2012.

AA.VV., Campbell (ed.), International Corporate Insolvency Law, Butterworths, 1992.

AA.VV., Dennis Campbell y Anthony E. Collins (eds.), Corporate insolvency and rescue: the international dimension, Kluwer, Deventer, 1993.

AA.VV., Clarke (ed.), Current Issues in Insolvency Law, Stevens and Sons, 1991.

AA.VV., Cooper y Jarvis (eds.), Recognition and Enforcement of Cross-Border Insolvency, 1996.

AA.VV., Cranston (ed.), Making Commercial Law: Essays in Honour of Roy Goode, Clarendon Press, 1997.

AA.VV., Cross border insolvency, Problems and legal principles, London, The British Institute of International and Comparative Law, 1986.

AA.VV., Cross-Border Insolvency - A Commentary on the UNCITRAL Model Law, General Editor Look Chan HO, 2 ed., London, Globe Business Publishing Ltd, 2009. 
AA.VV., Kortmann, McBryde y Flessner (eds.), Principles of European Insolvency Law, Kluwer, Deventer, 2003.

AA.VV., Ian F. Fletcher (ed.), Cross-Border insolvency: comparative dimensions, The Aberystwyth Insolvency Papers, London, The United Kingdom National Committee of Comparative Law, 1990.

AA.VV., Ian F. Fletcher (ed.), Cross-border insolvency: National and Comparative studies, Reports delivered at the XIII International Congress of Comparative Law, Montreal, 1990, Mohr Siebeck, Tübingen, 1992.

AA.VV., Leonard E. Bruce y Christopher W. Besant (eds.), Current issues in cross-border insolvency and reorganizations, London, International Bar Association Series, 1994.

AA.VV., Enciclopedia del diritto, Milano, Giuffrè, 1967.

AA.VV., Gerhard Kegel y Jürgen Thieme (eds.), "Vorschläge und Gutachten zum Entwurf eines EG- Konkursübereinkommens". En Auftrag einer Sonderkommission des Deutschen Rates für internationales Privatrecht, Tübingen, 1988.

AA.VV., Graf-Schlicker y Marie Luise (eds.), Kommentar zur Insolvenzordnung: InsO, 2 Auflage, Köln, RWS Verl. Kommunikationsforum, 2010.

AA.VV., Guía Legislativa de UNCITRAL sobre el Régimen de la Insolvencia, Madrid, La Ley y Wolters Kluwer Group, 2006.

AA.VV., Idées nouvelles dans le droit de la faillite. Travaux de la 4. journée d'études juridiques Jean Dabin. 17 mai 1968. Préf. De Jacques van der Gucht. Bruxelles, Biblithèque de la Faculté de Droit de l’Université Catoholique de Louvain, 1969.

AA.VV., James Farley y Bruce Leonard y John Birch (eds.), Cooperation and Coordination in Cross Border Insolvency Cases, International Insolvency Institute, 6th Annual International Insolvency Conference, New York, 2006, en www.iiiglobal.org.

AA.VV., Klaus Wimmer (ed.), FK-InsO, Frankfurter Kommentar zur Insolvenzordnung: mit EuInsVO, InsVV und weiteren Nebengesetzen, 6 Auflage, Köln, Luchterhand, 2011.

AA.VV., L'Unificazione del diritto internazionale privato e processuale, Studi in memoria di Mario Giuliano (1914-1986), Padova, Cedam, 1989.

AA.VV., Pierre Lalive y Frank Vischer (eds.), Colloque international sur le droit international privé des groupes de sociétés, Gèneve, Centre d'Etudes Juridiques Européennes de la Faculté de Droit de Genève, Georg, 1973. 
AA.VV., Le Cannu et al., Entreprises en Difficulté, Joly Editions, 1994.

AA.VV., Les problemes internationaux de la faillite et le marche commun, Actes du colloque international sur l'avant-projet de convention CEE en matière de faillite, concordats et procédures analogues, Milan, 12-14 Juin 1970, Padova, Cedam, 1971.

AA.VV., Lessing y Corkery (eds.), Corporate Insolvency Law, Australia, Taxation and Corporate Research Centre, Bond University , 1995.

AA.VV., Lipstein (ed.), Harmonisation of Private International law by the EEC, London, Chameleon e lnstitute of Advanced Legal Studies, 1977.

AA.VV., Martin Gebauer (ed.), Zivilrecht unter europäischem Einfluss: die richtlinienkonforme Auslegung des BGB und anderer Gesetze. Kommentierung der wichtigsten EU-Verordnungen, 2., überarb. und erw. Aufl., Boorberg, Stuttgart, München, Hannover, Berlin, Weimar y Dresden, 2010.

AA.VV., William W. McBryde, Axel Flessner y S. C. J. J. Kortmann (eds.), Principles of European Insolvency Law, Deventer, 2003.

AA.VV., Klaus Pannen (ed.), Europäische Insolvenzverordnung, Berlin, Kommentar, 2007.

AA.VV., Paul J. Omar (ed.) International Insolvency Law, Themes and Perspectives, Aldershot, 2008.

AA.VV., Potok (ed.), Cross Border Unilateral: Legal Risk and the Conflict of Laws, 2002.

AA.VV., Premier Séminaire de Droit International et de Droit Européen. Neuchâtel, 11-12 octobre 1985. Le droit de la faillite international, Zürich, Schulthess Plygraphischer Verlag, 1986.

AA.VV., Probleme des internationalen Insolvenzrechts, Verhandlungen der Fachgruppe für vergleichendes Handels- und Wirtschasftsrecht anläßlich der Tagung für Rechtsvergleichung 1981 in Frankfurt a. M. Herausgegeben von Wolfgang Frühr, Marschall von Bieberstein, Bonn, mit Referaten von Hans Hanisch, Genf, Jacques Lemontey, Paris, Stefan Riesenfeld, Berkeley und mit einem Bericht über die Diskussion von Peter Gottwald, Bonn. Arbeiten zur Rechtsvergleichung. Schriftenreihe der Gesellschaft für Rechtsvergleichung. Begründet von Hans Dölle. Herausgegeben von Ernst von Caemmerer und Hans-Heinrich Jescheck. Band 113. Frankfurt am Main, Alfred Metzner Verlag, 1982.

AA.VV., Rajak, Horrocks y Bannister (eds.), European Corporate Insolvency: A Practical Guide, Wiley, 1995.

AA.VV., Runkel (ed.), "Anwalts-Handbuch Insolvenzrecht”, 2. Aufl. 2008. AA.VV., Rauscher (ed.), Europäisches Zivilprozeßrecht, 2 Bände, 2 Auflage, 2006. 
AA.VV., "Seminar on the occasion of the Tenth Anniversary of Forum Internationale. Cross border insolvency", en Forum Internationale 199 (1994), pp. 3-55.

AA.VV., Richard Sheldon (ed.), Cross-Border Insolvency, 3 ed., Haywards Heath, 2011.

AA.VV., Hans Jürgen Sonnenberger (ed.), Vorschläge und Berichte zur Reform des europäischen und deutschen internationalen Gesellschaftsrechts. Vorgelegt im Auftrag der zweiten Kommission des Deutschen Rates für Internationales Privatrecht, Spezialkommission Internationales Gesellschaftsrecht, Tübingen, 2007.

AA.VV., Anker Sørensen (ed.), Directors' Liabilities in Case of Insolvency, Kluwer, 1998.

AA.VV., Hans Stoll (ed.), Stellungnahmen und Gutachten zur Reform des deutschen Internationalen Insolvenzrechts. Im Auftrag der Sonderkommission "Internationales Insolvenzrecht" des Deutschen Rates für Internationales Privatrecht, Tübingen, 1992.

AA.VV., Wheeler y Oldfield (eds.), International Insolvency Procedures, 2 ed., Blackstone, 1997.

AA.VV., Ziegel, Jacob S. (ed.), Current Developments in International and Comparative Corporate Insolvency Law, Oxford, Clarendon Press, 1994.

Aderhold, Eltje, Auslandskonkurs im Inland. Entwicklung und System des deutschen Rechts mit praktischen Beispielen unter besonderer Berücksichtigung des Konkursrechts der Vereinigten Staaten von Amerika, England, Frankreichts sowie der Schweiz, Berlin, Dunker und Humblot, 1992.

Aird, J. N. St. C. Jameson, The Scots Dimension to Cross-Border Litigation, W. Green y Sweet and Maxwell, 1996.

American Law Institute, Principles of Cooperation among the NAFTA Countries Proc. Prin, pp. 10, 57 and App. B, 2003.

Aronofsky, David, "Piercing the Transnational Corporate Veil: Trends, Developments and the Need for Widespread Adoption of Enterprise Analysis", en North Carolina Journal of International Law and Commercial Regulation 10 (1985), pp. 31-86.

Baierlipp, Matthias, Die Haftung der Muttergesellschaft eines multinationalen Konzerns für die Verbindlichkeiten ihrer ausländischen Tochtergesellschaft. Eine vergleichende Untersuchung nach deutschem und französischem Recht, Hamburg, Verlag Dr. Kovac̃, 2002.

Banco Mundial, Principios de los Sistemas Efectivos de Insolvencia y Derechos de los Acreedores, 2001, en www.worldbank.org/gild. 
Basedow, Jürgen, "The Communitarization of the conflict of laws under the Treaty of Amsterdam", en CML Rev. 2000, pp. 687 y ss.

Becker, Christoph, “Insolvenz in der Europäischen Union, Zur Verordnung des Rates über Insolvenzverfahren”, en ZEuP 2002, pp. 287 y ss.

Beckmann, Jochen, Internationales Insolvenzrecht im Mercosur, Baden Baden, Nomos Verlagsgesellschaft, 2000.

Beicher, Corporate Rescue, Sweet and Maxwell, 1997.

Beltrán Sánchez, “El Reglamento de la Union Europea sobre procedimientos de insolvencia", Tribunales de Justicia, 2001, pp. 31 y ss.

Benning, Olaf y Axel Das Wehling, "Model Law on Cross-Border lnsolvency" der Vereignten Nationen", en EuZW 1997, pp. 618 y ss.

Bezelgues, Sarkis, Konzerninsolvenzen in der Europäischen Union, Mamburg, 2008.

Bhala, Raj, "International dimensions of Japanese insolvency law: a contextual approach", en Discussion Paper n. 99-E-26. Institute for Monetary and Economic Studies y Bank of Japan, 1999.

Blom-Cooper, Louis Jacques, Bankruptcy in Private International Law, London, 1954.

Blumberg, Phillip I. y Jonathan Fowler, The law of corporate groups. Problems in the bankruptcy or reorganization of parent and subsidiary corporations, including the law of corporate guaranties, New York, Aspen Law \& Business, 2000.

Blumberg, Phillip I., Blumberg on corporate groups, 2 ed., New York, Wolters Kluwer Law and Business, 2002.

Blumberg, Phillip I., The multinational challenge to corporation law. The search for a new corporate personality, New York y Oxford, Oxford University Press, 1993.

Bogart, Daniel B., "Liability of Directors of Chapter 11 Debtors in Possession: "Don't Look Back-Something May be Gaining on You"", en 68 Am Bankr. L. J. 155 (1994).

Bogdan, Michael, "Insolvency Law in the European Union”, en von Hoffmann, Bernd (ed.), European Private International Law, Nijmegen, 1998, pp. 181 y ss.

Bogdan, Michael, "The EU Bankruptcy Convention”, en Int. Insolv. Rev. 6 (1997), pp. 114 y ss.

Bogdan, Michael, “The Nordic Bankruptcy Convention”, Ziegel, Jacob S. (ed.), Current Developments in International and Comparative Corporate Insolvency Law, Oxford, 1994, pp. 701 y ss. 
Bogdan, Michael, Gerhard Kegel y Jürgen Thieme (eds.), "Vorschläge und Gutachten zum Entwurf eines EG-Konkursübereinkommens. Im Auftrag einer Sonderkommission des Deutschen Rates für internationales Privatrecht", en RabelsZ 53 (1989), pp. 573 y ss.

Borrás, Alegría, "Derecho internacional privado y Tratado de Amsterdam", en REDI 2 (1999), pp. 383 y ss.

Bos, Titia M., "The European Insolvency Regulation and the Harmonization of Private International Law in Europe", en NILR 50 (2003), pp. 31 y ss.

Boutin, Gilberto, La quiebra en el derecho internacional privado panameño y comparado, Panamá, 1986.

Brown, Corporate Rescue: Insolvency Law in Praclice, Wiley, 1996.

Brünkmans, Christian, Die Koordinierung von Insolvenzverfahren konzernverbundener Unternehmen nach deutschem und europäischem Insolvenzrecht, Berlin, 2009.

Calvo Caravaca, Alfonso Luis y Carrascosa González, Javier, "Insolvencia de la empresa y Derecho internacional privado", en Justicia 98, pp. 419 y ss.

Calvo Caravaca, Alfonso Luis y Javier Carrascosa González, "Reglamento (CE) núm 1346/2000 sobre procedimientos de insolvencia y cuestiones de ley aplicable", en AA.VV., Estudios sobre la Ley Concursal. Libro homenaje a Manuel Olivencia, Tomo I, Madrid-Barcelona, 2005.

Candelario Macias, "Aproximación a la iniciativa de Reglamento del Consejo europeo sobre procedimientos de insolvencia", en Dir. Fall. 6 (1999), pp. 1226 y ss.

Carstens, Nis, Die internationale Zuständigkeit im europäischen Insolvenzrecht, Berlin, München, Köln, 2005.

Centre for cooperation with the Economies in Transition, Procédures de faillite et de restructuration des entreprises dans les pays de l' OCDE et d'Europe, Organisation de Coopération et de Développement Économique, Paris, 1994.

Chalupsky, Ernst y Axel IV Bierbach, “Die Europäische Insolvenzverordnung (EUIns VO). Grundlagen, Ausblick und Praxisanwendung", en KSI (2013), pp. 23 y ss.

Cheffins, Company Law Theory Structure and Operation, Oxford University Press, 1998.

Clift, Jenny, "The UNCITRAL Model Law on Cross Border Insolvency - A Legislative Framework to Facilitate Coordination and Cooperation in CrossBorder Insolvency", en Tulane Journal of International and Comparative Law 12 (2004), pp. 307 y ss. 
Clift, Jenny, The UNCITRAL Model Law on Cross-Border Insolvency - A Brief Introduction, en www.ibanet.org.

Cooper, Neil H. y Rebecca Jarvis, Recognition and enforcement of cross-border insolvency. A guide to international practice, Chichester, John Wiley \& Sons, 1996.

Council of Europe Press, "Aspects internationaux de la faillite", en International aspects of bankruptcy. Explanatory report on the Istanbul Convention (5 June 1990), Strasbourg, 1991.

Cranshaw, Friedrich F., Zehn Jahre EulnsVO y Centre of Main Interests, “Motor dynamischer Entwicklung im Insolvenzrecht?", en DZWIR (2012), pp. 133 y ss.

Dalhuisen, J. H., Dalhuisen on international insolvency and bankruptcy, Vol. I, New York, Mattew Bender, 1986.

Dammann, Reinhard, "Mobility of Companies and localization of assets - Arguments in favor of a dynamic and teleological Interpretation of the EC Regulation No 1346/2000 on insolvency proceedings", en AA.VV., Georges Affaki (ed.), Faillite internationale et conflit de juridictions. Regards croises transatlantiques - Cross-border insolvency an conflict of jurisdictions. Paris, Brüssel, A US-EU Experience, 2007, pp. 105 y ss.

Daniele, Luigi, Il fallimento nel Diritto Internazionale Privato e Processuale, Padova, Cedam, 1987.

Daniele, Luigi, "La convenzione europea su alcuni aspetti internazionali del fallimento prime riflessioni”, en RDIPP 30 (1994), pp. 499 y ss.

Davies, Gower's Principles of Modern Company law, 6 ed., Sweet and Maxwell, 1997.

de Boer, Margreet BJ y Bob Wessels, "The Dominance of Main Insolvency Proceedings under the European lnsolvency Regulation", en Omar, Paul J. (ed.), International Insolvency Law. Themes and Perspectives, Aldershot 2008, pp. 185 y ss.

Degueé, «La directive 2001/24/CE sur l'assainissement et la liquidation des ètablissements de credit: une solution aux defaillances bancaires internationales?», en Euredia (2001-2002), pp. 242 y ss.

Deipenbrock, Gundula, Das neue europäische Insolvenzrecht - von der "quantite negligeable" zu einer "quantite indispensable", EWS, 2001, pp. 113 y ss.

Dicey and Morris, Conflict of Laws, 11 ed., Stevens and Sons, 1987, y Fourth Cumulative Supplement, 1991.

Dordi, "La Convenzione dell'Union Europea sulle procedura di insolvenza", en Riv.Dir.Internat. Pr. e Proc. (1997), pp. 333 y ss. 
Doyle, Administrative Receivership: Law and Practice, Law and Tax, 1995.

Drobnig, Ulrich, "Bemerkungen zur Behandlung der Rechte Dritter, inbesondere von Sicherungsrechten", en Stoll (ed.), Stellungnahmen und Gutachten zur Reform des deutschen Internationalen Insolvenzrecht, 1992, pp. 177 y ss.

Drobnig, Ulrich, "Secured credit in international insolvency proceedings", en Texas International Law Journal 33 (1998), pp. 54-70.

Duursma-Kepplinger, Henriette-Christine, Duursma, Dieter Duursma y Ernst Chalupsky, Europäische Insolvenzverordnung, Wien, Kommentar, 2002.

Ehricke, Ulrich y Julian Ries, "Die neue Europäische Insolvenzverordnung", en JuS (2003), pp. 313 y ss.

Ehricke, Ulrich, "Die neue Europäische Insolvenzordnung und grenzüberschreitende Konzerninsolvenz", en EWS (2002), pp. 101 y ss.

Ehricke, Ulrich, "Probleme der Verfahrenskoordination - Eine Analyse der Kooperation von Insolvenzverwaltern und Insolvenzgerichten bei grenzüberschreitenden Insolvenzverfahren nach der EulnsVO", en Gottwald, Peter (ed.), Europäisches Insolvenzrecht - Kollektiver Rechtsschutz, Bielefeld, 2008, pp. 127 y ss.

Ehricke, Ulrich, "Verfahrenkoordination bei grenzüberschreitenden Unternehmensinsolvenzen", en AA.VV., Basedow, Jürgen $u$. $a$. (ed.), $A u$ fbruch nach Europa, 75 Jahre MaxPlanck-Institut für Privatrecht, Tübingen, 2001, pp. 337 y ss.

Ehricke, Ulrich. Das abhängige Konzernunternehmen in der Insolvenz. Wege zur Vergrößerung der Haftungsmasse abhängiger Konzernunternehmen im Konkurs und Verfahrensfragen. Eine rechtsvergleichende Analyse, Tübingen, Mohr Siebeck, 1998.

Eidenmüller, Horst, "Der nationale und der internationale Insolvenzverwaltungsvertrag", en ZIP (2001), pp. 3 y ss.

Eidenmüller, Horst, "Abuse of Law in the Context of European Insolvency Law", en Rita de la Feria y Stefan Vogenauer, (eds.), Prohibition of Abuse of Law. A New General Principle of EU Law?, Oxford, Portland, 2011, pp. 137 y ss.

Eidenmüller, Horst, “Europäische Verordnung über Insolvenzverfahren und zukünftiges deutsches internationales Insolvenzrecht", en IPRax (2001), pp. 2 y ss.

Eidenmûller, Horst, Unternehmenssanierung zwischen Markt und Gesetz. Mechanismen der Unternehmensreorganisation und Kooperationspflichten im Reorganisationsrecht, Köln, 1999. 
Espiniella Menéndez, Ángel, Procedimientos de insolvencia y grupos multinacionales de sociedades, Cizur Menor, Thomson Civitas, 2006.

Esplugues Mota, Carlos A., La quiebra internacional, Barcelona, J.M. Bosch Editor, 1993.

Favoccia, Daniela, Vertragliche Mobiliarsicherheiten im internationalen Insolvenzrecht, Köln, Heymann, 1991.

Flessner, Axel, “Dingliche Sicherungsrechte nach dem Europäischen Insolvenzübereinkommen", en FS Drobnig (1998), pp. 277 y ss.

Flessner, Axel, "Internationales Insolvenzrecht in Europa", en Festschrift für Heinsius (1991), pp. 1 y ss.

Flessner, Axel, “Grundsätze des europäischen Insolvenzrechts", en ZEuP 2004, pp. 887 y ss.

Flessner, Axel, "Philosophies of Business Bankruptcy Law: An International Overview,: Ziegel", en Jacob S. (ed.), Current Developments in International and Comparative Corporate Insolvency Law, Oxford, 1994, pp. 19 y ss.

Flessner, Axel, Sanierung und Reorganisation. Insolvenzverfahren für Großunternehmen in rechtsvergleichender und rechtspolitischer Untersuchung, Tübingen, 1982.

Fletcher, Ian F., Insolvency in private international law: national and international approaches, 2 ed., Oxford, Clarendon Press, 2005.

Fletcher, Ian, Conflict of Laws and European Community Law, North-Holland Publishing Co., 1982.

Fletcher, Ian, "Maintaining the Momentum: The Continuing Quest for Global Standards and Principles to Govern Cross-Border Insolvency", en Brook. J. Intl, L. 32 (2007), pp. 767 y ss.

Fletcher, Ian, "The European Union Convention on Insolvency Proceedings: Choice-of-Law Provisions", en Tex. Int'l L. J. 33 (1998), pp. 119 y ss.

Fletcher, Ian, The Law of Insolvency, 3 ed., Sweet and Maxwell, 1999.

Florian, Matthias, Das englische internationale Insolvenzrecht, Heidelberg, Verlag für Recht und Wirtschaft, 1989.

Foerste, Ulrich, "Gläubigerautonomie und Sanierung im Lichte des ESUG", en ZZP 125 (2012), pp. 265 y ss.

Fois, Paolo, "Considerazioni sulla delibazione delle sentenze straniere di estensione del fallimento", en Rivista di Diritto Internazionale Privato e Processuale (1967), pp. 246-267. 
Fritz y Bähr, “Die Europäische Verordnung über Insolvenzverfahren - Herausforderungen an Gerichte und Insolvenzverwalter", en DZWIR (2001), p. 221.

Fritze, Marc, "Sanierung von Groß- und Konzernunternehmen durch lnsolvenzpläne DZ", en WIR (2007), pp. 89 y ss.

Fromm, Hartmut, "Haftungsfolgen bei der Verwaltung ausländischer Tochtergesellshaften", en IPRAX (1983), pp. 83-97.

Fumagalli, "II Regolamento comunitario sulle procedure di insolvenza", en Riv. Dir. Proc. (2001), pp. 677 y ss.

García Gutierrez, Laura, La compensación de creditos en Derecho internacional privado, Madrid, Eurolex, 2002.

Garcimartin Alférez, Francisco J., “El Reglamento de Insolvencia: una aproximación general", en Cuadernos de Derecho Judicial (2001), pp. 229 y ss.

Garrido, "Some Reflections on the EU Bankruptcy Convention and its Implications for Secured and Preferential Creditors", en Int. Insolv. Rev. (1998), pp. 79 y ss.

Geimer, Internacionales Zivilprozessrecht, 4. Auflage, 2001.

Gerbaudo, Germán Esteban, Insolvencia transfronteriza, Buenos Aires, Ed. Astrea, 2011.

Gewichtiger, Andreas, "Die Koordinierung von Parallelverfähren nach der EulnsVO", en AA.VV., Selena Clavora y Thomas Garber, (eds.), Grenzüberschreitende Insolvenzen im europäischen Binnenmarkt - die EulnsVO. 1. Österreichische Assistententagung zum Zivil- und Zivilverfahrensrecht der KarlFranzens-Universität Graz, Wien, Graz, 2011, pp. 123 y ss.

Gewichtiger, Andreas, Verfahrenskoordination im Europäischen Insolvenzrecht. Die Abstimmung von Haupt- und Sekundärinsolvenzverfahren nach der EulnsVO, Wien, 2010.

Gilliéron, Pierre-Robert, Les dispositions de la nouvelle loi fédérale de droit international privé sur la faillite internationale, Lausanne, 1991.

Giuliano, Mario, Il fallimento nel Diritto Processuale Civile Internazionale, Milano, Giuffrè, 1943.

Goode, Roy, Principles of Corporate Insolvency Law, 4 ed., London, 2011.

Gottwald, Peter, Grenzüberschreitende Insolvenzen. Europäische und weltweite Tendenzen und Lösungen, München, 1997.

Grace, A. D., "Law of liquidations: the recognition and enforcement of foreign liquidation orders in Canada and Australia, A critical comparison", en International and Comparative Law Quarterly 35 (1986), pp. 664-703. 
Graf-Schlicker, Marie Luise y Ursula Schlegel, Insolvency Law \& Restructuring in Germany, München, Beck, 2015.

Graham, David, "In Search of Jabez Henry - Part II: The Readership of Foreign Law", en Int. Insolv. Rev. 14 (2005), pp. 223 y ss.

Graham, David, "Discovering Jabez Henry. Part I. Cross-Border Insolvency Law in the 19th Century", en Int. Insolv. Rev. 10 (2001), pp. 153 y ss.

Grasmann, «Effets nationaux d'une procédure d'execution collective étrangère», en Rev. Crit. Dr. Internat. Prive (1990), pp. 421 y ss.

Graveson, Ronald Harry, Conflict of laws, 7 ed., Sweet and Maxwell, 1974.

Großfeld, Bernhard, Internationales Unternehmensrecht. Das Organisationsrecht transnationaler Unternehmen, Heidelberg, C. F. Müller Juristischer Verlag, 1986.

Guzman, Andrew T., "International Bankruptcy: In Defense of Universalism”, en Mich. L. Rev. 98 (2000), pp. 2177 y ss.

Haidmayer, Barbara, "Sanierungsverfahren in der EulnsVO-Schwierigkeiten bei der Eröffnung von Sekundärinsolvenzverfahren", en ZIK 65 (2013), pp. 46 y ss.

Hanisch, Hans, "Die Wende im deutschen internationalen Insolvenzrecht", en ZIP (1985), pp. 1233 y ss.

Hanisch, Hans, “Universality versus Secondary Bankruptcy: A European Debate", en Int. Insolv. Rev 2 (1993), pp. 151 y ss.

Hanisch, Hans, "Die Wirkung dinglicher Mobiliarsicherungsrechte im grenzüberschreitenden Insolvenzverfahren", en Etudes de Droit International en l'Honneur de Paul Lalive (1993), pp. 61 y ss.

Hanisch, Hans, "Einheit oder Pluralität oder ein kombiniertes Modell beim grenzüberschreitenden Insolvenzverfahren?", en ZIP (1994), pp. 1 y ss.

Hanisch, Hans, "Grenzüberschreitende Insolvenz. Drei Lösungsmodelle im Vergleich", en Andreas Heldrich y Takeyoshi Uchida, (eds.), Festschrift für Hideo Nakamura zum 70. Geburtstag am 2, Tokyo, März, 1996, pp. 221 y ss.

Hanisch, Hans, "Bemerkungen zur Geschichte des internationalen Insolvenzrechts", en Von Walter Gerhardt (ed.), Festschrift für Franz Merz. Zum 65. Geburststag am 3. Februar 1992, Köln, Kommunikationsforum Recht, 1992.

Hanisch, Hans, "Internationale Insolvenzrechte des Auslandes und das Gegenrecht nach Art. 166 Abs. 1 IPRG", en Sweizerische Zeitschrift für internationales und europäisches Recht (1992), pp. 3-32. 
Hanisch, Hans, "Parallel-insolvenzen und Kooperation im internationalen Insolvenzfall", en Festschrift für F. W. Bosch, Bielefeld, 1976, pp. 381-392.

Hansmann y Kraakman, "The Essential Role of Organizational Law”, en Yale L. J. (2000), pp. 387 y ss.

Haß, Detlef, Peter Huber, Urs Gruber y Bettina Heiderhoff, EU-Insolvenzverordnung Kommentar zur Verordnung (EG) Nr. 1346/2000 über Insolvenzverfahren (EulnsVO), München, 2005.

Haß, Detlef, EU-Insolvenzverordnung, Kommentar zur Verordnung (EG) Nr. 1346/2000 über Insolvenzverfahren (EuInsVO), München, Beck, 2005.

Haubold, "Europäisches Zivilverfahrensrecht und Ansprüche im Zusammenhang mit Insolvenzverfahren", en IPRax (2002), pp. 157 y ss.

Haubold, "Mitgliedstaatenbezug, Zuständigkeitserschleichung und Vermögensgerichtsstand im Internationalen lnsolvenzrecht", en IPRax (2003), pp. 34 y ss.

Henckel, “Die internationalprivatrechtliche Anknüpfung der Konkursanfechtung", en AA.VV., Beiträge zum internationalen Verharensrecht und zu Schiedsgerichtsbarkeit, Festschrift für Heinrich Nagel zum 75. Geburtstag, herausgegeben von Walther J. Babscheid und Karl Heinz Schwab, Münster, Aschendorff, 1987, pp. 93 y ss.

Herchen, Axel, Das Übereinkommen über Insolvenzverfahren der Mitgliedstaaten der Europäischen Union vom 23.11.1995, Würzburg, Ergon Verlag, 2000.

Heredia, Pablo D., Tratado exegético de derecho concursal, ley 24.522 y modificatorias comentada, anotada y concordada, tomo I (arts. 1 a 40), Buenos Aires, Ed. Ábaco de Rodolfo Depalma, 2000, pp. 250-317.

Hess, Burkhard, Europäisches Zivilprozessrecht: ein Lehrbuch, Müller, Heidelberg, 2010.

Heß, Harald, “Die Europäisierung des internationalen Zivilprozeßrechl durch den Amsterdamenvertrag. Chancen und Gefahren", en NJW (2000), pp. 23 y ss.

Heyers, Christian Bernhard, Das französische Internationale Insolvenzrecht unter Berücksichtigung des neuen Europäischen Konkursübereinkommens, Münster, Dissertation, 1997.

Homann, "System der Anerkennung eines ausländischen Insolvenzverfahrens", en KTS (2000), pp. 343 y ss.

Honorati, Costanza y Giorgio Conto, "A double lesson from Interedil: higher courts, lower courts and preliminary ruling and further clarifications on 
COMI and establishment under EC lnsolvency Regulation", en IILR (2013), pp. 18 y ss.

Hopt, Klaus J., "Legal issues and questions of policy in the comparative regulation of groups", en AA.VV., I gruppi di società. Atti del Convegno Internazionale di studi. (Venezia. 16-18 novembre 1995), Milano, Giuffrè, 1996, pp. 45-64.

Hortig, Mario, Kooperation von Insolvenzverwaltern, Baden-Baden, 2008.

Huber, Peter, "Die Europäische Insolvenzverordnung”, en EuZW (2002), pp. 490 y ss.

Huber, Peter, "Internationales Insolvenzrecht in Europa”, en ZZP 114 (2001), pp. 133 y ss.

Huber, Ulrich, “Inländisches Insolvenzvertahren über Auslandsgesellschaften nach der Europäischen Insolvenzverordnung", en Wagner, Gerhard y Kreß, Gerhart Eckardt, Diederich (eds.), Festschrift für Walter Gerhardt zum 70. Geburtstag am 18. Köln, 2004, pp. 397 y ss.

Israel, Jona, European Cross-Border Insolvency Regulation. A Study of Regulation 1346/2000 on Insolvency Proceedings in the Light of a Paradigm of Co-operation and a Comitas Europaea, Oxford, Antwerpen, 2005.

Jackson, Thomas H., The Logic and Limits of Bankruplcy Law, Cambridge, Harvard University Press, 1986.

Jacot, Louis, La faillite dans les relations de droit international privé de la Suisse. Thèse de Doctorat, Neuchatel, Imprimeries Réunies Borel \& Seiler SA, 1932.

Jahr, Günther, "Vis attractiva concursus", en AA.VV., Kegel y Thieme, Vorschläge und Gutachten zum Entwurfeines EG-Konkursübereinkommens, 1988, pp. 305 y ss.

Jayme, Erick y Kohler, “Europäisches Kollisionsrecht 2000: Interlocales Privatrecht oder universelles Gemeinschaflsrecht?”, en IPRax (2000), pp. 454 y ss.

Jitta, Josephus, La Codification du Droit international de la Faillite, Den Haag, 1895.

Johnson, Gordon W., “The Europe Union Convention on Insolvency Proceedings: A Critique of the Convention's Corporate Rescue Paradigm", en Int. Insolv. Rev. 5 (1996), pp. 80 y ss.

Kahn-Freund, Otto, General Problems of Private International Law, Nijhof, 1976.

Kaiser, Thomas, "Weltweite Haftung transnationaler Unternehmen für Verbindlichkeiten ihrer Tochtergesellschaften", en RIW (1988), pp. 589-598.

Kennedy, Frank R., “Creative Bankruptcy? Uses and Abuses of the Bankruptcy Law - Reflection on Some Recent Cases", en Iowa L. Rev 71 (1985), p. 199. 
Keppelmüller, Rudolf C., "An der Schwelle zu einem europäischen Insolvenzrecht? Das EU-Übereinkommen über Insolvenzverfahren", en WBL (1996), pp. 337 y ss.

Keppelmüller, Rudolf C., Österreichisches internationales Konkursrecht, Wien, Verlag Österreich, 1997.

Kieser, Markus, Die Typenvermischung über die Grenze, Ein Beitrage zum internationalen Gesellschafts- und Insolvenzrecht, Konstanz, Dissertation, 1988.

Kindler, Peter y Josef Nachmann, Handbuch Insolvenzrecht in Europa, 4 ed., München, Beck, 2014.

Kirhhof, Hans-Peter, Rolf Stürner y Horst Eidenmüller, (eds.), Münchener Kommentar zur Insolvenzordnung, 3 ed., München, Beck.

Kolmann, Stephan, "Europäisches internationales lnsolvenzrecht - die Verordnung (EG) Nr. 1346/2000 über Insolvenzverfahren”, en ELF (2002), pp. 167 y ss.

Kolmann, Stephan, Kooperationsmodelle im internationalen Insolvenzrecht - Empfiehlt sich für das deutsche internationale Insolvenzrecht eine Neuorientierung?, Bielefeld, 2001.

Kompat, Birgit Melanie, Die neue Europäische Insolvenzverordnung. Ihre Auswirkungen auf das Internationale Insolvenzrecht ausgewählter Mitgliedstaaten, Hamburg, 2006.

Krings, "Unification legislative internationale récente en matière d'insolvabilité et de la faillile", en Uniform L. Rev. (1997), pp. 657 y ss.

Kropholler, Jan, “Die Auslegung von EG-Verordnungen zum Internationalen Privat- und Verfahrensrecht", en Basedow, Jürgen u. a. (ed.), Aufbruch nach Europa, 75 ed., Tübingen, Jahre Max-Planck-Institut für Privatrecht, 2001, pp. 583 y ss.

Kropholler, Jan, Internationales Privatrecht, 6 ed., Tübingen, 2006.

Kübler, Bruno, Hanns Prütting y Reinhard Bork, “Insolvenzordnung”, en Loseblatt Schmidt (ed.), Hamburger Kommentar zum Insolvenzrecht, 3 ed., 2009.

Laubacher, Johann, Die Haftungsproblematik bei Konkurs einer Gesellschaft innerhalb eines transnationalen Unternehmens: eine Untersuchung auf der Grundlage des deutschen Aktienkonzernrechts, Konstanz, Hartung-Gorre, 1984.

Laut, Thomas, Universalität und Sanierung im internationales Insolvenzrecht, Berlin, Duncker \& Humblot, 1997.

Lazic, Vesna, Insolvency proceedings and commercial arbitration, Stichting, The Hague, 1998. 
Lechner, Roland, "Waking from the Jurisdictional Nightmare of Multinational Default: The European Council Regulation on Insolvency Proccedings”, en Ariz. J. Int. E Comp. L. 19 (2002), pp. 975 y ss.

Leible, Stefan y Ansgar Staudinger, “El artículo 65 TCE: ¿Carta blanca de la Comunidad Europea para la unificación del Derecho internacional privado y procesal?", en AEDIP (2001), pp. 89 y ss.

Leible, Stefan y Ansgar Staudinger, “Die europäische Verordnung über Insolvenzverfahren", en KTS (2000), pp. 533 y ss.

Leipold, Dieter, "Zum künftigen Weg des deutschen internationalen Insolvenzrechts", en AA.VV., Stoll (ed.), Vorschläge und Gutachten zur Umsetzung des EU-Übereinkommens über Insolvenzverfahren im deutschen Recht, 1997, pp. 185 y ss.

Leipold, Dieter, “Internationale Zuständigkeit, inländische Einzelrechtsverfolgung trotz eines Auslandskonkurses, Auswirkungen eines ausländischen Konkurses auf im Inland anhängige Zivilprozesse. Bemerkungen zum Vorentwurf für eine Regelung des Internationalen Insolvenzrechts, insbesondere aus verfahrensreclitlicher Sicht", en AA.VV., Hans Stoll (ed.), Stellungnahmen und Gutachten zur Reform des deutschen Internationalen Insolvenzrechts. Im Auftrag der Sonderkommission, Internationales Insolvenzrecht" des Deutschen Rates für Internationales Privatrecht, Tübingen, 1992, pp. 72 y ss.

Leipold, Dieter, "Zur internationalen Zuständigkeit im Insolvenzrecht", en AA.VV., Festschrift für Gottfried Baumgärtel zum 70. Geburtstag. Herausgegeben von Hanns Prütting, Köln, Carl Heymanns Verlag KG, 1990, pp. 291-309.

Leitner, Robert, Der grenzüberschreitende Konkurs, Lösungsmöglichkeiten undmodelle aus österreichischer Sicht, Wien, Manzscha Verlags- und Universitätsbuchhandlung, 1995.

Leonhardt, Peter, Stefan Smid y Mark Zeuner (eds.), Internationales Insolvenzrecht Kommentar, 2 ed., Stuttgart, Kohlhammer, 2012.

Lieder, Solveig, Grenzüberschreitende Unternehmenssanierung im Lichte der EulnsVO, Berlin, 2007.

LoPucki, Lynn M., “Cooperation in International Bankruplcy: A Post-Universalist Approach", en Cornell L. Rev. (1999), pp. 696 y ss.

LoPucki, Lynn, "The Case for Cooperative Territoriality in international Bankruptcy", en Mich. L. Rew. (2000), pp. 2216 y ss.

Lüer, "Zur Neuordnung des deutschen Internationalen lnsolvenzrecht", en Stoll (ed.). Stellungnahmen und Gutachten zur Reform des deutschen Internationalen Insolvenzrecht, 1992, pp. 96 y ss. 
Lüer, Hans-Joachim, "Art. 3 Abs. 1 EuInsVO - Grundlage für ein europäisches Konzern- insolvenzrecht oder Instrumentarium eines 'Insolvenz-Imperialismus'”, Horst Piepenburg, (ed.), Festschrift für Günter Greiner zum 70. Geburtstag am 19. März 2005, Köln, 2005, pp. 201 y ss.

Lüke, Wolfgang, "Das europäische internationale lnsolvenzrecht", en ZIP (1998), pp. 275 y ss.

Lüke, Wolfgang, “Europäisches Zivilverfahrensrecht - das Problem der Abstimmung zwischen EulnsU und EuGVÜ", en AA.VV., FS Schlitze, 1999, pp. 467 y ss.

Lüke, Wolfgang, "Das europäische Internationale Insolvenzrecht", en ZZP 111 (1998), pp. 275 y ss.

Lüke, Wolfgang, “The New European Law on International Insolvencies: A German Perspective", en Bankr. Dev. J. 17 (2001), pp. 369 y ss.

Lupone, Angela, L'insolvenza transnazionale, Procedure concorsuali nello stato e beni all'estero, Padova, Cedam, 1995.

Manfred, Balz, "Das neue Europäische Insolvenzübereinkommen", en ZIP (1996), p. 948.

Manfred, Balz, "The European Union Convention on Insolvency Proceedings", en Am. Bankr. L. J. 70 (1996), pp. 485 y ss.

Mankowsky, "Konkursgründe beim inländischen Partikularkonkurs", en ZIP (1995), pp. 1650 y ss.

Mann, Frederick Alexander, "Bemerkungen zum Internationalen Privatrecht der Aktiengesellschaft und des Konzerns, Wirtschaftsfragen der gegenwart", en Herausgegeben von Robert Fischer, Philipp Möhring und Harry Westermann (eds.), Festschrift für Carl Hans Bärz zum 65. Geburtstag am 6. Dezember 1974, New York, Berlin, Walter de Gruyter. 1974, pp. 219-238.

Manóvil, Rafael Mariano, Grupos de sociedades en el derecho comparado, Buenos Aires, Abeledo-Perrot, 1998.

Martinez Ferber, Michael, European Insolvency Regulation - Substantive Consolidation, the threat of Forum Shopping and a German point of view, Osterspai, Ditmar Weis, 2004.

Mayer, Droit International Prive, 4 ed., Monchrestien, 1994.

McKenzie Skene, Donna, "The EC Convention on Insolvency Proceedings", en Eur Priv. L. 4 (1996), pp. 181 y ss.

Meili, Friedrich, Die geschichtliche Entwicklung des internationalen Konkursrechtes, Zürich, 1908. 
Meili, Friedrich, Lehrbuch des internationalen Konkursrechts, Zürich, 1909.

Meili, Friedrich, Moderne Staatsverträge über das internationale Konkursrecht, Zürich, 1907.

Menjucq, Michel, “EC-Regulation No 1346/2000 on Insolvency Proceedings and Groups of Companies", en ECFR (2008), pp. 135 y ss.

Meriggi, Lea, Contributo alla dottrina del fallimento in diritto internazionale privato, Genova, Società editrice del "Nuovo stato", 1936.

Metzger, Ingrid, Die Umsetzung des Istanbuler Konkursürbereinkommens in das neue deutsche Internationale Insolvenzrecht, Pfaffenweiler, Centaurus Verlag, 1994.

Meunier-Dollfus, Des effets de la faillite et de la liquidation judiciaire dans les rapports internationaux, Paris, Larose, 1903.

Mevorach, Irit, "Forum shopping in time of crisis: A directors' duties perspective", en ECFR (2013), pp. 523 y ss.

Mevorach, Irit, Insolvency within Multinationl Enterprise Groups, New York, Oxford University Press, 2009.

Mevorach, Irit, "On the Road to Universalism: A Comparative and Empirical Study on the Uncitral Model Law on Cross-Border Insolvency", en EBOR 12 (2011), pp. 517 y ss.

Mion, Micol C., "An Analysis of the European Community regulation on insolvency proceedings: Its past, present and future", en NENGJ1CL 13 (2006), pp. 17 y ss.

Morscher, Martin, Die europäische Insolvenzverordnung (EuInsVO), Wien, 2002.

Moss, Gabriel, "The impact of the EU regulation on UK insolvency proceedings", en Int. Insolv. Rev. 11 (2002), pp. 139 y ss.

Moss, Gabriel, Ian Fletcher y Stuart Isaacs (eds.), "The EC Regulation on Insolvency Proceedings: A Commentary and Annotated Guide", 2 ed., Oxford, New York, 2009.

Moss, Gabriel, Ian F. Fletcher y Stuart Isaacs (eds.), The EU Regulation on Insolvency Proceedings, 3 ed., Oxford, Oxford University Press, 2016.

Müller-Seils, Carsten Oliver, Rescue Culture und Unternehmenssanierung in England und Wales nach dem Enterprise Act 2002, Baden-Baden, 2006.

Nachbaur, Paul, De la faillite en droit international prive ou des effets du Jugement déclaratif rendu à l'étranger, Nancy, Typographie G. Crépin-Leblond, 1883. 
Nadelmann, Kurt H., "An International Bankruptcy Code: New Thoughts on an Old Idea", en Int. Comp. Law Q. 10 (1961), pp. 70 y ss.

Nadelmann, Kurt H., “Ausländisches Vermögen unter dem Vorenlwurf eines Konkursabkommens für die EWG-Staaten", en KTS (1971), pp. 65 y ss.

Nadelmann, Kurt H., "Bankruptcy Treaties", en University of Pennsylvania Law Review (1944), pp. 58-97.

Nadelmann, Kurt H., "Codification of Conflicts Rules for Bankruptcy”, en Schw. Jb. Int. R. 30 (1974), pp. 57 y ss.

Nadelmann, Kurt H., "Creditor Equality in Inter-State Bankruptcies: A Requisite of Uniformity in the Regulation of Bankruptcy", en U. Pa. Law Rev. 98 (1949), pp. 41 y ss.

Nadelmann, Kurt H., "Discrimination in Foreign Bankruptcy Laws Against Non-Domestic Claims", en Am. Bankr. L. J. 47 (1973), pp. 147 y ss.

Nadelmann, Kurt H., "Henry Wheaton on 'American Law' in The Jurist (London)", en N. Y. L. F. 4 (1958), pp. 59 y ss.

Nadelmann, Kurt H., “The Common Market Bankruptcy Convention Draft: Foreign Assets and Related Problems", en Kurt H. Nadelmann, (ed.), Conflict of Laws: International and Interstate, Den Haag, Selected Essays, 1972, pp. 340 y ss.

Nadelmann, Kurt Hans, Conflicts of Law: International and Interstate - Selected Essays, Nijhoff, The Hague, 1972, p. 425.

Nadelmann, Kurt Hans, Fallimenti concorrenti ed uguaglianza dei creditori nelle Americhe, Estratto dall' Annuario di Diritto Comparato e di Studi Legislativi, Vol. 25 Fascículo $2^{\circ}-3^{\circ}$. Edizione dell’ Istituto Italiano di Studi Legislativi, Roma, Ministerio di Grazia e Giutizia, 1950.

North, Peter M., James J. Fawcett y Geoffrey C. Chesire, Cheshire and North's Private International Law, 13 ed., Butterworths, 1999.

Oberhammer, "Europäisches Insolvenzrecht in praxi - „Was bisher geschah”, en ZInsO (2004), p. 761.

Omar, Paul J., European Insolvency Law, Burlington, Hants, 2004.

Omar, Paul J., "Genesis of European Initiative in Insolvency Law", en Int. Insolv. Rev. 12 (2003), pp. 147 y ss.

148 Omar, Paul J., "The European Insolvency Regulation 2000: A Paradigm of International Insolvency Cooperation", en Bond. L. Rev. 15 (2003), pp. 213 y ss. 
Omar, Paul J., "The Landscape of International Insolvency Law”, en Int. Insolv. Rev. 11 (2002), pp. 173 y ss.

Omar, Paul J., "Jurisdiction in the European Insolvency Convention. A practical problema", en 1. C. C. L. R. 10 (1999), pp. 225 y ss.

Omar, Paul J., “The European Insolvency Regulation 2000: A Paradigm of International Insolvency Cooperation", en Bond. L. Rev. 15 (2003), pp. 213 y ss.

ONU, Documentos Oficiales de la Asamblea General, quincuagésimo quinto período de sesiones, Suplemento n. 17 (A/55/7), párrs. 400 a 409.

Pannen, Klaus, "Aspekte der europäischen Konzerninsolvenz", en ZInsO (2014), pp. 222 y ss.

Pastor Ridruejo, J. A., "La faillite in droit international privé", en Recueil des Cours 133 (1971), pp. 141-221.

Paulus, Christoph G., “ ̈̈nderungen des deutschen Insolvenzrechts durch die Europäische Insolvenzverordnung", en ZIP (2002), pp. 729 y ss.

Paulus, Christoph G., "Anfechtungsklagen in grenzüberschreitenden Insolvenzverfahren", en ZInsO (2006), pp. 295 y ss.

Paulus, Christoph G., "Anmerkung zu BGH, Urteil vom 13.10.2009 - X ZR 79/06", en ZZP 123 (2010), p. 247.

Paulus, Christoph G., "Das inländische Parallelverfähren nach der Europäischen Insolvenzverordnung", en EWS (2002), pp. 497 y ss.

Paulus, Christoph G., "Die EulnsVO - wo geht die Reise hin?”, en NZI (2008), pp. 1 y ss.

Paulus, Christoph G., "Die europäische Insolvenzverordnung und der deutsche Insolvenzverwalter", en NZI (2001), pp. 505 y ss.

Paulus, Christoph G., "EulnsVO: Änderungen am Horizont und ihre Auswirkungen", en NZI (2012), pp. 297 y ss.

Paulus, Christoph G., "Global Insolvency Law and the Role of Multinational Institutions", en Brook. J. Int l. L. 32 (2007), pp. 755 y ss.

Paulus, Christoph G., "Grundlagen des neuen Insolvenzrechts - Internationales Insolvenzrecht", en DStR (2005), pp. 334 y ss.

Paulus, Christoph G., "Grundlagen des neuen Insolvenzrechts", en DStR (2002), pp. 1865 y ss.

Paulus, Christoph G., “Konturen eines modernen Insolvenzrechts - Überlappungen mit dem Gesellschaftsrecht", en DB (2008), pp. 2523 y ss. 
Paulus, Christoph G., Kurzkommentar zu AG München, Beschluss vom 04.05.2004 - 1501 IE 1276/04. EWiR Art. 3 EulnsVO 2/04, pp. 493 y ss.

Paulus, Christoph G., Kurzkommentar zu Arrondissementgericht Amsterdam, Beschluss vom 31.01.2007 - FT RK 07-93 u. 07-122, EWiR Art. 3 EulnsVO 1/07, pp. 143 y ss.

Paulus, Christoph G., "A New German Decision on International Insolvency Law", en American Journal of Comparative Law 41 (1993), pp. 667-674.

Paulus, Christoph G., “Die ersten Jahre mit der Europäischen Insolvenzverordnung: Erfahrungen und Erwartungen", en RabelsZ 70 (2006), pp. 458 y ss.

Paulus, Christoph G., Europäische Insolvenzverordnung, 4 ed., Frankfurt, Kommentar, 2013.

Paulus, Christoph G., "Josef Köhler und die Entwicklung des modernen Insolvenzrechts", en Grundmann, Stefan $u$. a. (ed.), Festschrift 200 Jahre Juristische Fakultät der Humboldt-Universität zu Berlin, Berlin, Geschichte, Gegenwart und Zukunft, 2010, p. 1131.

Paulus, Christoph G., Judicial Cooperation in Cross-Border Insolvencies. An outline of the presentantions and discussions at the GJF in Buenos Aires, 2006, en www.worldbank.org/gild.

Paulus, Christoph G., Kurzkommentar zu LG Patra, Beschluss vom 02.05.2007 316/06, EWiR Art. 16 EulnsVO 1/07, pp. 563 y ss.

Paulus, Christoph G., “Über den Einfluss des europäischen Insolvenzrechts auf das deutsche Insolvenzverfahren", en Heribert Hirte, Ikms Haarmeyer, Hans-Peter Kirchhof y Friedrich Graf von Westphahlen, (eds.), Verschulden - Haftung - Vollstreckung - Insolvenz. Festschrift für Gerhart Kreit zum 65, Geburtstag, Recklinghausen, 2004, pp. 469 y ss.

Paulus, Christoph G., "Protokolle ein anderer Zugang zur Abwicklung grenzüberschreitender Insolvenzen", en ZIP (1998), pp. 977 y ss.

Paulus, Christoph, "Group Insolvency - Some Thoughts About New Approaches", en Tex. Int' l. L. J. 42 (2007), pp. 819 y ss.

Paz-Ares, Cándido y Francisco Garcimartin, “Conflictos de leves y garantías sobre valores anotados en intermediarios financieros", en RDM (2000), pp. 1479 y ss.

Pennetti, Vincenzo, Fallimento delle società commerciali nei rapporti internazionali, Torino-Paris, 1898.

Pennington, Corporate Insolvency Law, 2 ed., Butterworths, 1997. 
Peter Gottwald (ed.), Insolvenzrechts-Handbuch, 5 ed., München, Beck, 2015.

Pielorz, "Inlandsvermögen im Auslandskonkurs. Zur Handlungsbegugnis ausländischer Konkursorgane in Deutschland", en ZIP (1980), pp. 239 y ss.

Potthast, Klaus-Peter, Probleme eines Europäischen Konkursübereinkommens, Das Internationale Insolvenzrecht in den Entwürfen der Europäischen Gemeinschaft für ein Abkommen über Konkurse, Vergleiche und ähnliche Verfahren, Frankfurt am Main, Verlag Peter Lang, 1995.

Prütting, Hanns, “Die Europäische Insolvenzordnung und das grenzüberschreitende insolvenzverlahren", en Andreas Konecny, (ed.), Insolvenz-Forum 2004. Vorträge anlässlich des 11. Insolvenz-Forums Grundlsee im November 2004, Wien, Graz, 2005, pp. 157 y ss.

Quittner, Arnold M., "Cross-border Insolvencies. Ancillary and Full Cases: the Concurrent Japanese and United States Cases of Maruko Inc." , en International Insolvency Review 4 (1995), pp. 171-188.

Radzyminski, Alejandro P., "'La acción de ineficacia concursal en el Derecho Internacional Privado Argentino', comentario a Federal SA (Delbene Hnos y Sabia Ltda.) s/ quiebra s/inc. de medidas cautelares, del Juzgado Nacional de Primera Instancia en lo Comercial n² 2, del 14.10.1987", El Derecho, pp. 132-371.

Rainey, Kaie, "The European Insolvency Regulation and the Treatment of Group Companies: An Analysis", en Int. C. R 3 (2006), pp. 322 y ss.

Rajak (ed.), Insolvency Law Theory and Practice, Sweet and Maxwell, 1993.

Rammeskow, "Asset Distribution in Transnational Insolvencies: Combining Predictability and Protection of Local Interests", en ABIJ (1999), pp. 385 y ss.

Rasmussen, Robert K., "Where are all the Transnational Bankruptcies? The Puzzling Case for Universalism", en Brook. J. Int'l. L. 32 (2007), pp. 983 y ss.

Rauls, Henning, Das Reorganisationsverfahren der USA gemäß Chapter 11 BC im Deutschen Internationalen Privatrecht, Göttingen, Dissertation, 1993.

Reinhart, "Zur Anerkennung ausländischer Insolvenzverfahren, Eine Besprechung des Works- Data-Urleils des Bundesgerichtshofes", en ZIP (1997), pp. 1734 y ss.

Reinhart, Stefan, Sanierungsverfahren im internationalen Insolvenzrecht. Eine rechtsvergleichende Untersuchung über die besonderen internationalrechtlichen Probleme liquidationsabwender Insolvenzverfahren, Berlin, Scriften des Instituts für internationales Recht des Spar-, Giro- und Kreditwesens an der Universität Mainz, Band 93, Duncker \& Humblot, 1995. 
Reisenhofer, Barbara, "Zur Insolvenzmasse nach der EulnsVO - Lohnpfändungsschutz in der grenzüberschreitenden Insolvenz", en AA.VV., Selena Clavora y Thomas Garber, (eds.), Grenzüberschreitende Insolvenzen im europäischen Binnenmarkt - die EulnsVO, Österreichische Assistententagung zum Zivil- und Zivilverfahrensrecht der Karl-Franzens-Universität Graz, Wien, Graz, 2011, pp. 157 y ss.

Rémery, Jean-Pierre, La faillite internationale, Paris, Presses Universitaires de France, 1996.

Reumers, Michele, "Cooperation between Liquidators and Courts in Insolvency Proceedings of Related Companies under the Proposed Revised EIR", en ECFR (2013), pp. 554 y ss.

Riesenfeld, Stefan, "Das neue Gesicht des deutschen Internationalen Konkursrechts aus ausländischer Sicht", en AA.VV., Festschrift für Franz Merz. Zum 65. Geburststag am 3. Februar 1992. Hrsg. Von Walter Gerhardt, Köln, Kommunikationsforum Recht, 1992.

Ringe, Wolf-Georg, "Forum Shopping under the EU Insolvency Regulation”, en $E B O R 9$ (2008), pp. 579 y ss.

Ringe, Wolf-Georg, "Sekundärinsolvenzverfahren nach der Europäischen Insolvenzverordnung", en Iprax (2013), pp. 330 y ss.

Rohr, Andreas, Der Konzern im IPR unter besonderer Berücksichtigung des Schutzes der Minderheitsaktionäre und der Gläubiger, Zürich, Schulthess Polygraphischer Verlag, 1983.

Rolin, Albéric, "Des conflicts de lois en matière de faillite", en Recueil des Cours 14 (1926), pp. 5-160.

Rordorf, Renato, “Cross Border Insolvency”, en IILR (2010), pp. 16 y ss.

Rosch, Wolfgang, "Grenzüberschreitende Insolvenzen im Lichte der Verordnung (EG) Nr. 1346/2000", en ELR (2000), pp. 378 y ss.

Rottstegge, Jochen P., "Zuständigkeitsfragen bei der Insolvenz in- und ausländischer Konzerngesellschaften", en ZIP (2008), pp. 935 y ss.

Rouillon, Adolfo A. N. "Rules of International Private Law, Priorities on Insolvency and the Competing Rights of Foreign and Domestic Creditors, under the New Argentine Bankruptcy Law No. 24522", Understanding International Insolvency - Rescues, Bankruptcies $\mathcal{E}$ Credit Extensions, Book of Proceedings INSOL 97, New Orleans, 1997.

152 Rouillon, Adolfo A. N., Reformas al régimen de los concursos, Buenos Aires, Astrea, 1986. 
Rouillon, Adolfo A. N., "Aproximación esquemática al régimen argentino de insolvencia y a sus reglas aplicables a los concursos con repercusión transfronteriza", en Revista de la Facultad de Derecho de la Universidad Católica Andrés Bello 56 (2001), pp. 419 y ss.

Rouillon, Adolfo A. N., "Concursos con repercusión transnacional, La Ley Modelo de la CNUDMI (Uncitral) sobre Insolvencia Transfronteriza", en Derecho y Empresa 12-13, Homenaje a Guillermo Mosso (2004), pp. 785 y ss.

Rouillon, Adolfo A. N., "Cooperación internacional en materia concursal. La Ley Modelo de la CNUDMI (Uncitral) sobre Insolvencia Transfronteriza", La Ley, 12 de junio de 2002.

Rouillon, Adolfo A. N., "Cross Border insolvency under Argentine Law", en Global Insolvency \& Restructuring Review (2000), pp. 24-26.

Rouillon, Adolfo A. N., “Cuestiones de derecho internacional privado en la Ley Concursal argentina 24.522", en Anales de la Academia Nacional de Derecho y Ciencias Sociales de Buenos Aires 37 (XLIII, Segunda Época).

Rouillon, Adolfo A. N., "Cuestiones de Derecho Internacional Privado en la ley concursal argentina (a propósito de la reforma legislativa de 1983)", en Revista del Derecho Comercial y de las Obligaciones (1984) y Rivista Il Diritto Fallimentare e delle Societa Commerciali, 1-2 (1985), p. 79.

Rouillon, Adolfo A. N., "Iniciativas internacionales sobre Insolvencia", en Seminario Internacional de Insolvencia, insolvencia transfronteriza y contratación pública, Bogotá, Cámara de Comercio de Bogotá, 2006.

Rouillon, Adolfo A. N., Insolvencias Internacionales en la ley argentina de concursos No. 24522, trabajo presentado al Sexto Encuentro Jurídico ArgentinoGermano, organizado por la "Asociación Jurídica Argentino-Germana" ("Argentinisch - Deutsche Juristenvereinigung"), Munich, 1998.

Rouillon, Adolfo A. N., "Quiebra internacional e iniciativas internacionales sobre insolvencia", en La insolvencia en el Derecho Concursal Iberoamericano, Buenos Aires, Ad-Hoc, 2006, pp. 171-184.

Rouillon, Adolfo A. N., "Rules of International Private Law, Priorities on Insolvency and the Competing Rights of Foreign and Domestic Creditors, under the Argentine Bankruptcy Law no. 24522", en Derecho y Empresa 9 (2000), pp. 294 y ss.

Rouillon, Adolfo A. N., “Concursos con repercusión trasnacional. La Ley Modelo de la CNUDMI (Uncitral) sobre Insolvencia Transfronteriza", en Anales de la Academia Nacional de Derecho y Ciencias Sociales de Buenos Aires, 38 (XLV, segunda época) (2000), pp. 144 y ss. 
Rouillon, Adolfo A. N., "El cambio del paisaje concursal a comienzos del siglo XXI", en Anuario de Derecho Concursal, Madrid, Thomson - Civitas, 2007, pp. 253 a 261.

Rouillon, Adolfo A.N. (dir.) y Daniel F. Alonso (coord.), Código de Comercio Comentado y Anotado, tomo VII, Buenos Aires, La Ley, 2009.

Rouillon, Adolfo A.N., Fourth Multinational Judicial Colloquium - UNCITRAL - INSOL International, London, 2001.

Rouillon, Adolfo A.N., Reformas al régimen de los concursos, Buenos Aires, Astrea, 1986, pp. 29 y ss.

Rüfner, Thomas, "Neues internationales Insolvenzrecht in den USA", en ZIP (2005), pp. 1859 y ss.

Rumberg, Carsten, “Entwicklung der Rescue Culture im englischen Insolvenzrecht", en RIW (2010), pp. 358 y ss.

Sánchez Lorenzo, Sixto, Garantías reales en el comercio intenacional, Madrid, Civitas, 1993.

Sanchez Lorenzo, Sixto, "Eficacia de la declaración de un concurso pronunciado en el extranjero: paralización de las acciones individuales", en La Ley (España) 2 (1989), pp. 1029-1036.

Santa María, Alberto, "Problemi attinenti al diritto internazionale privato e processuale delle società", en Rivista delle Società (1987), pp. 1473-1500.

Schilling, Simon y Jessica Schmidt, "COMI und vorläufiger Insolvenzverwalter" Problem gelöst?", en ZInsO (2005), pp. 113 y ss.

Schmidt, Claudia, Der Haftungsdurchgriff und seine Umkehrung im internationalen Privatrecht, Eine systematische Untersuchung des direkten und des umgekehrten Haftungsdurchgriff im internationalen Privatrecht Deutschlands, der Schweiz und Österreichs, Tübingen, Studien zum ausländischen und internationalen Privatrecht, Band 31, Mohr (Paul Siebeck), 1993.

Schmidt, Jürgen, System des deutschen internationalen Konkursrechtes, Frankfurt am Main, Vittorio Klostermann, 1972.

Schollmeyer, Eberhard, Gegenseitige Verträge im internationalen Insolvenzrecht, Köln Berlin, Bonn, 1997.

Schollmeyer, Eberhard, "The New European Convention on International Insolvency", en Bankr. Dev. J. 13 (1997), pp. 421 y ss.

154 Schwemmer, Anja Sophia, “Die Verlegung des centre of main interests (COMI) im An wendungsbereich der EuInsVO", en NZI (2009), pp. 355 y ss. 
Segal, Nick, "The Choice of Law Provisions in the European Union Convention on Insolvency Proceedings", en Brook. J. Int'l. L. 23 (1997), pp. 57 y ss.

Seidl, Andrew y Andreas Paulick, "Sekundärinsolvenz und Sanierungsinsolvenzplan, Das Zustimmungserfordernis des Art. 34 Abs. 2 EulnsVO", en ZInsO (2010), pp. 125 y ss.

Siehr, Kurt, "International Aspects of Bankruptcy", en Transnational aspects of procedural law, 1998, pp. 873 y ss.

Smart, Philip St. J., "International insolvency and the enforcement of foreign revenue laws", en International and Comparative Law Quarterly 35 (1986), pp. 704-710.

Smart, Philip, "Rights in Rem, Article 5 and the EC Insolvency Regulation: An English Perspective", en Int. Insolv. Rev. 15 (2006), pp. 17 y ss.

Smart, Philip, Cross-Border Insolvency, 2 ed., London, Charlottesville, Dublin, 1998.

Smid, Stefan, Deutsches und Europäisches Internationales Insolvenzrecht, Kohlhammer, Stuttgart, Berlin, Köln, 2004.

Soinne, Traité des Procedures Collectives, 2 ed., L1TEC, 1995.

Sorensen, Anker y Paul Omar, Corporate Rescue Procedures in France, Kluwer, 1996.

Spahlinger, Andreas, Sekundäre Insolvenzverfahren bei grenzüberschreitenden Insolvenzen, Eine vergleichende Untersuchung zum deutschen, US-amerikanischen, schweizerischen und europäischen Recht, Tübingen, Mohr Siebeck, Max Planck Institut, 1998.

Spellenberg, "Des ordre public im Internationalen Insolvenzrecht", en AA.VV., Stoll (ed.), Stellungsnamen und Gutachten zur Reform des deutschen Internationalen Insolvenzrechts, 1992, pp. 183 y ss.

Spennemann, Gert, Insolvenzverfahren in Deutschland -Vermögen in Amerika: Das Beispiel Herstatt, Fragen des Internationalen Insolvenzrechtes der Bundesrepublik Deutschland und der USA, Düsseldorf, Verlag Dr. Peter Mannhold, 1981.

Spindler, Gerald, "Der Gläubigerschutz zwischen Gesellschafts- und Insolvenzrecht", en JZ (2006), pp. 839 y ss.

Spindler, Gerald, "Libertad de establecimiento y elección de la ley societaria, desarrollos recientes en la jurisprudencia del Tribunal de Justicia de la Union Europea", en AEDIPr 12 (2012), pp. 365 y ss. 
Staak, Kai S., “Mögliche Probleme im Rahmen der Koordination von Hauptund Sekundärinsolvenzverfahren nach der Europäischen Insolvenzverordnung (EulnsVO)", en NZI (2004), pp. 480 y ss.

Staak, Kai S., Der deutsche Insolvenzverwalter im europäischen Insolvenzrecht. Eine Analyse der EG-Verordnung Nr. 1346/2000 des Rates vom 29. Mai 2000 über Insolvenzverfahren unter besonderer Berücksichtigung der Person des deutschen Insolvenzverwalters, Frankfurt a. M., Berlin, Bern, 2004.

Staehlin, Die Anerkenung ausländischer Konkurse und Nachlassverträge in der Schweiz (Art. 166 ff. IPRG), 1989.

Steffek, Felix, “Insolvenzgründe in Europa - Rechtsvergleich, Regelungsstrukturen und Perspektiven der Rechtsangleichung", en KTS (2009), pp. 317 y ss.

Steffek, Felix, "WrongfuI Trading - Grundlagen und Spruchpraxis", en NZI (2010), pp. 589 y ss.

Stoll, Hans, Stellungnahmen und Gutachten zur Reform des deutschen Internationalen Insolvenzrechts, Tübingen, Mohr Siebeck, 1992.

Stoll, Hans, Vorschläge und Gutachten zur Umsetzung des EU-Übereinkommens über Insolvenzverfahren im deutschen Recht, Tübingen, Mohr Siebeck, 1997.

Strub, Andreas, "Zwischen Universalität und Territorialität", en EuZW (1994), pp. 424 y ss.

Takahashi, Eiji, Konzern und Unternehmensgruppe in Japan, Regelung nach dem deutschen Modell?: Eine vergleichende Untersuchung nach japanischem und deutschem Konzernrecht, Studien zum ausländischen und internationalen Privatrecht, Band 38, Tübingen,Mohr, 1994.

Taupitz, "Das zukünftige europäische Internationale Insolvenzrecht - insbesondere aus international - privatrechlicher Sicht", en ZZP (1998), pp. 315 y ss.

Taylor, Stephen J., “Beyond CoMi - The Duty to Cooperate under EU Insolvency Regulation 1346/2000", en Int. C. R. 2 (2005), pp. 173 y ss.

Taylor, Stephen J., “Avoiding Secondary Proceedings in EU Insolvency Regulation Cases", en Int. C. R 4 (2007), pp. 7 y ss.

Teipel, Klemens, Die Bedeutung der lex fori für die Anknüpfung des Haftungsdurchgriff, Heidelberg, Verlag Recht und Wirtschaft GmbH, 1994.

Thaller, Edmond Eugene, Des faillites en droit compare avec une etude sur le règlement des faillites en droit international, tomo 2, Paris, 1887.

Thieme, Jürgen, "Partikularkonkurs, Stellungnahme zu den Artt. 1 II, 2, 9, 10, 111, 15 I, 16 I, 20, 21 Satz 2, 26-34 des Vorentwurfs zur Neuregelung des 
Internationalen lnsolvenzrechts von 1989", en Hans Stoll, (ed.), Stellungnahmen und Gutachten zur Reform des deutschen Internationalen Insolvenzrechts. Im Auftrag der Sonderkommission, Tübingen, Internationales Insolvenzrecht" des Deutschen Rates für Internationales Privatrecht, 1992, pp. 213 y ss.

Thieme, Jürgen, "Der Entwurf eines Konkursübereinkommens der EG-Staaten von 1980. Überblick und allgemeine Kritik", en RabelsZ 45 (1981), pp. 459 y ss.

Thieme, Jürgen, “Der revidierte Entwurf eines EG-Konkursübereinkommens von 1984, Allgemeine Stellungnahme zu den Vorschlägen zweiter Lesung der Arbeitsgruppe beim Rat der EG", en Stoll (ed.), Stellungnahmen und Gutachten zur Reform des deutschen Internationalen Insolvenzrecht, 1992, pp. 465 y ss.

Thieme, Jürgen, Grundsätze des EG-Konkursübereinkommens, Allgemeine Stellungnahme zum Entwurf von, 1989, pp. 213 y ss.

Thole, Christoph y Arthur Swierczok, "Der Kommissionsvorschlag zur Reform der Eulns VO", en ZIP (2013), pp. 550 y ss.

Thole, Christoph, "Das COMI-Prinzip und andere Grundfragen des Europäischen Insolvenzrechts", en ZEuP (2007), pp. 1137 y ss.

Thole, Christoph, "Die Reform der Europäischen Insolvenzverordnung", en ZEuP (2014), pp. 39 y ss.

Tilman, Ulrich, Regeln des internationales Privatrechts über die Haftung des Gesellschafters oder der Verwaltung einer Kapitalergesellschaft, Göttingen, Dissertation, 1972.

Tolmie, Introduction to Corporate and Personal Insolvency Law, Sweet and Maxwell, 1998.

Torremans, Paul L. C., "Coming to Terms with the COMI Concept in the European Insolvency Regulation", en Paul J. Omar, (ed.), International Insolvency Law, Aldershot, Themes and Perspectives, 2008, pp. 173 y ss.

Torremans, Paul L. C., Cross Border Insolventes in EU, English and Belgian Law. London, New York, Den Haag, 2002.

Trautman, Donald T., Jay Lawrence Westbrook y Emmanuel Gaillard, "Four models for international bankruptcy", en The American Journal of Comparative Law 41 (1993), pp. 573-625.

Trieber, Jacob, “The Abuses of Receiverships", en Yale L. J. 19 (275) (1910).

Trochu, Michel, Conflits de lois et conflits de juridicitions en matière de faillite, Paris, Librairie Sirey, 1967. 
Trunk, Alexander, "Regelungsschwerpunkte eines Ausführungsgesetzes zum Europäischen Insolvenzübereinkommen", en AA.VV., Stoll (ed.), Vorschläge und Gutachten zur Umsetzung des EU-Übereinkommeus über Insolvenzverfahren im deutschen Recht, 1997, pp. 232 y ss.

Trunk, Alexander, Internationales Insolvenzrecht, Systematische Darstellung des deutschen Rechts mit rechtsvergleichenden Bezügen, Tübingen, Mohr Siebeck, 1998.

Tschernig, Klaus, Haftungsrechtliche Probleme der Konzerinsolvenz: eine untersuchung nach deutshcem und US-amerikanischen Recht unter besonderer Berücksichtigung der Problematik grenzüberschreintender Konzerninsolvenzen, Frankfurt am Main, Verlag Peter Lang, 1995.

Turck, Iris-Claude, Das Internationale Insolvenzrecht in Spanien in rechtsvergleichender Betrachtung, Frankfurt am Main, Verlag Peter Lang, 1995.

Uhlenbruch, Wilhelm, Insolvenzordnung, 12 ed., 2003.

Uncitral, WP (Working Paper) n 114 de abril de 2013, WP 103 de mayo de 2012, WP n 101 de noviembre de 2011 y WP n 95 de diciembre de 2010, en www.uncitral.org.

Undritz, Sven-Holger, "Restrukturierung in der Insolvenz", en ZGR (2010), pp. 201 y ss.

Uzal, María Elsa, Procesos de insolvencia en el Derecho Internacional Privado, Buenos Aires, La Ley, 2008.

Vallender, Heinz, "Gerichtliche Kommunikation und Kooperation bei grenzüberschreitenden Insolvenzverfahren im Anwendungsbereich der EulnsVO - eine neue Herausforderung für Insolvenzgerichte", en KTS (2008), 59 y ss.

Vallender, Heinz, "Die Aussetzung der Verwertung nach Art. 33 EulnsVO in einem deutschen Sekundärinsolvenzverfahren", en Heribert Hirte, Ikms Haarmeyer, Hans-Peter Kirchhof y Friedrich Graf von Westphahlen, (eds.), Verschulden - Haltung - Vollstreckung - Insolvenz. Festschrift für Gerhart Kreft zum 65. Geburtstag, Recklinghausen, 2004, pp. 565 y ss.

Vallender, Heinz, "Die Insolvenz von Scheinauslandsgesellschaften", en ZGR (2006), pp. 425 y ss.

Vallender, Heinz, "Gefahren für den Insolvenzstandort Deutschland", en NZI (2007), pp. 129 y ss.

Vallender, Heinz, "Die Voraussetzungen für die Einleitung eines Sekundärin158 solvenzverfahrens nach der EulnsVO", en Andreas Konecny, (ed.), Insolvenz-Forum 2004. Vorträge anlässlich des II. Insolvenz-Forums Grundlsee im November 2004, Wien, Graz, 2005, pp. 225 y ss. 
Vallender, Heinz, “Gerichtliche Kommunikation und Kooperation bei grenzüberschreitenden Insolvenzverfahren im Anwendungsbereich der EulnsVO - eine neue Herausforderung für Insolvenzgerichte", en KTS (2008), pp. 59 y ss.

Vallender, Heinz, "Sanierungsoptionen bei grenzüberschreitenden Insolvenzen nach dem ESUG", en Gesetz zur weiteren Erleichterung der Sanierung von Unternehmen (GrnbHR) (2012), pp. 478 y ss.

Vallender, Heinz, "Wirkungen und Anerkennung einer im Ausland erteilten Restschuldbefreiung”, en ZInsO (2009), pp. 616 y ss.

Vallender, Heinz, "Aufgaben und Befugnisse des deutschen Insolvenzrichters in Verfahren nach der EulnsVO", en KTS (2005), pp. 283 y ss.

Vallens, Jean-Luc, "Le droit europeen de la faillite: premiers commentaires de la Convention relative aux procedures d'insolvabilité", en Recueil Dalloz (1995), pp. 307 y ss.

Vallens, Jean-Luc, "Transfert du siege statutaire et transfert du centre des interets principaux", en Dalloz (2011), pp. 2915 y ss.

Vallens, Jean-Luc, L'insolvabilite des entreprises en droit compare, Paris, 2011.

van der Gucht, Jacques, Droit de la faillite dans les six pays du Marché Commun, Bruxelles, Éditions Simon Stevin, 1964.

Veder, Paul Michael, "The Future of the European Insolvency Regulation Applicable law, in particular security rights", en IILR (2011), pp. 285 y ss.

Veder, Paul Michael, Cross-Border Insolvency Proceedings And Security Rights. A Comparison of Dutch and German Law, the EC Insolvency Regulation and the UNC1TRAL Model Law on Cross-Border Insolvency, Deventer, 2004.

Verhoeven, Alexander, "Ein Konzerninsolvenzrecht für Europa - Was lange wahrt, wird endlich gut?", en ZInsO (2012), pp. 2369 y ss.

Virgós Soriano, Miguel y Francisco J. Garcimartín Alférez, Comentario al Reglamento Europeo de Insolvencia, Madrid, 2004.

Virgós Soriano, Miguel y Francisco J. Garcimartín Alférez, Derecho procesal civil internacional. Litigación internacional, 2 ed., Cicur Menor, Civitas, 2007.

Virgós Soriano, Miguel y Etienne Schmit, “Erläuternder Bericht zu dem EUÜbereinkommen über Insolvenzverfahren, abgedruckt", en Hans Stoll, (ed.), Vorschläge und Gutachten zur Umsetzung des EU-Übereinkommens über Insolvenzvertahren im deutschen Recht. Im Auftrag der Sonderkommission, Tü- 
bingen, Internationales Insolvenzrecht des Deutschen Rates für internationales Privatrecht, 1997, pp. 32 y ss.

Virgós Soriano, Miguel, “The 1995 European Community Convention on Insolvency Proceedings: an insider's View", en Forum Internationale 25 (1997), pp. 1-37.

Virgós, Soriano, Miguel y Francisco J. Garcimartín Alférez, The European Insolvency Regulation: Law and Practice, Kluwer Law International, The Hague, 2004.

Volken, Paul, Europäische Harmonisierung des Konkursrecht: frühe Staatsverträge, Beiträge zum schweizerischen und internationalen Zivilprozeßrecht. Festschrift für Oscar Vogel, Schweiz, Universitätsverlag, Freiburg, 1991, pp. 465-481.

Von Westpfahl, Lars, Uwe Goetker y Jochen Wilkens, Grenzüberschreitende Insolvenzen, RWS-Verl, Köln, Kommunikationsforum, 2008.

Von Wilmowsky, Peter, "Aufrechnung in internationalen Insolvenzfällenkollisionsrecht der Insolvenzauchrechnung", en KTS (1998), pp. 343 y ss.

Von Wilmowsky, Peter, "Choice of Law in International Insolvencies - A Proposal for Reform -", en Jürgen Basedow y Toshiyuki (eds.), Legal Aspects of Globalization, 2000, pp. 197 y ss.

Von Wilmowsky, Peter, "Aufrechnung in internationalen Insolvenzfällen", en KTS (1998), pp. 343 y ss.

Von Wilmowsky, Peter, Europäisches Kreditsicherungsrecht. Sachenrecht und Insolvenzrecht under dem EG-Vertrag, Tübingen, 1996.

Von Wilmowsky, Peter, "Internationales Insolvenzrecht - Plädoyer für eine Neuorientierung", en WM (1997), pp. 1461 y ss.

Von Wilmowsky, Peter, “Sicherungsrechte im Europäischen Insolvenzübereinkommen", en EWS (1997), pp. 295 y ss.

Von Zipperer, Helmut, “Übertragende Sanierung" - Sanierung ohne Grenzen oder erlaubtes Risiko?", en NZI (2008), pp. 206 y ss.

Vormstein, Frank, Zuständigkeit bei Konzerninsolvenzen. Verfahrensablauf bei grenz überschreitenden Konzerninsolvenzen unter besonderer Berücksichtigung der Europäischen Insolvenzverordnung (EulnsVO), München, 2005.

Walters, Adrian y Anton Smith, "Bankruptcy Tourism" under the EC Regulation on solvency Proceedings: A View front England and Wales", en Int. Insov. Rev. 19 (2010), pp. 181 y ss.

Warren, Elizabeth, Chapter 11: Reorganizing American Businesses, Austin, Boston, Chicago, New York, The Netherlands, Aspen Publishers, Wolters Kluwer Law \& Business, 2008. 
Wazlawik, Thomas, Die Konzernhaftung der deutschen Muttergesellschaft für die Schulden ihrer US-amerikanischen Tochtergesellschaft, Tübingen, Mohr Siebeck, 2004.

Werlen, Sandra, Haftung für ausländische Gesellschaften. Sonderanknüpfung gesellschaftsrechtlicher Verantwortlichkeit. Art. 159 IPRG im Vergleigh mit den Equal Treatment Statutes und der Rechtsprechung zur Pseudo-Foreign Corporation in den Kollisionrechten der USA, Zürich, Dissertation, Universität Zürich, Schulthess Plygraphischer Verlag AG, 1999.

Weller, Marc-Philippe, “Die Verlegung des Center of Main Interest von Deutschland nach England", en ZGR (2008), pp. 835 y ss.

Weller, Marc-Philippe, "Forum Shopping im Internationalen Insolvenzrecht?" en IPRax (2004), pp. 412 y ss.

Werner, Rike, Der Insolvenzplan im Anwendungsbereich der europäischen Insolvenzverordnung, Jena, 2010.

Wessels, Bob y Gert-Jan Boon, Cross-border Insolvency Law, International Instruments and Commentary, 2 ed., Alphen aan den Rijn, Wolters Kluwer, 2015.

Wessels, Bob, Bruce A. Markell y Jason J. Kilborn, International Cooperation in Bankruptcy and Insolvency Matters, New York, A Joint Research Project of American College of Bankruptcy and International Insolvency Institute, 2009.

Wessels, Bob, "Current Developments Towards International Insolvencies in Europe", en Int. Insolv. Rev. 13 (2004), pp. 43 y ss

Wessels, Bob, Current topics of international insolvency law, Deventer, Kluwer, 2004.

Wessels, Bob, European Union Regulation on Insolvency Proceedings. An Introductory Analysis, Alexandria, 2003.

Wessels, Bob, International Insolvency Law, 3 ed., Deventer, Kluwer, 2012.

Wessels, Bob, "Realization of the EU Insolvency: Regulation in Germany, France an The Netherlands", en EBLR 15 (2004), pp. 73 y ss.

Wessels, Bob, "EU Insolvency Regulation: Where to go from here?", en IILR (2011), pp. 298 y ss.

Wessels, Bob, "Tax Claims: Lodging and Enforcing in Cross-border Insolvencies in Europe", en IILR (2011), pp. 131 y ss.

Westbrook, Jay Lawrence, "International Judicial Negotiation", en Tex. Int' L. J. 38 (567) (2003). 
Westbrook, Jay Lawrence, "A Global Solution to Multinational Default", en Mich. L. Rev. 98 (2000), pp. 2276 y ss.

Westbrook, Jay Lawrence, "Avoidance of Pre-Bankruptcy Transactions in Mulitnational Bankruptcy Cases", en Tex. Int l, L. J. 42 (2007), pp. 899 y ss.

Westbrook, Jay Lawrence, "Universal Participation in Transnational Bankruptcies", en AA.VV., Ross Cranston, (ed.), Making Commercial Law. Essays in honour of Roy Goode, Oxford, 1997, pp. 419 y ss.

Westbrook, Jay Lawrence, "Universal Priorities", en Tex. IntT. L. J. 33 (1998), pp. 27 y ss.

Westbrook, Jay Lawrence, “Extraterritoriality, conflict of laws, and the regulation of transnational Business", en Texas International Law Journal 25 (1990), pp. 71-97.

Westbrook, Jay Lawrence, "Theories of parent company liability and the Prospects for an International Settlement", en Texas International Law Journal 20 (1985), pp. 321-331.

Westbrook, Jay Lawrence, "Theory and pragmatism in global insolvencies: Choice of law and choice of forum", en Am. Bankr. L. J. 65 (1991), pp. 457 y ss.

Westpfahl, Lars, "Die Praxis der grenzüberschreitenden Konzerninsolvenz", en Michael Dahl, Lians-Gerd H. Jauch y Christian Wolf (eds.), Festschrift für Klaus Hubert Görg zum 70, München, Geburtstag, 2010, pp. 569 y ss.

Wharton, Francis, A Treatise on the Conflicts of Laws or Private International Law, Including a Comparative View of Anglo-american, Roman, German, and French Jurisprudence, Philadelphia, 1872.

Wick, Markus, Der Durchgriff und das auf ihn anwendbare Recht gemäss IPRG, Zürich, Schulthess Polygraphischer Verlag, 1996.

Wimmer, Klaus, "Die Besonderheiten von Sekundärinsolvenzverfahren unter besonderer Berücksichtigung des europäischen Insolvenzübereinkommens", en ZIP (1998), pp. 982 y ss.

Wimmer, Klaus, "Die EU-Verordnung zur Regelung grenzüberschreitender Insolvenzverfahren", en NJW (2002), p. 2427.

Wimmer, Klaus, "Die Verordnung (EG) Nr. 1346/2000 über Insolvenzverfahren", en ZInsO (2001), p. 97.

Wimmer, Klaus, "Anmerkungen zum Vorlagebeschluss des irischen Supreme Court in Sachen Parmalat", en ZInsO (2005), pp. 119 y ss. 
Wimmer, Klaus, “Die Besonderheiten von Sekundärinsolvenzverfahren unter besonderer Berücksichtigung des Europäischen Insolvenzrechtsübereinkommens", en ZIP (1998), pp. 982 y ss.

Wimmer, Klaus, “Die EU-Verordnung zur Regelung grenzüberschreitender Insolvenzverfahren", en NJW (2002), pp. 2427 y ss.

Wimmer, Klaus, “Die UNCITRAL-Modellbestimmungen über grenzüberschreitende insolvenzverfahren", en ZIP (1997), pp. 2220 y ss.

Wimmer, Klaus, “Die Verordnung (EG) Nr. 1346/2000 über Insolvenzverfahren", en ZInsO (2001), pp. 97 y ss.

Wimmer, Klaus, "Einpassung der EU-Insolvenzverordnung in das deutsche Recht durch das Gesetz zur Neuregelung des Internationalen Insolvenzrechts", en Hans Haarmeyer y Gerhart Kreß, (eds.), Insolvenzrecht im Wandel der Zeit. Festschrift für Richter am BGH Hans-Peter Kirchhof anlässlich der Vollendung seines 65, Lebensjahres, Recklinghausen, 2003, pp. 521 y ss.

Wimmer, Klaus, “Konzerninsolvenzen im Rahmen der EulnsVO - Ausblick auf die Schaffung eines deutschen Konzerninsolvenzrechts", en DB (2013), pp. 1343 y ss.

Wittinghofer, Mathias A., Der nationale und internationale Insolvenzverwaltungsvertrag. Koordination paralleler Insolvenzverfahren durch ad hoc-Vereinbarungen, Bielefeld, 2004.

Wittwer, Alexander, "Zuständigkeit, Anerkennung und ordre public im internationalen Insolvenzrecht - ein wegweisendes Urteil", en ELR (2006), pp. 221 y ss.

Wolf, Ulrich M., Der europäische Gerichtsstand bei Konzerninsolvenzen, Tübingen, 2012.

Woloniecki, J. W., “Co-operation Between National courts in International Insolvencies: recent United Kingdom legislation", en International and Comparative Law Quarterly 35 (1986), pp. 644-663.

Wood, Alexandra, "Improving Efficiency and Effectiveness: The EU Council Regulation on lnsolvency Proceedings", en Bus. L. R. 23 (2002), pp. 230 y ss.

Wood, Philip R., "Principles of international insolvency (Part I)", en International Insolvency Review 4 (1995), pp. 94-103 y 109-138.

Wood, Philip R., Principles of international insolvency, 2 ed., London, Sweet \& Maxwell, 2007.

Wright, David y Sam Fenwick, "Bankruptcy Tourism - what it is, how it works and how creditors can fight back", en IILR (2012), pp. 45 y ss. 
Yamauchi, Koresuke, "Internationales Konzernrecht in Japan”, en ZGR (1991), pp. 235-251.

Zenneck, Alexandra, Hauptverfahren grenzüberschreitender Insolvenzen von Kapitalgesellschaften und ihre Anerkennung durch unterstützende Nabenverfahren in Deutschland, der Schweiz und den USA, München, VVF, 1996.

\section{Páginas web base}

www.ali.org/doc/Guidelines.pdf.

www.ibanet.org.

www.iiiglobal.org

www.uncitral.org .

www.worldbank.org 